

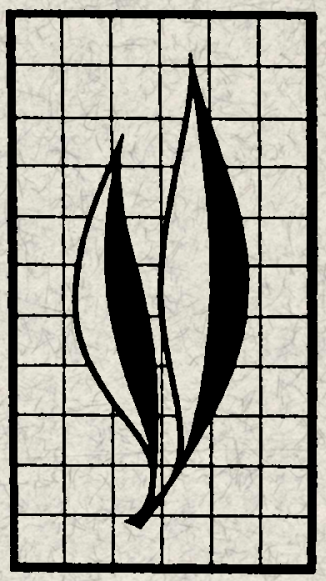

This study is primarily concerned with water storage control under conditions of conjunctive use and the role of storage control in guiding investment decisions in water resource development. Modern sequential decision theory is applied to water storage control in order to provide a theoretical framework for economic analysis. The theoretical model is utilized in an empirical investigation which is concerned with marginal value of imported water. The region chosen for study is serviced by Pine Flat Reservoir on the Kings River in the San Joaquin Valley.

THE AUTHOR:

Oscar R. Burt, at the time of the studies, was Assistant Professor of Agricultural Economics and Assistant Agricultural Economist in the Experiment Station and on the Giannini Foundation, Davis. He is now Associate Professor of Agricultural Economics at the University of Missouri. 


\section{The Economics of Conjunctive Use of Ground and Surface Water ${ }^{1}$}

\section{INTRODUCTION}

DevelopMent of water resources has largely become the responsibility of public institutions. Within some areas of the economy, it would appear that a large divergence between net social and private benefit exists; water resource development is one of these areas. Therefore, private enterprise lacks adequate incentive to undertake many investments in water resources which are justified from the point of view of welfare economics. This has led to extensive governmental activity in the development of our water resources.

Public agencies responsible for allocating investment funds are faced with an extremely complex problem. A public agency cannot rely entirely on market values and dollar measures of outcomes resulting from various choices.
Many factors which are taken as fixed by a private firm become variables for a public agency. An example is the quantity of ground water in storage. For an individual firm, the amount of water it withdraws from storage has a negligible influence on pumping costs in subsequent years. But a public agency formulating an optimal ground water inventory policy must evaluate the ef fect of present withdrawals upon future pumping costs.

With millions of dollars being spent each year in water resource development and considering the complexities in the optimal allocation of these funds, research on efficient methods for making investment decisions in this area will bring high returns.

\section{OBJECTIVES}

The present study is concerned with only one phase of investment decisions. To place this research in the over-all public investment problem, an echelon of decisions associated with public investment is defined. The first level of decision concerns the quantity of funds to be allocated for public investment as opposed to private investment. The second level is deciding how a fixed amount of funds available for public investment is to be divided among various broad categories of outlets such as education, national defense, and water resources development. The third level is allocation of limited funds for water resources development among potential water resource projects. A fourth level of decision is determining the optimal design or physical structures for a specific project. Finally, the fifth level of decision is optimal management of

\footnotetext{
${ }^{1}$ Submitted for publication, December 3, 1963.
} 
water over time. We are primarily concerned with this last type of decision under conditions of conjunctive use of ground and surface water.

The question for which we try to help provide an answer is: given physical storage and distribution facilities for water, how can present value of net output from a basin operating under conditions of conjunctive use of ground and surface water be measured empirically? A satisfactory answer to this question clears the way for objective evaluation of alternative uses for limited investment funds in water re- source development programs where conjunctive use is feasible.

The primary objective of this study is to explore methodological procedures for measuring expected present value of net output from a basin under specified storage and distribution facilities for water, and to illustrate these procedures by an empirical application. A secondary objective is to estimate the marginal value of imported water to the basin chosen for study, taking into consideration the time dimension with respect to delivery of additional water.

\section{INVESTMENT DECISIONS UNDER CONJUNCTIVE USE}

To arrive at an optimal investment policy one has to evaluate various alternative possibilities for allocating limited investment funds, available now and in the future. The evaluation is economic; an essential feature is the temporal use of the water of a basin under consideration: the choice of allocating investment funds depends on how the basin's water supply is managed. We specify water supply to be managed by a policy which maximizes present value of expected net benefits. Thus, measures of benefits obtained by methods of this study are appropriate if investment decisions are made subject to a water management policy which is optimal in this sense.

\section{Some important interrelationships}

Important relationships exist among several alternative outlets for investment funds in a basin operated under conditions of conjunctive use. There are three competing segments (with respect to their relative magnitudes) of a water resource development on a stream with a highly variable flow: (1) surface storage, (2) the surface distribution system (involving canal capacities), and (3) artificial recharge. ${ }^{2}$
Surface storage permits capture of large flows when the water cannot be used productively because of low irrigation demand or limited canal capacity, and storing the impounded water until it can be utilized economically. Increasing the reservoir size permits capture of more water and/or using the water when it has a higher economic value. Under conditions of conjunctive use, artificial recharge or increased canal capacity can substitute for reservoir capacity.

A larger canal system permits irrigation of more area with surface water and provides a productive outlet for larger quantities of stream flows as they occur randomly during the irrigation season. The water can be used as it becomes available in the stream and need not be stored (stored as long a time) to have an economic use. Firms using surface water during the season when it is available rely on ground water during the dry season when supply of surface water is inadequate.

Artificial recharge is a substitute for either of the other two outlets for investment funds because the underground reservoir can be recharged as

\footnotetext{
${ }^{2}$ Artificial recharge is the deliberate transfer of surface water to underground storage. Such transfer requires investment in additional facilities other than surface storage and many times is implemented without utilizing a surface storage facility. For a discussion of artificial recharge methods see Todd (1959).
} 
water becomes available and drawn from later in the season as water is needed. These three means of providing water are, of course, not complete substitutes. A given temporal supply of water can be provided with various combinations of development of these three competing outlets for investment funds. The economic question is: to what level should each be developed in an optimal investment policy? Essentially, we want to maximize net benefits from a limited supply of investment funds allocated to these three categories of development.

It is instructive to think of an expected net benefit surface composed of three arguments; one each for surface storage, surface distribution, and artificial recharge. The objective of an investment policy is to attain as high a point on the surface as possible with limited funds for financing development. The expected net benefit surface is implicitly defined subject to an optimal water management policy. A fourth dimension may be ground water pumping capacity and its spatial arrangement. This, however, is usually determined by private decisions, not by a public agency. If private decisions on pumping capacity could be projected in relation to public decisions on the other three variables, public investment policy could be made conditionally on private behavior.

This study focussed attention only on those factors in conjunctive water use that are most important as to investment decisions. An excellent summary of economic advantages and disadvantages of conjunctive use of ground and surface water is given by Todd (1959, pp. 215-17). Most of these factors would enter into the analysis of the investment problem through evaluation of net benefits from various alternative investments. Careful consideration of each in relation to the basin being analyzed delineates the set of alternatives. The number of possible alternatives is infinite and a feasibly small number must be selected for analysis since evaluation of each alternative is costly.

\section{$W$ ater management for a given investment situation}

Attention is now turned to the question of how water is to be allocated over time under a specified level and pattern of development. Interest centers primarily on cases where water supply is stochastic. A part of the supply in some basins may be regarded as provided with certainty but part of the supply will be random, thus making total supply stochastic.

Dealing with ground and surface water management decisions jointly is complicated by the fact that the relevant time period for decisions is different for each source of water. Surface water storage policy is primarily concerned with intra-year storage decisions while ground water storage is primarily for cyclical or inter-year storage. The logical time period for ground water decisions is a year or longer while that for surface water decisions is a month or shorter period. A further complication is the seasonal nature of agricultural production. The total quantity of water to be used during a year must be specified early in the year to permit rational planning of production, and preferably the annual quantity used should be known several years in advance.

As to maximizing net benefits, two conflicting forces are operating: On the one hand, the decision on how much water to use during a forthcoming period can be made most advantageously by waiting until the beginning of the period and utilizing the information about water storage conditions at that time. (Storage conditions are known in advance only as a probability distribution.) On the other hand, greater net benefits can be obtained by advance planning as far as organizing production is concerned.

Let us suppose a farmer does not 
know how much water will be available during the year ahead; he is notified only at the beginning of each month as to how much he will receive. The quantity for each month is determined by a random stream flow. He knows the probability distribution for his monthly supply and must make decisions on the basis of this information. In this situation net returns would probably be lower than if the monthly supply were known with certainty. But on the other hand, random stream flows could be captured more efficiently on a monthby-month decision rule than by specifying a year in advance the guaranteed monthly water supply. This is an extreme example as to the length period for which water supply decisions might be made, and we would expect that any period shorter than a year is impractical for such decisions. Conceptually the length of period is a variable with choice of its magnitude a part of the optimization process.

Ideally, we would like a surface water policy specified by short periods, say by months, and a ground water policy defined by longer periods, say five years. The policy can be formulated in such a way that total water to be used annually is specified by five-year intervals, but the amount to be pumped annually from ground water is a random variable dependent upon the monthly surface water supply. Ground water pumped each month is the difference between total quantity to be consumed during the month and the amount provided under the surface water policy for that month. The ground water policy defines the total water quantity to be used annually during each five-year period; the primary decision variable here is quantity of ground water available in storage at the beginning of the five-year period. The surface water policy defines the amount of water to be used each month as a function of surface water in storage at the beginning of the month and other relevant variables (explained in Chapter II).

The surface water decision rule is applied each month, the ground water decision rule each five-year period. By this type of over-all management of water in the basin, a stable water supply for planning production is combined with a flexible surface water policy to capture as much of the random supply as possible. It is convenient to think of the surface water policy as determining the quantity of water captured in the basin and the ground water policy as controlling the temporal allocation of water presently in storage and captured in the future. However, the two policies should be determined together and are closely interrelated. The time periods chosen for discussion are those used later in the empirical analysis. Applying the procedures sketched above, a model for deriving an optimal water management policy is given in Chapter II.

\section{THE EMPIRICAL PROBLEM}

The study area was chosen because the results would be potentially useful there, data were available, and a realistic model would be computationally feasible. A further possible advantage was the existence of a public institution which could conceivably become the water management agency for the entire area, at least with respect to ground water.

A sketch of the study area is given in figure 1. Its boundary coincides with the Kings River Conservation District except for the hatched areas.

The northeastern part of the area is presently serviced by surface water primarily from Pine Flat Reservoir on the Kings River. Surface water is used when available and supplemented by ground water as needed. The western and most southern portion of the area, comprising about one-half the total 


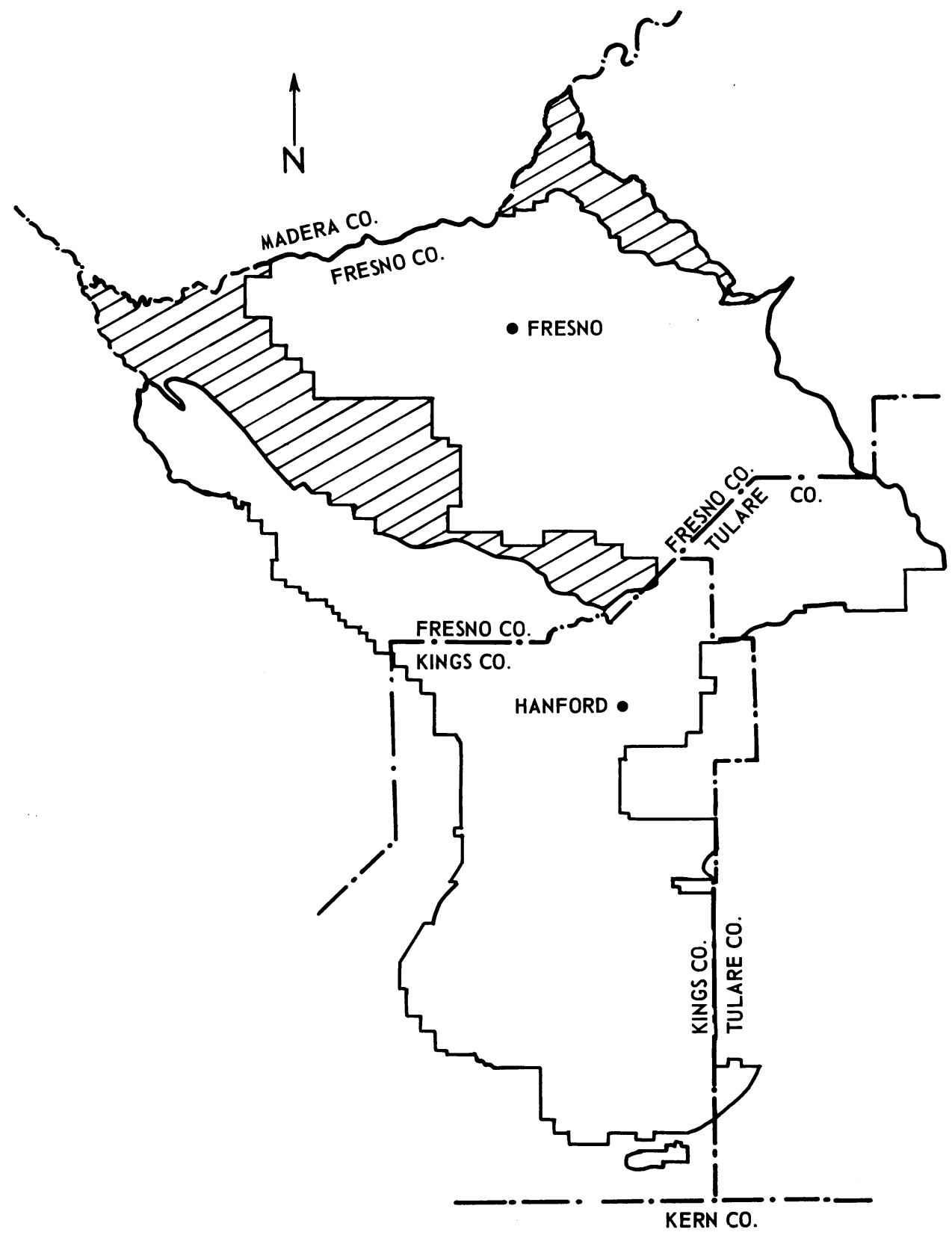

Fig. 1. Present study area. 
area, depends almost entirely on ground water.

There exists little or no potential for further water development within the study area, its only source of additional water being from some outside source such as the Central Valley Project. The maximum price which the area could pay per acre-foot of water imported is one of the questions considered in this study. The present mean supply is augmented by an increment of 250,000 acre-feet for this analysis. An answer to the question is of practical importance since the Kings River Conservation District is presently considering the procurement of additional water. The analysis of this study abstracts from institutional difficulties, while a complete answer requires consideration of present water rights and controlling agencies' behavior.

It is assumed that ground water quality is equivalent to that of surface water and does not change with depth of pumping. The maximum depth permitted is slightly greater than 400 feet. This maximum was chosen in part to facilitate empirical analysis; presumably water could be pumped from greater depths. Preferably, economic costs of pumping or physical limitations would determine the lower limit to ground water pumping.

The study area is not a true basin, that is, the ground water reservoir is not an isolated unit. The area is partially isolated by mountains on the east and the San Joaquin River on the north but these only partially restrict ground water flows in and out of the area. A preliminary evaluation of the area by the California Department of Water Resources indicated no large net flows into or out of the area under existing ground water conditions. However, this tells us very little about what the situation would be with changing depths to ground water in this and surrounding areas. We proceed as if the study area were an isolated basin, recognizing that conclusions will be in error if net ground water flows, from or into the area, are large. The large size of the study area (over 1,000,000 acres) reduces chances of a gross error due to net flows of ground water. Any net flows into or from the unit will be small relative to total ground water storage. To take account of ground water movement, complete hydrological data specifying net movements of water into or out of the area as a function of depth to ground water would be required. Data of such detail are practically impossible to obtain.

The entire study area is treated as a single aquifer of free ground water. Small portions of the area contain confined ground water but these are of relatively minor importance. They are located below the region of recharge and do not interfere in this way.

A considerable amount of technical data was provided by the California Department of Water Resources, most of which is unpublished. Practically all are tentative estimates subject to revision as more information is compiled.

\section{OPTIMAL STORAGE UNDER CONJUNCTIVE USE OF GROUND AND SURFACE WATER}

Investment decisions, as here viewed, involve comparison of net benefits resulting under various alternatives, where an alternative completely specifies physical facilities for storage and distribution of water. Net benefits for any given alternative depend on the way in which water is to be used over time. We are presently concerned with finding a policy for using water over time which will maximize the mathematical expectation of net benefits at present value when a specific investment alternative has been defined.

The problem confronted is stochastic since net benefit accruing in a time in- 
terval is a random variable. The stochastic nature of net benefits arises from uncertainties associated with many economic variables as well as future water supplies. Fortunately, the uncertainties associated with economic variables can be analyzed separately from the variable water supply. This study assumed that a measure of expected net benefits can be ascertained for a specific time interval if the quantity of water consumed within that interval is given. Thus we concentrate on the problem of optimal water management independently of the problems involved in estimating net benefit per time period for a given consumption of water per period.

Water management is an inventory problem under conditions of uncertain supply and controlled demand. The objective is to control demand in such a way that expected value of net benefits at present value is maximized. This inventory control is of extreme importance for ground water because its quantity in storage is often large relative to the annual use rate. The inventory problem is similar for surface reservoirs, but the time periods are different: usually, ground water storage can be treated as cyclical or inter-year storage, and surface water storage as seasonal or intra-year storage. This is especially true for a surface reservoir which is small relative to the annual stream flow feeding the reservoir. In this case the opportunity cost for cylical storage in the small surface reservoir is too great to warrant its use in this way. The average annual quantity of water supplied by the small surface reservoir is much less when using it for cyclical storage since the reservoir must be kept more nearly full, thus increasing the frequency with which water escapes because the reservoir is filled to capacity.

The supply of water becoming available for possible capture is a random variable and solution of the inventory problem requires an estimate of the probability distribution for this water supply. It is assumed that the probability distribution is known or a good estimate is available from time series data.

Origin of the sequential decision model used traces back to Massé (1945). Early pioneering works in the theory of inventory control are those by Arrow et al. (1951) and by Dvoretzky et al. (1952). Bellman (1957) generalized the concepts of sequential decision processes and coined the term dynamic programming. One of the first applications of modern sequential decision theory to water storage problems was by Little (1955). Several other water storage problems have been formulated in the general dynamic programming model during recent years, but interest has concentrated on hydroelectric systems. A model for a single, multiple purpose reservoir which is applicable under rather restricted conditions is considered by Thomas and Watermeyer (1962). This paper also contains additional references to recent work in the theory of water storage.

In our study the simplest water management problem is considered firstthe case of only underground storage. A mathematical model is constructed which permits maximization of present value of expected net benefits for any length planning horizon, under specified physical conditions of recharge, storage capacity, etc.

The case of two storage facilities is considered next: a single surface reservoir and one underground reservoir. The mathematical model formulated as a basis for quantitative analysis of this situation becomes quite complex and the need for simplification is recognized. Approximation procedures are suggested, but completely rigorous mathematical analysis to support them is not given. Solution of the empirical problem represents a simplified application of the approximation methods discussed here. Most of the analysis in subsequent chapters will be understandable with only the immediately following singlestorage facility case as background. 


\section{SOLUTION OF THE INVENTORY PROBLEM WITH ONE STORAGE FACILITY}

The one-reservoir case may be regarded as characterizing the problem existing in a basin or it may be considered as part of an iterative process for solution of a problem involving a more complicated set of storage facilities. For instance, some management rule might be assumed for the surface reservoir which effectively determines the probability distribution of annual water supply to the underground aquifer, thus reducing a two-storage facility case to a one-storage facility case. The reduction of problems to simpler ones by such means will be discussed in detail later.

Let us now formulate the inventory problem for a basin having only ground water storage in a stochastic dynamic programming model. Net output per period from the basin is a function of the quantity of water used during a period and the level of storage at the beginning of the period. Level of storage influences the pumping costs required to deliver the water at the surface for use in production. For expository convenience, we assume no effective upper limit on storage capacity, but the model is easily modified to ac- count for an upper limit. The computations are essentially the same in an application under either situation.

The following definitions and notations are used:

$X_{n}=$ quantity of water used during the $n^{\text {th }}$ period from the end of the planning horizon.

$S=$ quantity of ground water in storage at the beginning of a period.

$W_{n}=$ water added to storage during the $n^{\text {th }}$ period from the end of the planning horizon (a random variable independently distributed over time).

$h\left(W_{n}\right) d W_{n}=$ probability density function for $W_{n}$.

$B_{n}\left(X_{n}, S\right)=$ net benefit (not discounted) resulting from $X_{n}$ units of water with storage at level $S$, during the $n^{\text {th }}$ period from the end of the planning horizon.

$r=$ relevant discount rate to reduce the stream of benefits to present value.

Using the "principle of optimality" (Bellman, 1957, p. 83) and thinking of our problem as a multistage decision process over time we can write the functional equation

$$
\begin{aligned}
f_{n}(S)= & \operatorname{Max}_{X_{n} \leqq S}\left[B_{n}\left(X_{n}, S\right)+(1+r)^{-1} E\left(f_{n-1}\left(S+W_{n}-X_{n}\right)\right)\right] \\
= & \operatorname{Max}_{X_{n} \leqq S}\left[B_{n}\left(X_{n}, S\right)+(1+r)^{-1} \int_{0}^{\infty} f_{n-1}\left(S+W_{n}-X_{n}\right) h\left(W_{n}\right) d W_{n}\right] .
\end{aligned}
$$

The above functional equation for an $n$-stage process may be interpreted literally as the maximization, with respect to water consumption at stage $n$, of the immediate net benefit plus the discounted expected value of net benefit in the $(n-1)$ remaining stages, given that an optimal policy will be used during the remaining $(n-1)$ stages (the maximization being carried out for all relevant storage levels at the begin- ning of the $n$-stage process).

Making the variables, $X, W$, and $S$ discrete will reduce the problem to a finite Markovian decision process which can be solved by a digital computer. Define $N$ discrete levels for storage, $S_{1}$, $S_{2}, \ldots S_{N}$. Let $W$ and $X$ take on $m$ discrete values $W^{1}, W^{2}, \ldots W^{m}$ and $X^{1}$, $X^{2}, \ldots X^{m}$. The value $S_{i}$ must be thought of as an interval but always assigned its mid-value such that $S_{i}+$ 
$W_{n}{ }^{j}-X_{n}{ }^{k}$ takes on the discrete value $S_{t}$ if it falls in the interval covered by
$S_{t}$. The functional equation can be rewritten as the recursive relation

$$
\begin{aligned}
f_{n}\left(S_{i}\right)= & \operatorname{Max}_{k}\left[B_{n}\left(X_{n}^{k}, S_{i}\right)+(1+r)^{-1} \sum_{j=1}^{N} f_{n-1}\left(S_{i}+W_{n}^{j}-X_{n}^{k}\right) P\left(W_{n}=W_{n}^{j}\right)\right] \\
& X_{n}^{k} \leqq S_{i} .
\end{aligned}
$$

For $S_{i}$ we can define a probability, $p_{i j}^{k}$, for each $X^{k}$, which is the probability of going to state $S_{j}$, given that storage level $S_{i}$ existed at the beginning of the period and $X^{k}$ units are withdrawn from storage during the period. The discrete intervals for $W$ and $X$ are quite arbitrary and need not be the same for both variables. There may exist more than one $W^{t}$ such that $S_{i}+W^{t}-$ $X^{k}=S_{j}$ (the equality meaning that the left side falls in the interval implied by $S_{j}$ ) and therefore, the $p_{i j}^{k}$ do not coincide with $P\left(W=W^{j}\right)$ but are a simple function of the latter probabilities. The recurrence relation can be written in terms of the $p_{i j}^{k}$ as

$$
f_{n}\left(S_{i}\right)=\operatorname{Max}_{k}\left[B_{n}^{k}\left(S_{i}\right)+(1+r)^{-1} \sum_{j=1}^{N} p_{i j}^{k} f_{n-1}\left(S_{j}\right)\right], n=0,1,2, \cdots .
$$

The solution procedure is easily illustrated. Start with a one-stage process (the last unit of the planning period) carrying out the maximization for all $S_{i}$. Then take a two-stage process, using the results from a one-stage process, to carry out the maximization on $k$ for all $S_{i}$. Then a three-stage, four-stage, ... $n$-stage process is treated giving the largest expected net social benefit obtainable. The optimum management rule is implicit in the solution to the functional equations. The $n$-stage process supposedly leaves us at the current period looking $n$ periods into the future with the problem of managing the water used each period. We know the quantity of water in storage at the beginning of the current period and $f_{n}\left(S_{i}\right)$ gives us a value for $k$ which is optimum. Upon reaching the $(n-1)$ stage we will find ourselves in another state (not known until the period following the current one) and $f_{n-1}\left(S_{i}\right)$ gives us a $k$ which is optimum, etc.

The quantity of water that will be used each period is not known until that period is reached; the information on the quantity of water in storage is used sequentially as it becomes available. The functional equation, however, gives the expected net social benefit at present value for the entire planning period given that an optimal policy is followed with respect to periodic water use (optimal within the accuracy of our discrete model simplification).

A numerical example will help clarify the conceptual framework and show the mechanics of solving relation (2.2). The example is the very simplest case-two storage states and two alternative quantities of water for use per period. Since the actual magnitude of the quantity in storage does not enter in numerical solution of the problem after it is formulated in the form of (2.2), the storage level is denoted by the subscript, $i$. Table 1 summarizes the data for the numerical example. Note that the net benefit function, $B_{n}{ }^{k}\left(S_{i}\right)$, is invariant over $n$, the stage of the process. The discount factor, $(1+r)^{-1}$, is specified at 0.9 .

For $n=0$, we assign $f_{n}\left(S_{i}\right)$ the value zero. The justification for this value is implied by the definition of $f_{n}\left(\boldsymbol{S}_{\boldsymbol{i}}\right)$ which is the present value of expected net benefits from $n$ periods under an optimal policy. Thus we see by relation (2.2) that $f_{1}\left(S_{i}\right)=\operatorname{Max} B^{k}\left(S_{i}\right)$ which is the maximum expected immediate net benefit. This is the result that would be 
TABLE 1

ILLUSTRATIVE PROBLEM

\begin{tabular}{|c|c|c|c|c|}
\hline \multirow{2}{*}{$\underset{i}{\text { State }}$} & \multirow{2}{*}{$\begin{array}{c}\text { Alterna- } \\
\text { tive } \\
k\end{array}$} & \multicolumn{2}{|c|}{ Probabilities } & \multirow{2}{*}{$\begin{array}{c}\text { Expected } \\
\text { net benefit } \\
B^{k}\left(\boldsymbol{S}_{\boldsymbol{i}}\right)\end{array}$} \\
\hline & & $p^{k_{i 1}}$ & $p^{k}{ }_{i 2}$ & \\
\hline \multirow[t]{2}{*}{$1 . \ldots \ldots$} & 1 & .3 & .7 & 38 \\
\hline & 2 & .9 & .1 & 40 \\
\hline \multirow[t]{2}{*}{$2 \ldots \ldots$} & 1 & .1 & .9 & 41 \\
\hline & 2 & .5 & .5 & 43 \\
\hline
\end{tabular}

expected with only one period left in the planning horizon. From table 1 it is seen that $f_{1}\left(S_{1}\right)=40$ and $f_{1}\left(S_{2}\right)=43$; these numbers are used to compute $f_{2}\left(S_{i}\right)$.

Applying relation (2.2), $f_{2}\left(S_{1}\right)=$ $\operatorname{Max}[38+.9((.3)(40)+(.7)(43)), 40+$ $.9((.9)(40)+(.1)(43))]=$

$\operatorname{Max}(75.89,76.27)=76.27$, given by alternative two. Likewise, $f_{2}\left(\boldsymbol{S}_{2}\right)=$

$\operatorname{Max}[41+.9((.1)(40)+(.9)(43)), 43+$ $.9((.5)(40)+(.5)(43))]=$

$\operatorname{Max}(79.43,80.35)=80.35$, given by alternative two. We now have $f_{2}\left(S_{i}\right)$ and can proceed to compute $f_{3}\left(S_{i}\right)$ in exactly the same way as $f_{2}\left(S_{i}\right)$ was computed above.

Table 2 summarizes the iterations for $n=1,2, \ldots 5$, where $d_{i}(n)$ denotes the optimal alternative for state $i$. Observe that the decision rule appears to have converged to the same rule regardless of the stage for $n$ greater than two. It can be shown that such convergence will always take place when the net benefit function is invariant over stages (Bellman, 1957, p. 121). With respect to the numerical example, we may conclude that the optimal policy is to use alternative use rates one and two for storage levels one and two, respectively, if the public agency's planning horizon is greater than two periods. The next section gives a method to verify whether the decision rule has converged and the method is applied to this example for illustrative purposes.

TABLE 2

NUMERICAL SOLUTION OF THE EXAMPLE

\begin{tabular}{c|c|c|c|c|c}
\hline & $n=1$ & $n=2$ & $n=3$ & $n=4$ & $n=5$ \\
\cline { 2 - 3 }$f_{n}\left(S_{1}\right) \ldots \ldots \ldots \ldots$ & 40 & 76.27 & 109.22 & 138.98 & 165.76 \\
$d_{1}(n) \ldots \ldots \ldots \ldots$ & 2 & 2 & 1 & 1 & 1 \\
$f_{n}\left(S_{2}\right) \ldots \ldots \ldots \ldots$ & 43 & 80.35 & 113.48 & 143.22 & 169.99 \\
$d_{2}(n) \ldots \ldots \ldots \ldots$ & 2 & 2 & 2 & 2 & 2 \\
\hline
\end{tabular}

\section{AN OPTIMAL POLICY INVARIANT OVER STAGES}

The recursive relation of (2.1) has a convenient property when $B_{n}{ }^{k}\left(S_{i}\right)$ is invariant over $n$, thus denoted by $B^{k}\left(S_{i}\right)$. The property is convergence to an optimal policy which is independent of the stage when the number of stages becomes very large. In other words, the optimal quantity of water to be used at the $i^{\text {th }}$ storage level is the same whether $n$ or $n+1$ periods remain in the planning horizon when $n$ is very large.

It is convenient to write relation (2.2) in matrix form. Define, $f(n)=N$-component column vector with $i^{\text {th }}$ component $f_{n}\left(S_{i}\right)$

$q=N$-component column vector with components comprised of magnitudes of $k$

$b_{n}(q)=N$-component column vector with $i^{\text {th }}$ component $B_{n}{ }^{k}\left(\boldsymbol{S}_{\boldsymbol{i}}\right)$

$P(q)=N \times N$ matrix elements $p_{i j}{ }^{k}$, where $k$ for the $i^{\text {th }}$ row is determined by the $i^{\text {th }}$ component of $q$.

$\beta=(1+r)^{-1}<1$.

Then matrix form relation (2.2) is written

$$
f(n)=\operatorname{Max}_{q}\left[b_{n}(q)+\beta P(q) f(n-1)\right], n=0,1,2, \cdots .
$$

Solution of (2.3) is accomplished by specifying a terminal value of the op-

eration for the end of the planning horizon. This value is conveniently 
taken as zero; thus giving $f(0)=0$. for $n=1,2,3, \ldots$ as follows: Equation (2.3) is solved successively

$$
\begin{aligned}
& f(1)=\operatorname{Max}_{q}\left[b_{1}(q)+\beta P(q) f(0)\right]=\operatorname{Max} b_{1}(q) \\
& f(2)=\operatorname{Max}_{q}\left[b_{2}(q)+\beta P(q) f(1)\right] \\
& \vdots \\
& f(n+1)=\operatorname{Max}_{q}\left[b_{n+1}(q)+\beta P(q) f(n)\right] .
\end{aligned}
$$

When $n$ reaches the number of periods in the entire planning horizon, the solution being sought has been found. That is, maximum expected present value of net benefits is given by $f(n)$ and an optimal decision rule $q(n)$ is given by the $q$ which maximizes the right-hand side of (2.3). Note that $f(n)$ and $q(n)$ are vectors with $i^{\text {th }}$ components being the respective measure and rule for water storage level $S_{i}$ of (2.2).

It is quite likely that decisions in water storage control will involve an infinite planning horizon. Obviously the iterations of (2.3) must stop at a finite number and from the point of view of computational economy the number of iterations should be as small as possible. With these facts in mind, we exploit a convergence property of (2.3) for the case where $b_{1}(q)=b_{2}(q)=\ldots=b_{n}(q)$. This is the situation where expected immediate net benefits from a water use policy are invariant over time.

The convergence property can be precisely stated

$$
\begin{aligned}
& \lim _{n \rightarrow \infty} q(n)=q^{*}=\text { a constant vector, } \\
& \lim _{n \rightarrow \infty} f(n+1)=f(n) .
\end{aligned}
$$

Convergence to a fixed optimal policy, $q^{*}$, is usually much more rapid than convergence of the functional value $f(n)$ to a constant vector. We would like a means to verify whether a policy actually has converged when the iterations of (2.3) suggest convergence has taken place.

Such a means is provided by the work of Howard (1960) although he develops a different approach to solving the problem and does not explicitly con- sider the following method. We first look at the asymptotic solution of (2.3) under a constant policy and invariant return function over $n$. Denote the constant vector $b_{n}(q)$ by $b$ and the constant matrix $P(q)$ by $P$. Iterating (2.3), $f(n)=b+\beta P f(n-1)=b+\beta P b$

$$
\begin{aligned}
& +\beta P f(n-2) \\
& =b+\beta P b+\beta^{2} P^{2} b+\beta P f(n-3) \\
& =\left(I+\beta P+\beta^{2} P^{2}+\ldots+\beta^{n-1} P^{n-1}\right) b,
\end{aligned}
$$

where $I$ is the identity matrix. It is easily established that $\lim _{n \rightarrow \infty} f(n)=(I-$ $\beta P)^{-1} b$ by the limit of the matrix $(I+$ $\beta P+\beta^{2} P^{2}+\ldots+\beta^{n} P^{n}$ ). (Kemeny and Snell, 1960, p. 22.) Obtaining expected present value of net benefits over an infinite planning horizon, under a constant policy and net benefit function, is seen to require solution of $N$ linear equations. That is, solution of

(2.5) $\quad(I-\beta P) X=b$

for the $N$-component, unknown vector $X$.

The computational algorithm can now be stated:

(1) Carry out the iterations of (2.4) until several repetitions of the same policy have taken place, giving an indication that convergence to a single optimal policy has been attained.

(2) Solve the system of equations of (2.5) for the constant policy suggested in step (1).

(3) Obtain the solution to (2.6) $Y=\operatorname{Max}[b(q)+\beta P(q) X]$. If $Y=X$, the policy associated with $X$ is the optimal policy for an infinite planning horizon and the policy derived in (2.6) will 
be that same policy. If $Y \neq X$, then the iterations of (2.4) must be continued, and ultimately a different policy will result for some larger $n$. The above procedure is repeated again when it appears convergence has taken place on another policy. In practice the iterations of (2.4) and solution of (2.6) are carried out component by component instead of by vectors, i.e., in the form of relation (2.2). Justification of step (3) of the algorithm is implied by the work of Howard (1960, pp. 86-87).

The above computational method is used in the empirical investigation of this study because it provides a convenient means to analyze alternative dates at which water might be imported to the study area. The method also
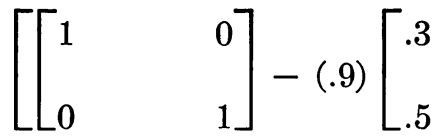

with the solution being makes economical use of machine storage capacity and the same program can be used with a variable as well as constant return function over stages. The invariant return function case without discounting can be worked as a linear programming problem (Manne, 1960). Only very recently was a method developed for handling discounting in a linear programming model (d'Epenoux, 1963).

The method of verifying that a policy is optimum for an infinite planning horizon is now applied to the numerical example of table 1 . The first step is to solve the system of equations given by (2.5) for the policy that is repeating itself in the computational procedure. This policy is given by table 2 as: use rates one and two in storage states one and two, respectively. Therefore, the system of equations to be solved is

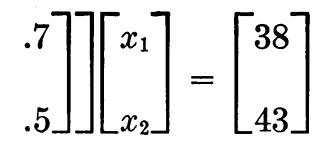

$$
\left[\begin{array}{l}
x_{1} \\
x_{2}
\end{array}\right]=\left[\begin{array}{l}
406.69 \\
410.93
\end{array}\right]
$$

The next step is to substitute the vector $X$ into relation (2.6) and solve for $Y$.

$$
\begin{aligned}
y_{1}= & \operatorname{Max}[38+.9((.3)(406.69)+(.7) \\
& (410.93)), 40+.9((.9)(406.69) \\
& +(.1)(410.93))]=\operatorname{Max}(406.69, \\
& 406.40)=406.69 . \\
y_{2}= & \operatorname{Max}[41+.9((.1)(406.69)+(.9) \\
& (410.93)), 43+.9((.5)(406.69) \\
& +(.5)(410.93))]=\operatorname{Max}(410.46, \\
& 410.93)=410.93 .
\end{aligned}
$$

Since $y_{i}=x_{i}$ and the optimal decision rule is unchanged, we conclude that the policy suggested by Table 2 is the optimal policy for an infinite planning horizon.

An approximate decision rule for the model of this section has been derived by Burt (1964). In order for the approximation to give good results, water in storage must be large relative

to the optimal periodic rate of use. Therefore, the approximation will not be in serious error for basins in early stages of development where current inventory is large compared to rate of use, even though at some later date storage will have been reduced to the point where the method would no longer be appropriate. The approximation will always be acceptable for basins in which cost of increased pumping depths limits ground water mining (as contrasted to physical limits on pumping depth being the limiting factor). These assertions are justified in the above mentioned reference.

\section{An infinite planning borizon}

The convergence property of recursive relation (2.2) for an invariant benefit function gives us a fairly general 
method of working with an infinite planning horizon. Assumption of a constant net benefit function after a finite number of periods from the present is required. For example, we might feel reasonably comfortable making net benefit projections separately for each period from the current period up to say 50 years into the future. Uncertainty about periods beyond fifty years may be so great that extension of the 50 th year's projection indefinitely into the future is considered essentially as reliable as additional projections. Suppose our stage is defined to be a year and $t$ measures time from the present with $t=0$ being the current year. Under our hypothetical case we have an estimated net benefit function

$$
B_{t}^{k}\left(S_{i}\right), t=0,1,2, \cdots 49
$$

and

$$
B_{50}^{k}\left(S_{i}\right), t=50,51, \cdots
$$

where $B_{t}{ }^{k}\left(S_{i}\right)$ is the net benefit under the $k^{\text {th }}$ level of water consumption during the $t^{\text {th }}$ year, if ground water in storage is at the $i^{\text {th }}$ level. Time, $t$, has been substituted for the stage, $n$, of the decision process; care must be exercised to avoid confusion in interpreting $t$ and $n$ ( $t$ denotes time measured from the present and $n$ denotes the number of stages remaining in the planning horizon ).

The first step in solving the problem is solution of recurrence relation (2.2) using $B_{n}{ }^{k}\left(S_{i}\right)=B_{50}{ }^{k}\left(S_{i}\right), n=0,1,2, \ldots$ for $n \rightarrow \infty$. The next step is to consider a finite planning horizon of fifty periods with a variable return function $B_{n}{ }^{k}\left(S_{i}\right)$, $n=0,1,2, \ldots 50$. We set $f_{o}\left(S_{i}\right)$ equal to $\lim _{n \rightarrow \infty} f_{n}\left(S_{i}\right)$ obtained above using $B_{50}{ }^{k}\left(S_{i}\right)$ in the recurrence relation. Then we perform the iterations

$$
\begin{aligned}
& f_{1}\left(S_{i}\right)=\operatorname{Max}_{k}\left[B_{1}^{k}\left(S_{i}\right)+\beta \sum_{j=1}^{N} p_{i j}^{k} f_{0}\left(S_{j}\right)\right] \\
& f_{2}\left(S_{i}\right)=\cdots \\
& \vdots \\
& f_{5_{0}}\left(S_{i}\right)=\operatorname{Max}_{k}\left[B_{50}^{k}\left(S_{i}\right)+\beta \sum_{j=1}^{N} p_{i j}^{k} f_{49}\left(S_{j}\right)\right] .
\end{aligned}
$$

Note that the subscript on the net benefit function denotes the stage in the above iterations; $n=50$ is equivalent to $t=0$ and $n=1$ corresponds to $t=49$.

\section{Continuous variable refinements}

Numerical solution in the preceding discrete models gives points as approximations to the continuous variable equation (2.1). A curve can be fitted to the derived points in order to estimate the continuous relationship which actually underlies the analysis. This continuous function can be used to fill in the gaps in the discrete approximation and the calculus can be used to refine the optimal levels of $X_{n}$ for any quantity in storage $S$.

Relation $(2.1)$ is conveniently written

$$
f_{n}(S)=\operatorname{Max}_{X_{n}}\left[B_{n}\left(X_{n}, S\right)+\beta E f_{n-1}\left(S+W_{n}-X_{n}\right)\right]
$$

can be expressed by an additional equation under the proper specifications, i.e.,

$$
f_{n}(S)=B_{n}\left(X_{n}, S\right)+\beta E f_{n-1}\left(S+W_{n}-X_{n}\right)
$$




$$
\begin{aligned}
& \frac{\partial B_{n}}{\partial X_{n}}-\beta E f_{n-1}^{\prime}\left(S+W_{n}-X_{n}\right)=0 \\
& \frac{\partial^{2} B_{n}}{\partial X_{n}^{2}}+\beta E f_{n-1}^{\prime \prime}\left(S+W_{n}-X_{n}\right)<0 .
\end{aligned}
$$

It will be found advantageous to in order to obtain a convenient form approximate $f_{n-1}\left(S+W_{n}-X_{n}\right)$ by a for $E f_{n-1}{ }^{\prime}\left(S+W_{n}-X_{n}\right)$. The relationTaylor's series in the proximity of $S$ ship is

$$
\begin{aligned}
E f_{n-1}\left(S+W_{n}-X_{n}\right)= & f_{n-1}(S)+E\left(W-X_{n}\right) f_{n-1}^{\prime}(S) \\
& +\frac{E\left(W-X_{n}\right)^{2}}{2 !} f_{n-1}^{\prime \prime}(S)+\cdots
\end{aligned}
$$

This relationship is particularly useful when a polynomial is fitted to estimate

$f_{n-1}(S)$. For example, a quadratic in $f_{n-1}(S)$ would let $(2.9)$ be simplified to

$$
\frac{\partial B_{n}}{\partial X_{n}}=\beta\left[f_{n-1}^{\prime}(S)+E\left(W-X_{n}\right) f_{n-1}^{\prime \prime}(S)\right] .
$$

If $B_{n}\left(X_{n}, S\right)$ could also be approximated in the interval where solution takes place by a quadratic function, (2.12) gives a linear decision rule.

An economically important measure in our continuous model is $f_{n}^{\prime}(S)$ which is marginal value of stored ground water. This marginal value is an indicator of the merit of investment to increase the basin's water supply. Caution must be exercised, however, because additional water supplies might alter the function for net benefits- $B_{n}\left(X_{n}, S\right)$.

\section{A PROBLEM INVOLVING TWO STORAGE FACILITIES}

The basin for which the following model is most appropriate has a single isolated aquifer for underground storage and a surface reservoir. The underground reservoir receives recharge from natural runoff, artificial recharge from the surface reservoir, and incidental recharge from the surface water distribution system. We note that the latter two sources are variables subject to manipulation for purposes of economic optimization although the incidental recharge is a fixed proportion of the surface water used directly for productive purposes.

Straightforward treatment of the larger problem in the same manner as the one storage facility case leads to several difficulties. In nearly all cases storage capacity of a surface reservoir is small relative to annual stream flows feeding the reservoir. Extremely in- efficient management of the reservoir would result if the decision variable were quantity of water in storage at the beginning of the year and the maximum amount that could be used was that quantity. In other words, a year is too long a period upon which to base surface water management decisions.

On the other hand, allocation of water for productive purposes should preferably have at least one year as the length of period for which water supply needs to be known. We could proceed on a short period decision basis, leaving producers with an uncertain water supply from one period to the next, but this approach is not considered practical, particularly under conditions of conjunctive use. It would be more suitable if the only supply of water were a surface reservoir.

It is concluded that under conditions 
of conjunctive use, it is reasonable that producers have a known water supply at least a year in advance and preferably longer. At the same time, surface water supply should be managed on the basis of a relatively short period, perhaps a month or even a shorter period. This is especially true if artificial recharge is to be a productive investment. These two conditions rule out the simple model used for the previous case involving only ground water storage.

Another consideration in surface water management based on short periods is stochastic dependence among stream flows of different periods. But this can be handled with a Markov dependence relationship in most instances.

Our first approach is to formulate a complex dynamic programming model with several variables in the functional equation to express the state of the process. This can be done by making long period decisions as to the total quantity of water used during that period and optimizing short period decisions subject to each possible long period decision. The stage of the process is defined on the short period and the long period is a simple multiple of the short period. For convenience in discussion, let the long period be comprised of $m$-short periods.

Decisions on surface water utilization are made at each stage while decisions on total water used over the $m$-stage period are made systematically for each $m$ stages and primarily based on ground water storage conditions. Assume the stream flow carrying water to the surface reservoir can be adequately described by a Markov probability distribution with respect to the short period (stage of the process). Formulation of the problem in a dynamic programming model requires four variables to describe the state of the process: (1) ground water storage, (2) surface water storage, (3) stream flow during the preceding stage (short period), and (4) total water to be used during the long period ( $m$ stages or short periods) within which the present stage is contained.

Maximization takes place with respect to surface water for direct consumption and surface water for artificial recharge at each stage. However, maximization with respect to total water used at each stage takes place at the beginning of each $m$-stage (long) period. It is assumed that optimum allocation of water within an $m$-stage period can be determined exogenously from the present model, for any specified quantity. For example, if the long period is a year and the short period a month, the stage is a month and $m$ stages are a year $(m=12)$. The preceding assumption is that the monthly allocation of a specified annual supply of total water consumed can be made without incorporating the decision into the dynamic programming model.

The example of months and years for short and long periods, respectively, is continued for convenience in discussion. We shall consider interrelationships among variables of the model from stage to stage. Direct consumption of surface water contributes to the ground water supply during subsequent periods through incidental recharge from the surface distribution system and possibly deep percolation of irrigation water applied to farm land. Artificial recharge in one stage contributes to ground water in following stages. The quantity of surface water used for both direct consumption and artificial recharge influences the water in surface storage during subsequent periods. In summary, the two variables, direct surface use and artificial recharge, determine parameters in the joint probability distribution of surface and ground water storage for the following period, given storage conditions in the current period. The above is with reference to short periods (months), although true in the aggregate for long periods 
(years). The variable, total water to be used during a year, which implies total quantity used each month, also affects parameters of the joint probability distribution of ground and surface water storage. This variable is manipulated only at the beginning of each year and remains unchanged during the following twelve months, but direct surface water consumption and artificial recharge magnitudes are subject to change each month.

Let us now introduce the recursive relation,

$$
\begin{array}{ll}
f_{n}(i(n))=\operatorname{Max}_{k(n)}\left[b_{i n}^{k(n)}+\beta \sum_{j=1}^{N} p_{i j}^{k(n)} f_{n-1}(j(n))\right], i=1,2, \cdots N \\
0<\beta<1 & n=1,2, \cdots . \\
f_{0}(i(n))=c_{i} . &
\end{array}
$$

This system of discrete relations is used as an approximation to the continuous model described above. The state, $i(n)$, is determined by one of the possible set of discrete values which the four state-variables are permitted to take. The four variables defining the state of the process, which we call statevariables, are listed on page 45 . An alternative, $k(n)$, is defined by a set of discrete values assigned to the decision variables: (1) direct surface consumption, (2) artificial recharge, and (3) total water to be used. The alternatives permitted are a function of the stage, $n$, because the third decision-variable is permitted to change only at the stage defining the beginning of a year. The states, $i(n)$, are a function of $n$ because the fourth state-variable (total water to be used during the forthcoming year) is a decision-variable at the stage defining the beginning of the year and thus missing from the set of statevariables. In other words, the fourth state-variable is the third decisionvariable and it is either one or the other, but not both, at any stage of the process. It is a decision-variable one-twelfth of the time and a statevariable eleven-twelfths of the time when our short and long periods are months and years, respectively.

Solution of relation (2.13) gives a decision rule which depends on three variables: (1) ground water in storage at the beginning of the long period,
(2) surface water in storage, and (3) stream flow in the preceding short period. After solution of the problem is complete, quantity to be consumed during the long period is no longer a state-variable at any time because a one-to-one correspondence exists between the above listed state-variables and the consumption rate of the long period.

The model can be solved theoretically by the iterative methods previously described with a variable return function over stages, but a serious difficulty is met in practice. The number of states required to obtain acceptable precision in analysis is likely to be beyond the capacity of available computers. The difficulty is accentuated by the necessity of having discrete ground water storage intervals in the same order of magnitude as short period recharges. Ground water storage capacity is extremely large relative to this magnitude making the number of discrete storage intervals prohibitively large.

In order to show the necessity of having a maximum limit on the size of discrete storage intervals, let us look at the one storage facility case where only ground water storage exists. A very large interval is considered first and we look at the consequences. Some discrete measure must be used for the interval; we assign the mid-value of the interval. The probability of moving out of the interval is next considered. At 
least a periodic recharge equal to onehalf the interval is needed to show a movement into another interval because measurements are made at the mid-value of each discrete interval. Obviously, as the storage interval is increased, the probability of moving from the present storage state goes to zero. The decision model for a given discrete approximation will tend to choose consumption rates giving an expected net effect which puts storage below the midpoint of the present interval but not into the lower interval, and an analogous expected net effect for movement to higher or lower storage states. This tendency leads to a bias, the size being determined by the crudeness of the discrete approximation to the true continuous relation.

In case of only underground storage, the time period defining the stage of the process can be increased to compensate for a larger storage interval. The quantity of recharge per stage increases with the length of the stage and permits a larger discrete storage interval. When both ground and surface water storage are incorporated in the problem, lengthening the stage is not possible because the stage is determined by surface storage decision requirements.

There is a method of meeting the difficulties associated with a large number of state-variables (in dynamic programming a large number is more than two). The method is essentially representation of the function, $f_{n}(i(n))$, by a polynomial approximation with the arguments being the statevariables. A discussion of the method, in general, is given by Bellman (1961, p. 244). Computer time required for solution may become excessive; but if the problem is important enough economically, a solution can be obtained. The method has the advantage that it can be adapted to less precise discrete approximations without making the analysis invalid. That is, less precision is lost by a crude approximation to continuous variables with discrete intervals when using a polynomial approximation to the function, $f_{n}(i(n))$, than when working directly with the discrete values.

For example, a small quantity recharged to ground water during a single stage, $n$, of the process exerts its influence because the polynomial of $f_{n-1}(i(n-1)$ is evaluated for the new storage level resulting from the small increment of recharge. Without the polynomial approximation, the storage level with the small increment of recharge would fall in the same discrete interval as that existing in the current stage, $n$. Thus, the storage state would show no change from the $n^{\text {th }}$ to $(n-1)^{\text {th }}$ stage with respect to ground water storage. In this situation optimum decisions would not be made since one of the interrelationships between the $n^{\text {th }}$ and $(n-1)^{\text {th }}$ stages is not taken into consideration; namely, the effect surface water decisions in stage $n$ have upon ground water conditions in stage $(n-1)$.

To show how rapidly the number of states increases when several statevariables are present, consider a problem with four state-variables. Suppose each variable is permitted ten discrete values. The number of states is $10^{4}=10,000$ which is beyond the rapid computing storage capacity of present computers when the $p_{i j}^{k}$ associated with each of the 10,000 states are considered.

Several assumptions are implicit in the preceding discussion. The model requires that pumping of ground water be uniformly distributed over the basin so that local overdrafts do not occur. A quantity of water in storage must reflect a depth to ground water which has a unique pumping cost associated with it.

Our solution can only be optimum within the limits of the discrete approximation to the more realistic continuous model. We note that time has been treated as discrete from the be- 
ginning of the discussion, which is also a convenient approximation to a more precise continuous formulation of the problem.

Several variables have been left out which could be important under some circumstances. Precipitation has not been included explicitly as a determining variable in the net benefit function. It does contribute to agricultural output even in the most arid regions of irrigated farming. The importance of including precipitation explicitly depends on its absolute contribution to net benefit and its variance. If either is small, little precision is lost by assuming an average contribution by precipitation to net benefit during each period.

Evaporation from surface reservoirs and inflow or outflow of ground water to or from the basin aquifer have not been considered. These additional variables can easily be included in the model at the expense of introducing more alternative decision rules and states in the multistage decision process, or by adopting a less precise discrete approximation to the problem. The magnitudes of these variables will be the primary criteria in deciding whether to include them in the model.

The quantity of water in surface storage is a relevant variable in the net benefit function when hydroelectric power is being generated from the dam. There is also the problem of scheduling short period releases from the surface reservoir for generating power. This problem was dealt with using a dynamic programming model, by Little (1955). Under the conjunctive use problem considered, the scheduling of releases for power generation is only one of several variables to be managed optimally. This can be handled by a more detailed model than the one presented, but the basic principles are the same, and it could be reduced to a finite Markovian decision process by allowing variables to take on only suitable discrete values.

A different approach to numerical solution of the complex two storage facility problem is presented in the following section. The method most appropriate for a particular basin is determined largely by characteristics of the basin and computer facilities available. A tolerable level of accuracy under restrictions on funds for the analysis is another factor. The method which follows has the advantage of requiring only a small computer and a simple program, and can make use of a priori knowledge very effectively.

\section{AN ALTERNATIVE APPROACH FOR MULTIPLE STORAGE UNITS}

If we are willing to assume that ground water in storage dominates the decision on total water consumption for the long period, making the influence of other state variables negligible, the decision rule can be thought of as comprised of two components. First, there is a total water consumption policy for the long period which is defined on the basis of ground water in storage at the beginning of the long period. Second, there exists a family of surface water policies, one for each of the possible states of ground water storage at the beginning of the long period.
In order to facilitate the exposition, only one surface water reservoir will be assumed. However, the basic approach can be extended to more than one surface reservoir although computational burdens increase rapidly. The surface reservoir is permitted to release water for direct surface use or for artificial recharge and benefits might be partially derived from generation of hydroelectric power and from flood control.

The first step in the approximating procedure is to guess an optimal policy for surface water based on a fairly 
short time period, say a month. The rule specifies how much water will be released for artificial recharge and direct use in production, given the quantity of water in the surface reservoir at the beginning of the month being considered. The rule will change from month to month, but remain constant annually with respect to monthly decisions. A more precise rule may be desired, taking into consideration the stochastic dependence of stream flows for periods as short as months. The number of states would be increased for a given number of discrete reservoir levels. The more complete decision process would have the state defined by the calendar month, quantity of surface water in storage at the start of the current month, and stream flow of the preceding month.

In some basins, excellent estimates of stream flow for a short period into the future are available. Better results can be obtained by utilizing these estimates, taking full advantage of all information available. The model is not adequate to take errors in estimation into account, but can be adapted to the case where estimates are completely correct. Errors in estimation will reduce the present value of expected net benefits attainable, but are not likely to change the decision rule significantly unless the errors are relatively large and the estimates quite biased. The state of the process (with stream flow for the next stage known) is defined by quantity of surface water in storage, identification of the period (the month), and stream flow during the next period. A surface water policy designates the amount of water to be allocated each to artificial recharge and direct consumption, with one of the states as defined above specified.

The decision rule for management of surface water defines the probability distribution of annual recharge to ground water. We therefore have an inventory problem that fits the model with one storage facility presented earlier. The problem is small enough to be easily computed with a reasonable degree of precision on a modest size computer. The solution implies a marginal value of ground water for any quantity in storage. The marginal value function is obtained as the first derivative of a fitted function to the discrete empirical relation (2.2).

This marginal value function for stored ground water serves as a basis for deriving a new approximation to the optimal surface water policy. Surface water used directly is worth the same as marginal value of ground water plus pumping cost. Thus, at a given ground water level we have a price to apply to surface reservoir releases determined by the ultimate destination of the water. Hydroelectric and flood control benefits are added to the value as ground or surface water.

The approximate per unit values of surface and ground water let us formulate the decisions relative to surface water in a finite Markovian model exemplified by equation (2.3). The state is determined by a set of magnitudes of the state-variables, which in this case is quantity of surface water in storage and the predicted stream flow to occur during the stage (or the stream flow having occurred during the preceding stage, whichever is applicable). An alternative is defined by a combination of the decision-variables, which are the quantity of surface water used directly and the amount devoted to artificial recharge. The expected immediate net benefit for a given state and alternative is determined by the two prices and the magnitudes of the decision-variables. The magnitudes of the decision-variables determine flows from the reservoir, which can be used to estimate hydroelectric benefits and expected flood control benefits (negative of flood damages). Therefore, estimates of per unit value of surface and ground water for irrigation and industry permit relatively complete optimization of surface water releases. 
At this phase of the estimation procedure, we have a choice of two levels of precision in determining an optimal water policy. A separate surface water policy can be estimated for each ground water storage condition or we can be more crude in our optimization and use the same surface water policy at all ground water levels.

In either case the surface water policy (or policies) is used in place of the initially assumed surface water policy in the next cycle of iterations. The second surface water management policy (or policies) yields a probability distribution for recharge to ground water and a second ground water management policy can be derived, completing another cycle in the computational algorithm. The iterations are continued until the improvement in total net benefit for the basin is no longer considered significant enough to warrant further computations. The result gives us expected present value of net benefit for a particular investment situation, given that the water in storage and subsequent additions to storage are used in an optimum way over the entire planning period of the public agency.

Provided that convergence is quite rapid, this method has the advantage of treating surface water with a decision period which is short (perhaps a month) and ground water with an annual or longer decision period. Agricultural production is conveniently put on an annual basis. A probability distribution with stochastic independence over time is feasible using the year as a unit, and the large storage capacity and inventory associated with ground water make the year (or a longer period) necessary in order to give adequate precision and computational feasibility. The small storage capacity of a surface reservoir, relative to the annual supply of water serving the storage facility, makes a smaller period than the year desirable for management decisions. The month appears to be a feasible unit and has the added convenience of being the unit in which stream flows are summarized.

An optimal surface water policy must give the right weighting to saved pumping costs by direct surface use relative to lost water and flood damages resulting from a more nearly full surface reservoir. More surface water is made available for direct use by carrying a larger inventory of surface water, but the larger storage on the surface uses reservoir space and lets more water escape capture. The uncaptured water has a positive opportunity cost in itself and is of negative value in the sense that flood damages may result from its escape. The marginal value function for stored ground water is important because it reflects the opportunity cost of uncaptured water. These interrelationships are very complex and explicit marginal conditions for an optimal policy apparently cannot be derived. We can only formulate a mathematical model to permit numerical solution.

The two-storage facilities problem involving a surface and underground reservoir was analyzed by Buras and Hall (1961). However, their simplifying assumptions completely removed the water inventory question. It was assumed that periodic water demands were known and in the form of fixed requirements. Thus gross benefits (benefits before deduction of storage and withdrawal costs) were taken as independent of rinanagement of surface and underground storage, and the conjunctive use problem reduces to minimizing costs of storage and withdrawal of water.

In reference to the model outlined in the preceding section, the BurasHall model assumes that the policy for what was called the "long period" is known a priori, and that the policy is independent of either ground or surface water storage levels. Although this simplified model might be appropriate for some basins, its limitations should be obvious. Even for a basin with stor- 
age near a level which would imply safe yield as the optimal quantity for withdrawal, we would expect that with normal fluctuations in the storage level, the optimal water consumption policy would not be invariant with respect to water in storage. Qualitative statements for optimal use rates in relation to ground water storage are derived by Burt (1964).

It is seen that a major problem in obtaining expected value of net benefit, for a given investment situation, is that of determining optimum management of the stochastic supply of water. Another difficult problem is that of evaluating the net benefit function in terms of the quantities of ground and surface water used during a period of time. A completely satisfactory solution is not available and compromises must be made. This part of the analysis must be treated separately for each basin considered. The methods used depend on the nature of production within the area and the data available. Therefore, the area being analyzed dictates, to a great extent, the methods. The techniques used in the empirical investigation are discussed in a later chapter. The next chapter considers the general problem of estimating net benefit per time period as a function of water use.

\section{ESTIMATING NET SOCIAL BENEFITS AS A FUNCTION OF WATER CONSUMED}

This chapter is concerned with the general methodology of obtaining net benefits as a function of the quantity of water made available per time period. Such a function is needed to solve the inventory problem concerned with optimal allocation of water over time under a specific state of investment. A simplified method is explained with the understanding that the model can be refined to the degree of accuracy appropriate for the problem under considera- tion. Additional constraints and changing functions through time would improve estimation, but at the expense of increased complexity.

Market value of net output from the region is used as a measure of net benefits. This measure is deemed appropriate for a partial equilibrium analysis although the usual limitations of partial equilibrium analyses are recognized.

\section{SOLUTION OF A LINEAR PROGRAMMING PROBLEM WITH DEMAND CONSTRAINTS ON THE ACTIVITIES AND SIMULATED PURE COMPETITION}

Linear programming is useful at one step in deriving an optimum decision rule with respect to water inventory control, and thus the discounted expected value of net benefits. The use of linear programming is limited to determination of the optimum combination of various activities under a specified water constraint per time period. We do not have a standard linear programming problem with linear objective function and linear constraints. If we disregard the pure competition requirement, we have a mathematical programming problem with a nonlinear objective function but linear constraints. Solution of that problem will give us the results which would prevail under a monopoly controlling the entire production of the study area. This is not the solution being sought.

Let us consider the monopoly problem in order to distinguish it from the problem with which we are confronted. Define $x_{i}$ as the level of the $i^{\text {th }}$ activity which specifies the quantity of a commodity or aggregate of commodities 
produced. Let $x_{i}=D_{i}\left(c_{i}\right)$ be the demand equation for activity $i$, where $c_{i}$ is the price of the commodity (or aggregate of commodities) associated with activity $i$, transformed into its activity equivalent. The function, $D_{i}$, is the demand function for the commodity (or aggregate of commodities) in terms of activity units. It is a net demand function in the sense that certain costs (negative benefits) have been deducted from the price $c_{i}$. The objective function is

$$
\sum_{j=1}^{n} c_{j} x_{j}=\sum_{j=1}^{n} D_{j}^{-1}\left(x_{j}\right) x_{j}
$$

where $D_{k}^{-1}$ is the inverse function of $D_{k}\left(c_{k}\right)$. We also have a system of linear constraints

$$
\sum_{j=1}^{n} a_{i j} x_{j} \leqq b_{i}, i=1,2, \cdots m
$$

and the restriction $x_{k} \geqq 0, k=1,2, \ldots$ $n$. The constraints are limitations on resources of the region, primarily land and water. We have a mathematical programming problem with a nonlinear objective function to be maximized and linear constraints in the form of inequalities. The maximizing solution of this problem takes into account the negatively sloped demand functions, $D_{i}\left(c_{i}\right)$, and gives the results applicable if the area of study were under control of a monopolist.

Suppose that all demand functions are completely elastic, then the probblem faced is a standard linear program since prices may be treated as constant. The solution is identical under simulated competition or monopoly control. Solution of the standard linear program with prices of activities at a fixed level will give the result which is implied by pure competition if prices happen to be consistent with the activity levels in the solution and the demand functions. Only when demands are infinitely elastic can we be sure that the levels of activities will be consistent with prices used in the objective function. We are forced to use fixed prices in the objective function because individual firms do not take into account the influence of their production on price. Therefore, prices of activities must be fixed in the maximizing procedure used in order to simulate the results implied by pure competition.

Pure competition contributes to the validity of fixed technical coefficients of production, a necessity for linear programming. The production function for an individual firm may be of any form, but long-run equilibrium conditions of pure competition under specified prices determine a set of fixed technical coefficients of production. We may think of production, in an aggregate model for a region, as being increased by the addition of firms instead of expansion of existing firms; thus giving fixed coefficients of production under the assumption that individual firms are at their long-run equilibrium positions. Conceptually, the coefficients change with the set of prices assigned to the activities. An activity price implies a price of the commodity aggregate comprising the activity and the price of any variable factors of production.

Usually only one set of prices for variable factors of production is used in empirical investigations and the coefficients of production are treated as constant regardless of prices implied by the ultimate solution. Justification of this simplification is possible if the solution does not diverge "too far" from the situation assumed to exist where the empirical measures were appropriate. Of course, the procedure can be justified by assuming the coefficients of production are applicable for all levels of production of the individual firm, but the reality of this assumption is open to serious criticism.

Define the linear programming problem with fixed prices to be

subject to

$$
\begin{array}{r}
\underset{x}{\operatorname{Max}} c^{\prime} x \\
A x \leqq b \\
x \geqq 0 .
\end{array}
$$


where $c, x$, and $b$ are vectors and $A$ is a $\quad c_{i}, x_{i}, b_{i}$, and $a_{i j}$, respectively. We may matrix with components and elements, think of a vector function

$$
F(c)=\operatorname{Max}_{x} c^{\prime} x
$$

subject to

$$
\begin{aligned}
A x & \leqq b \\
x & \geqq 0 .
\end{aligned}
$$

Define the demand equations for $x$ to $x_{j}=f_{j}\left(c_{1}, c_{2}, \ldots c_{n}\right)$ because $F(c)$ debe $x_{i}=D_{i}\left(c_{i}\right), i=1,2, \ldots n$; $n$ being termines a unique $x$ for each $c$. the dimension of $x$. From the function The system of equations $F(c)$ we may define a new function

$$
\begin{aligned}
& x_{i}=D_{i}\left(c_{i}\right), i=1,2, \cdots n \\
& x_{j}=f_{j}\left(c_{1}, c_{2}, \cdots c_{n}\right), j=1,2, \cdots n
\end{aligned}
$$

contains $2 n$ unknowns and is comprised of $2 n$ equations in $c_{1}, c_{2}, \ldots c_{n}, x_{1}, x_{2}$, ... $x_{n}$. Therefore, our problem does have a unique solution with nonnegative prices and levels of activities. The difficulty is that the solution only exists implicitly in the solution of an infinite number of linear programming problems.

Complete solution of this general problem does not appear to be possible.* The primary difficulty stems from the fact that the entire convex surface defined by $A x \leqq b$ must be considered in a solution method, and not only extreme points of the set as in conventional linear programming. Since the price vector $c$ is a variable changing with each change in the solution vector $x$, we are most likely to have a solution which is not an extreme point containing $m$ positive $x_{i}$, but instead a convex combination of two or more extreme points. The number of vectors $c$ which can be obtained from solving the demand equations for extreme point solutions of $A x \leqq b$ is finite and equal to the number of combinations of $m+n$ things taken $m$ at a time, where $m$ equals the number of inequality restrictions. Therefore, the odds are against our finding the solution of the linear pro- gramming problem which is consistent with the demand constraints at an extreme point of the convex set because the possible number of values of the vector $c$ is infinite.

The empirical problem encountered supports the above conjecture about solutions not being at extreme points. For example, one case where $m=2$ yielded a solution containing $m+3=5$ activities at a positive level instead of $m$ as would result with a fixed vector $c$.

An approximate solution to the problem expressed by (3.2) is possible by some iterative technique and one such procedure is outlined below. The constraints of (3.1) are augmented by $n$ inequalities

(3.3) $x_{j} \leqq D_{j}\left(c_{j}\right), j=1,2, \cdots n$.

We have a linear programming problem with more constraints than activities, but when slack variables are introduced to transform the inequalities into equalities the number of activities is $2 n+m$ and there are $m+n$ equations. A set of prices $\left\{c_{j}\right\}$ is chosen such that all dual prices associated with the constraints of (3.3) are positive. Denote these dual prices by $d_{j}, j=1,2, \ldots n$.

These dual prices are used to modify the prices in the objective function, i.e.,

* At the time this study was going to press, the author discovered a mathematical programming model which will solve this general problem. The objective function is the sum of the areas under activity demand functions with constraints as given in (3.1). Proof that this model is equivalent to the competitive equilibrium can be made by utilizing the Kuhn-Tucker theorem for nonlinear programming. 
the $c_{j}, j=1,2, \ldots n$. Solution to (3.2) is approximated when all the $d_{j}$ are sufficiently close to zero but still positive. The best way to obtain rapid convergence to an approximate solution is not clear and only computational experience will shed light on the problem. A tentative suggestion is to reduce $c_{j}$ directly in relation to the magnitude of $d_{j}$ and inversely in relation to elasticity of demand for the $j^{\text {th }}$ commodity relative to all commodities. It is noted that a zero $d_{j}$ is of no consequence if the level of the $j^{\text {th }}$ activity is insignificant e.g., at the unit level. This situation would imply a zero level for that activity within the limits of an approximate solution.

The linear programming problems appearing in the empirical work undertaken here turn out to be extremely simple and the problems just discussed are readily solved. Only the water constraint is effective and the reduced problem is solved in a straightforward way. This single study might be typical; in which case, we need not concern ourselves with solving the complicated general formulation just discussed. Nevertheless, the general model may have application elsewhere for regional economic activity analysis.

We now consider the case most likely to occur in analysis related to water resource development-physical restrictions in the linear programming model involving only water and land. The water and land available may be classified by quality, thus introducing a restriction for each quality of land or water. We assume water is homogeneous, giving only one water restriction.

An approximate solution procedure is proposed which selects one quality of land as the standard and all land is assumed to be of that quality for solution purposes. The linear programming problem now has only two restrictions, one each for water and land. The value of the objective function and the associated selection of activity levels is desired for various magnitudes of the water constraint, i.e., we wish to treat the water restriction as a parameter and derive the optimum solution for various magnitudes of the parameter. There must exist a small value for the water restriction such that the land restriction is not effective. For these values of the water parameter under which the land constraint is ineffective, it is easily shown that returns are maximized by equating returns per unit of water among those activities entering at a positive level. ${ }^{3}$ Recall that per unit return from an activity is a decreasing function of the level of the activity because of negatively sloped demand functions.

Likewise for large enough values of the water parameter, land is the only effective constraint and the optimum levels of activities entering at a positive level are those which equate returns per unit of land among the activities. Finding the activities which enter the solution is not too difficult, but requires an iterative procedure in most cases. When a relatively small number of activities is involved, finding the set of activities which enter at a positive level is quite feasible by trial and error. Starting from a small magnitude of the water parameter and going to larger values permits using a great deal of information from one magnitude of the water parameter to the next with respect to the set of activities entering the solution.

What about the values of the water parameter for which both the land and water constraints are effective, and how do we find them? This case is unimportant if the set of activities entering the solution is the same under either the water or land restriction considered

\footnotetext{
${ }^{3}$ Under monopoly the net marginal revenues with respect to water would be equated when water is the most limiting factor of production. Under pure competition each entrepreneur looks at price as his marginal revenue and the motive of profit maximization leads to equating of average returns with respect to water among all commodities (see Appendix C).
} 
separately. The reason it is unimportant is that only a single value of the water parameter can be involved in such a situation, and consequently, the chance of encountering it is extremely small.

Suppose the problem has been solved under our assumption of a homogeneous land constraint. The levels of activities specified by this solution are only approximations to those implied by solution of the general problem where land is not treated as homogeneous. We treat them as the solution to the more general problem, but evaluate returns from them in relation to the general problem, not the simplified one.

For example in the empirical problem, land is assumed homogeneous except for irrigation development costs. Net returns under the general problem (with activity levels specified by the simplified problem) are equal to returns under the simplified problem minus the minimum development costs for the quantity of land used. The activity levels used are not optimum for the general problem but provide a good approximate solution.

The procedure described in this section for cases involving only land and water constraints, with water homogeneous in quality, should prove quite satisfactory for most analyses. Nevertheless, situations may be encountered which require a great deal of trial and error calculation and we have no suggestions to avoid the dilemma. Suffice it to say that more research is needed in solution of the general problem described in the last section, i.e., a linear programming model subject to demand constraints on activities and simulated pure competition.

\section{LABOR AND CAPITAL CONSTRAINTS}

It is assumed that an unlimited supply of capital and labor exists at the prices prevailing during some base period chosen. It is further assumed that the opportunity cost of using the capital and labor in the study area is equal to its cost during the base period. The preceding assumptions imply perfect mobility of labor and capital as well as a full employment economy. It also extrapolates returns to capital and labor from the base period into the future.

The conditions imposed by these assumptions are not proposed as holding true exactly, but only as a reasonable approximation to the real situation. Complete mobility of labor and capital is not unreasonable when considering the long-run economic organization of an area. The assumption is here made for short-run adjustments, but adjustments are allowed to take place only at five-year intervals and the final solu- tion of the inventory problem is likely to indicate very small probabilities for large adjustments at the five-year intervals. Thus, what appears to be a questionable assumption may lead to final results which are largely free from these first impression objections. More precisely, the assumption would not have been necessary if we had had $a$ priori knowledge about the final solution to be obtained. It is seen that the final results must be derived before the consequences of certain initial assumptions can be evaluated. The mobility assumptions with respect to capital and labor can be reconsidered in light of the empirical results forthcoming. Some attention is given to this in Chapter VI, beginning page 83 .

The assumption pertaining to cost of labor and capital is here accepted due to its simplicity and due to lack of a feasible alternative. 


\section{RIGIDITIES IN PRODUCING CERTAIN AGRICULTURAL CROPS}

Tree crops are not subject to shortterm changes in production and must be given special treatment in the estimation of net output as a function of water. In a sense trees are a special type of capital goods that is completely immobile and requires a development period before contributing to production. The question is, what proportion of the study area should be devoted to each tree crop in order to maximize net output under an optimal water inventory policy? It is assumed that proportions will remain unchanged due to the lengthy production cycle of tree crop production. Projection of demand conditions to only a single point in time also makes constant proportions more acceptable in the model. Allowance of some changes over time would be more realistic but the computational burden prevents consideration of more than one point. The present discussion is easily extended to several discrete periods in time where tree crop production is held fixed only during each separate period.

Suppose the optimal inventory policy were known-then we face the task of determining the production of various tree crops, with a known probability distribution for water supply. Treated conceptually as a maximization problem subject to the constraints of pure competition and product demands, this is obviously an extremely complex problem. Ultimately we want a measure of net output which could result under an optimal water inventory policy carried out by a public agency. A method is desired which approximates the results which would occur in a competitive industry where private firms make the production decisions.

Under the supposition that the prob- ability distribution of water to be consumed in the area is known, we need to know how this water is to be allocated to individual firms in order to examine the firms' possible behavior. Let us assume water rights are attached to the land in a fairly uniform way over the entire region of study; thus each firm has a known probability distribution for water supply over time. What proportion of the farm will a firm plant to tree crops?

Trees represent a large fixed investment, and a conservative entrepreneur would not risk the loss of part of his acreage from a deficient water supply; at least the probability of loss would be kept quite low. We must hypothesize firms' behavior under conditions of risk and imperfect knowledge, choosing a policy which is optimum subject to this behavior. Imperfect knowledge is introduced recognizing that a firm will not be making decisions utilizing an abstract probability distribution, but rather, only some rough, subjective approximation to it.

A difficult situation is confronted in guessing private firms' behavior under the conditions implied by a known water management policy. Even if firm behavior were known, the choice of the optimum management rule would be extremely complex. It would involve comparing expected net output from all possible decision rules. A relatively simple approach is taken in the empirical study. Producers are assumed to use long-run mean supply of water as a fixed supply on the basis of which tree crop decisions are made. Thus land which is used in the production of tree crops is independent of the water inventory policy used by the public agency. 


\section{ESTIMATION OF THE NET OUTPUT FUNCTION FOR THE STUDY AREA}

The base period from which production costs are determined is 1957-1959. The year 1980 is used for demand, supply, and population projections. The projected relations of that year are used as an approximation to each year in the infinite planning horizon of the public agency. That is, each year is assumed identical to the projected year, 1980.

\section{THE INTEREST RATE}

A public agency should use the time preference rate which is relevant for the particular intertemporal measurement with which it is confronted. In the present case, the opportunity cost of production now relative to the future is the marginal rate of return on private investment. Water inventory management involves no investment and, consequently, the opportunity cost of public investment funds is not relevant. It is merely a question of when the stock of water in storage is going to be used.

The marginal rate of return on private investment for land owners in the study area is the discount rate which should be used to determine the optimum water inventory policy over time. Empirical measures of the rate of return on investment in or out of agriculture are not available. We shall carry out the analysis using rates of 5 and 6 per cent, and examine the sensitivity of the solution to the discount rate.

\section{CHOICE OF ACTIVITIES}

The activities chosen for this study were limited by practical considerations and data available on production costs. Some activities may be aggregated into a single activity forcing its component parts to be produced in fixed proportions. Others may be deleted, as for example, crops not adapted to the region. Aggregation is appropriate for certain groups of agricultural activities, for example, where forage must be provided to a livestock activity.

The nonagricultural sector is of only minor importance in the study area. Fresno is the only city of any significance. It is assumed that water and land requirements for nonagricultural use will be met under this situation, without any effect on the economic organization of the urban sector being induced by the land and water constraints. The nonagricultural land and water requirements are estimated by projecting urban population and speci- fying a fixed requirement per capita of land and water (see Appendix B). No estimate of net benefits attributable to the nonagricultural sector is made because these benefits would be constant under our assumptions. Nonagricultural production will not change with a change in the water constraint since it has been specified that water requirements of the projected urban population will have first priority and the requirements will always be less than the constraint. The net effect is a smaller quantity in each of the constraints on water and land available to agriculture for each water consumption level considered. The optimum water inventory policy is not affected by nonagricultural production. Solution of relation (2.2) is not affected by substituting $B_{n}{ }^{k}\left(S_{i}\right)+c$ in place of $B_{n}{ }^{k}\left(S_{i}\right), c$ being a scalar independent of $k$. The subscript $n$ on $B_{n}{ }^{k}$ may be dropped for our present problem, i.e., the net benefit function is invariant over time for a 
TABle 3

SUMMARY OF ACTIVITIES

\begin{tabular}{|c|c|c|c|c|c|c|c|}
\hline Activity & $\begin{array}{l}\text { Produc- } \\
\text { tion } \\
\text { units }\end{array}$ & $\begin{array}{l}\text { Produc- } \\
\text { tion for } \\
\text { market }\end{array}$ & $\begin{array}{l}\text { Labor* and } \\
\text { capital } \\
\text { costs }\end{array}$ & $\begin{array}{l}\text { Land } \\
\text { require- } \\
\text { ment }\end{array}$ & $\begin{array}{l}\text { Water } \\
\text { require- } \\
\text { ment }\end{array}$ & $\begin{array}{c}\text { Gross return } \\
\text { at base } \\
\text { prices }\end{array}$ & $\begin{array}{l}\text { Return } \\
\text { above capital } \\
\text { and labor }\end{array}$ \\
\hline & & & dollars & acres & acre/ft & \multicolumn{2}{|c|}{ dollars } \\
\hline Tree nuts............ & tons & 90 & 26,209 & 100 & 400.0 & 40,950 & 14,741 \\
\hline Cotton .............. & $\ldots$ & .. & 44,955 & 200 & 666.7 & 81,052 & 36,097 \\
\hline Lint............... & $500 \mathrm{lb}$ bales & 450 & . & .. & . & 72,675 & .. \\
\hline Seed..$\ldots \ldots \ldots \ldots$ & tons & 180 & .. & . & .. & 8,377 & $\ldots$ \\
\hline Oranges.............. & 77lb boxes & 11,000 & 20,070 & 40 & 146.8 & 39,380 & 19,310 \\
\hline Dry beans............ & cwt & 2,000 & 7,766 & 100 & 358.3 & 17,120 & 9,354 \\
\hline Deciduous............ & tons & 2,055 & 112,402 & 160 & 640.0 & 150,138 & 37,736 \\
\hline Truck crops.......... & cwt & 31,550 & 120,728 & 160 & 573.3 & 184,568 & 63,840 \\
\hline Grapes.............. & tons & 1,420 & 46,315 & 160 & 640.0 & 81,451 & 35,136 \\
\hline Milo-Barley . . . . . . . . & cwt & 7,000 & 8,962 & 100 & 350.0 & 14,840 & 5,878 \\
\hline Field corn ............ & cwt & 6,000 & 7,177 & 100 & 333.3 & 15,000 & 7,823 \\
\hline Beef................. & cwt & 1,725 & 33,712 & 88 & 440.0 & 39,037 & 5,325 \\
\hline Dairy............... & $\ldots$ & . & 51,776 & 220 & .. & 66,399 & 14,623 \\
\hline Barley.............. & cwt & 1,260 & . & 42 & .. & 2,684 & .. \\
\hline Alfalfa............. & tons & 35 & . & 72 & .. & 788 & . \\
\hline Cattle........... & $\cdots$ & $\ldots$ & . & 6 & . & 5,597 & . \\
\hline Milk............. & cwt & 13,000 & . & .. & . & 57,330 & .. \\
\hline Pasture.............. & $\ldots$ & .. & . & 84 & . & $\ldots$ & .. \\
\hline Corn silage.......... & $\ldots$ & . & .. & 18 & . & . & .. \\
\hline
\end{tabular}

* Land development costs are excluded.

given storage level of ground water and specified alternative with respect to water consumption.

Three activities, deciduous fruit (other than grapes), truck crops, and tree nuts are aggregates of commodities for which the proportion of each component was somewhat arbitrarily determined. The average acreage in the San Joaquin Valley during the base period was used to determine the relative weight given to each commodity within the aggregate. The form of avail- able data and cropping practices essentially determined the components of other aggregates defined as activities.

A summary of the activities, their respective labor and capital costs, land and water requirements, and production is given in table 3 . A detailed presentation of the activities and their associated labor and capital costs is given in Appendix A. The size of an activity at unit level is of no significance under fixed coefficients of production. Those used were chosen for convenience.

\section{ACTIVITY DEMAND FUNCTIONS}

\section{National market demand}

The relevant market for production coming from the study area is assumed to be the United States. The first step in getting the demand function faced by the study area is to obtain an estimated demand relation at the farm level for the national market.

Most statistical estimation of demand relations has focused on measuring elasticities. Therefore, the estimated de- mand parameters available for most commodities are elasticities. A constant elasticity of demand was assumed to facilitate the use of such estimates. Price elasticity of demand is defined as $\left(\mathrm{d} Q^{\prime} / \mathrm{\partial} P\right)\left(P / Q^{\prime}\right)$ where $P$ and $Q^{\prime}$ denote price and per capita quantity consumed, respectively. Setting the elasticity equal to a constant gives the partial differential equation $\mathrm{d} \boldsymbol{Q}^{\prime} / \mathrm{\partial} \boldsymbol{P}=\left(\boldsymbol{Q}^{\prime} / \boldsymbol{P}\right) \boldsymbol{E}_{p}$, with $E_{p}$ a constant. Likewise, income elasticity assumed constant gives the 
partial differential equation $\mathrm{\partial} Q^{\prime} / \partial Y=$ $\left(Q^{\prime} / Y\right) E_{y}$ where $Y$ denotes per capita income and $E_{y}$ is the constant income elasticity. Solution of the differential equations gives the Cobb-Douglas type function

$$
Q^{\prime}=c P^{E_{p}} Y^{E_{y}}
$$

where $c$ is an unknown constant to be determined by imposing some additional relationship. In this study, it is specified that the variables during the base period correspond to a point on the estimated demand function; thus, the parameter $c$ is determined. Only the variables price, per capita income, and population are considered in the demand functions, and all demand functions are projected for the year 1980. The statistical estimates of elasticities and their sources are given in table $4 .^{4}$
Only selected activities are considered; those for which production within the study area is expected to have a significant effect on price. Under our assumptions, activities which do not change much from their base period level will have about the same per-unit value as during the base period. Activities for which the level does change considerably may still have approximately the same price if production within the study area, both during the base period and the estimated conditions for 1980, is a small proportion of total United States production.

For given national market demand, price elasticity for study area demand is determined by the area's proportion of quantity sold in the national market. As the proportion goes to zero the elasticity becomes infinite, and as the pro-

TABLE 4

DEMAND PARAMETERS FOR SELECTED ACTIVITIES U. S. MARKET

\begin{tabular}{|c|c|c|c|c|c|c|}
\hline & $\begin{array}{c}\begin{array}{c}\text { Price } \\
\text { elasticity }\end{array} \\
\text { (1) }\end{array}$ & $\begin{array}{c}\text { Income } \\
\text { elasticity } \\
\text { (2) }\end{array}$ & $\begin{array}{c}\log c \text { of } \\
\text { relation (4.1) } \\
\text { (3) }\end{array}$ & $\begin{array}{c}\text { Projected } \\
\text { supply from } \\
\text { outside the } \\
\text { study area } \\
(4)\end{array}$ & $\begin{array}{l}\text { Units of } \\
\text { projected } \\
\text { supply } \\
(5)\end{array}$ & $\begin{array}{c}P_{2}-P_{1}=C \\
\text { (base period) } \\
(6)\end{array}$ \\
\hline & & & & 1,000 units & & \\
\hline Oranges........................ & -.62 & .83 & $7.42851-10$ & 239,475 & boxes & -0.58 \\
\hline 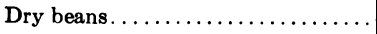 & -.97 & -.20 & 0.48257 & 15,086 & cwt & -1.60 \\
\hline 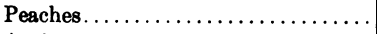 & -1.49 & 1.43 & . & .. & $\ldots$ & .. \\
\hline 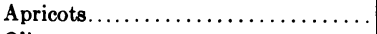 & -1.47 & 1.59 & .. & .. & $\ldots$ & . \\
\hline Olives $\ldots \ldots \ldots \ldots \ldots \ldots \ldots \ldots$ & -1.47 & 1.59 & .. & .. & $\ldots$ & .. \\
\hline Deciduous fruit activity*........ & -1.49 & 1.46 & $6.14718-10$ & 4,940 & tons & 18.37 \\
\hline 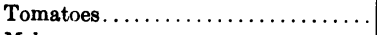 & -4.65 & .40 & . & .. & $\ldots$ & .. \\
\hline Melons...................... & -.90 & -.40 & . & .. & $\ldots$ & .. \\
\hline Sweet potatoes.................. & -1.30 & -.25 & .. & . & $\ldots$ & .. \\
\hline Truck crop activity* ${ }^{*} \ldots \ldots \ldots \ldots$ & -3.33 & .13 & 1.15654 & 87,531 & ewt & -2.08 \\
\hline 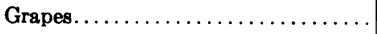 & -1.47 & 1.59 & 5.65894 & 5,925 & tons & 7.03 \\
\hline
\end{tabular}

* Elasticities are weighted average of components, using value at base period prices as weights.

Source:

Column 1: Oranges, dry beans, deciduous fruit, sweet potatoes, and grapes: Fox, 1953. (The estimate for the aggregate group of commodities to which the individual commodity belongs is used when an individual estimate is not available).

Tomatoes: Shuffet, 1954.

Melons: Suits, 1955. (Source gives estimate for watermelons only, but used for all melons)

Column 2: Oranges, deciduous fruit, and grapes: Computed from Fox, 1953, p. 65.

Dry beans and truck crops: Daly, 1956, p. 80 .
Dry

Dry beans and truck crops: Daly, 1956, p. 80 .
Column 3: Computed, using base period price, quantity, and disposable personal income.

Column 4: Computed as described in the text.

Column 6: Table A-9.

^The elasticities were chosen arbitrarily, particularly the income elasticities which are based partially on judgment of those originally making the estimates of the elasticties. A large number of the price elasticities were taken from a single source because it was felt that there is an advantage in using elasticities estimated by the same methods and sample of years. Relative price elasticities are extremely important in this study, as will become obvious when the solution procedure is examined. 
portion goes to 1 the elasticity becomes the national market elasticity. It is on this basis that demand relations for several of the activities are not estimated since production within the study region is an extremely small proportion of total quantity marketed in the United States. The base period price is taken as a constant price for these activities. Essentially, we are estimating the demand functions of these activities to be such that price equals a constant independently of the quantity produced within the study area (within the possible range of quantities to be considered).

\section{Supply function for United States outside the study area}

With the national market demand specified, we must know the supply function for the United States outside the study area to find the demand function for the study area. In the following discussion, assume that projected values for per capita income and population have been substituted into the demand equation, and the constant term includes the income and population terms. We have a national demand function, $Q=a P^{b}$, where $b$ is the price elasticity of demand and $Q$ is total quantity consumed. Denote production in the study area and the remainder of the United States by $Q_{1}$ and $Q_{2}$, respectively. The demand equation may be written $Q_{1}+Q_{2}=a P^{b}$ under the assumption that all production is consumed. Define the supply function for the United States outside the study area as $Q_{2}=S_{2}(P)$. Then the demand function for the study area is $Q_{1}=a P^{b}$ $S_{2}(P)$. An estimate of $S_{2}$ is required to derive a demand relation for the study area.

Obtaining an estimate of $S_{2}$ is extremely difficult, and the extensive empirical analysis required for statistical estimation is beyond the scope of this study. Instead a simple, though perhaps not too unrealistic, assumption is made.
Namely, $S_{2}(P)={Q_{2}}^{\circ}$, where $Q_{2}{ }^{\circ}$ is a constant for small fluctuations in price around the base period price. $Q_{2}{ }^{\circ}$ is determined in the following manner: The total quantity that would be demanded at the base price is obtained from the corresponding national demand relation; denote this quantity by $Q^{\circ}$. Compute the proportion of the commodity in question produced outside the study area during the base period; denote the proportion by $\alpha$. Then $Q_{2}{ }^{\circ}$ equals $\alpha Q^{\circ}$. We are essentially fixing production in the same proportion geographically as it was during the base period, provided price is at the base period level. Price, however, is determined by production in the study area under our assumed $S_{2}$, and is not equal to price during the base period except by coincidence.

\section{Study area demand functions}

We have assumed $S_{2}$ to be completely inelastic, but economic reasoning implies a positive relation between $Q_{2}$ and price. Elasticity of demand for production within the study area is

$$
\left(a b P^{b-1}-S_{2}^{\prime}(P)\right) \frac{P}{Q_{1}} .
$$

Our assumption of a completely inelastic supply function, $S_{2}$, implies $S_{2}^{\prime}(P)$ $=0$ while the more realistic situation, expected from economic reasoning, is $S_{2}{ }^{\prime}(P)>0$. Under the assumption that price elasticity in the national market, $b$, is negative, the absolute value of (4.2) is smaller if $S_{2}^{\prime}(P)=0$ than if it is positive. That is, demand for production within the study area is more elastic in reality than under our assumption that supply outside the study area is completely inelastic. The comparison is made for two demand relations at a single point such that each goes through the same point, $\left(P, Q_{1}\right)$, in the plane generated by all positive values of $P$ and $Q_{1}$.

Derivation of the study area demand functions from the national market demand functions is complete with projec- 
tions of supply functions except for a discrepancy between national market and study area prices for given quantities. For the base period, this discrepancy is large for several commodities (see Table A-1). The differences are explained by transportation costs from regions of production to consumption, the interseasonal distribution of sales, quality differences, and possibly other factors. It is necessary that demand relations for the study area be expressed in terms of study area prices.

The national price is a weighted average price which ean be expressed as a weighted average of prices for the study area and the remainder of the United States. Using the same notation as in the preceding section, consider the demand relation, $Q=a P^{b}$, with price, $P$, a weighted average, $\left(P_{1} Q_{1}+P_{2} Q_{2}\right) /$ $\left(Q_{1}+Q_{2}\right)$. Our projection of supply outside the study area results in $Q_{2}=Q_{2}{ }^{\circ}$, a constant. It is assumed that the relation existing between $P_{1}$ and $P_{2}$ during the base period is stable for the changes in $Q_{1}$ and $Q_{2}$ which will be considered, i.e., $\boldsymbol{P}_{2}=P_{1}+d$, where $d$ is the difference between prices during the base period. This assumption lets us derive the demand curve from $Q=a P^{b}$ as

$$
Q^{(1+b) / b}-a^{1 / b} P_{1} Q-a^{1 / b} d Q_{2}^{0}=0
$$

where $Q=Q_{1}+Q_{2}{ }^{\circ}$. We can solve (4.3) explicitly for $P_{1}$ but not for $Q_{1}$, and when going from price to the corresponding quantity, an iterative method must be used. Newton's method for solving equations is used when necessary in computations and proves very satisfactory for this type equation.

The demand relation for cotton is handled in a special way in view of the government program for this commodity. It is assumed that, under the program, cotton price will be maintained at the base period level and permit the same amount of cotton to be exported annually as during the base period. Exports and domestic consump- tion during the base period, as well as projections for 1980 , are given in table 5 . The projections are based on an income elasticity of .95 . (Cromarty, 1959, p. 573) Maximum production in the study area is estimated as the same proportion of projected United States production (consumption plus exports) as the study area produced of total United States production during the base period. That proportion is 0.03168 (table A-8).

Projected United States market demand equations for selected activities are given in table 6 , and demand functions for all activities under our assumptions are summarized in table 7 .

TABLE 5

COTTON: DOMESTIC CONSUMPTION AND EXPORTS (1,000 bales)

\begin{tabular}{|c|c|c|c|c|c|}
\hline & $\begin{array}{c}1957 \\
(1)\end{array}$ & $\begin{array}{c}1958 \\
(2)\end{array}$ & $\begin{array}{c}1959 \\
(3)\end{array}$ & $\begin{array}{c}\text { Average } \\
1957-59 \\
(4)\end{array}$ & $\begin{array}{c}\text { Projected } \\
1980 \\
(5)\end{array}$ \\
\hline 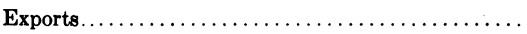 & 5,717 & 2,759 & 7,183 & 5,230 & 5,230 \\
\hline Consumption $\ldots \ldots \ldots \ldots \ldots \ldots \ldots \ldots \ldots \ldots \ldots \ldots$ & 7,973 & 8,671 & 9,024 & 8,556 & 19,100 \\
\hline Maximum production in study area............. & .. & . & . & . & 771 \\
\hline
\end{tabular}

Sources:

Col. 1, 2, 3: International Cotton Advisory Committee, 1960, pp. 104-06.

Col. 5: Computed under assumptions described in the text. 
TABLE 6

PROJECTED UNITED STATES MARKET DEMAND EQUATIONS IN 1980 FOR SELECTED ACTIVITIES

\begin{tabular}{|c|c|c|c|}
\hline Activity & Units & Demand function & $\begin{array}{l}\text { Production at } \\
\text { base prices }\end{array}$ \\
\hline Oranges... . & boxes & $\log Q=8.70287-.62 \log P$ & $255,300,000$ \\
\hline Dry beans.......... & cwt & $\log Q=8.17430-.97 \log P$ & $22,750,000$ \\
\hline Deciduous fruit... & tons & $\log Q=9.61285-1.49 \log P$ & $5,216,000$ \\
\hline 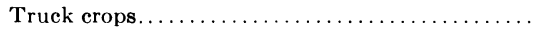 & cwt & $\log Q=9.99611-3.33 \log P$ & $118,300,000$ \\
\hline 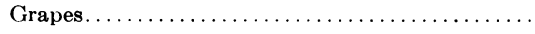 & tons & $\log Q=9.57680-1.47 \log P$ & $8,929,000$ \\
\hline
\end{tabular}

TABLE 7

STUDY AREA-ACTIVITY DEMAND EQUATIONS

\begin{tabular}{|c|c|c|}
\hline Activity* & Units & Demand equation \\
\hline Oranges............ & boxes & $\begin{array}{l}Q^{-.61}-(9736)(10)^{-18} P_{1} Q+(14,325)^{-10}=0 \\
Q_{1}=Q-253,629,000\end{array}$ \\
\hline Dry beans............. & cwt & $\begin{array}{l}Q^{-.03}-(3806)(10)^{-12} P_{1} Q+.1378=0 \\
Q_{1}=Q-22,632,000\end{array}$ \\
\hline Deciduous fruit....... & tons & $\begin{array}{l}Q^{.33}-(3626)(10)^{-10} P_{1} Q-28.1665=0 \\
Q_{1}=Q-4,228,000\end{array}$ \\
\hline Truck crops........... & cwt & $\begin{array}{l}Q^{\cdot 7}-(1003)(10)^{-6} P_{1} Q+245,020=0 \\
Q_{1}=Q-117,446,000\end{array}$ \\
\hline 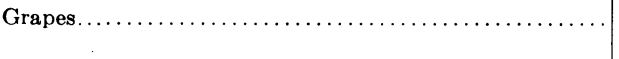 & tons & $\begin{array}{l}Q^{.32}-(3075)(10)^{-10} P_{1} Q-10.5081=0 \\
Q_{1}=Q-4,861,000\end{array}$ \\
\hline Cotton (lint) $\ldots \ldots \ldots \ldots \ldots \ldots \ldots \ldots \ldots \ldots \ldots \ldots$ & bales & $P_{1}=\$ 161.50 \quad Q_{1} \leqq 771,000$ \\
\hline Cotton (seed) $\ldots \ldots \ldots \ldots \ldots \ldots \ldots \ldots \ldots \ldots$ & tons & $P_{1}=\$ 44.65$ \\
\hline Field corn $\ldots \ldots \ldots \ldots \ldots \ldots \ldots \ldots \ldots \ldots \ldots \ldots \ldots$ & cwt & $P_{1}=\$ 2.50$ \\
\hline 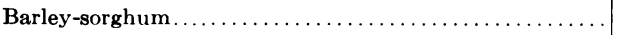 & cwt & $P_{1}=\$ 2.12$ \\
\hline 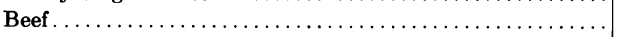 & cwt & $P_{1}=\$ 22.63$ \\
\hline 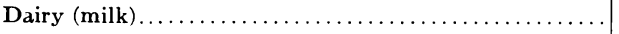 & cwt & $P_{1}=\$ 4.41$ \\
\hline
\end{tabular}

* Tree nuts are not included because returns per unit of water or land are too low to be significant.

Tree nuts are not included since returns per unit of water or land are so low relative to other tree crops at base prices that zero production of tree nuts in the study area would lead to a price still too low to compete with other tree crop activities. The study area produced only 2.8 per cent of United States production during the base period. Suppose price elasticity of tree nuts for the national market is minus one-tenth, very small (in absolute value) for an agricultural commodity. Then zero production of tree nuts in the study area would reduce national quantity marketed by 2.8 per cent and bring about a 28 per cent increase in price. The base price of $\$ 460$ per ton would be increased to $\$ 589$, but net returns per acre-foot of water would be only $\$ 67$. We shall see later that this return per acre-foot of water is not high enough to compete with other tree crop activities.

\section{LAND CONSTRAINTS}

A detailed land classification was not available for the study area such that a separate land constraint could be introduced for each homogeneous class of land. The entire area is therefore classified into only two units: (1) conjunctive use area and (2) nonconjunctive use area. The conjunctive use area is that in which most farms use some surface and ground water, while farms of the nonconjunctive use area depend entirely on ground water. Thus, reference to conjunctive use is at the farm level under the present situation, and 
is not related to solution of the conjunctive use problem for the entire area.

Separate development costs are estimated for each of these two classes. Development costs are for leveling and chemical treatment of the soil with gypsum. Large differences in leveling and gypsum requirements exist within each area, but we treat each area as a homogeneous unit and derive an average cost of development.

The number of feet cut required for leveling is estimated from tentative land classification data provided by the California Department of Water Resources. The costs of leveling for various depth cuts are estimated from costs for Kern County (Calif. Dept. of Water Resources, 1958, p. 82).

Gypsum requirements are estimated on the basis of the amount required to reduce the sodium percentage to 15 per cent in the top two feet of soil. This information for the various classes of soil was obtained from the California Department of Water Resources and applied to the respective soil classes in each area to obtain an estimate of total gypsum needed. The cost of pure gypsum was taken to be $\$ 5.85$ per ton. Computation of development costs is given in appendix table A-10. The land available in each area for irrigated agricultural production, total development costs, and development costs per acre are given in table 8 .

The land constraint in the linear programming problems for various water constraints is specified to be the sum for the two areas, i.e., 1,251,367 acres. Development costs for the two areas are taken into consideration in calculating net output from the optimum combination of activities obtained with only the total land constraint considered. In other words, land development costs are deducted from net output derived from a linear programming problem specifying land as homogeneous for the entire area with no development costs. For land requirements less than that available in the conjunctive use area, the cost per acre for that area is used. Larger land requirements are met by using whatever additional land (above 623,081 acres) is needed from the nonconjunctive use area. Thus, the procedure follows that suggested in Chapter III.

The development costs associated with a particular quantity of water used cannot be defined on a periodic basis (for example annually) without prior knowledge of the total number of periods in which that quantity of water will be used. In other words, development costs cannot be defined periodically independently of the water management policy. As a first approximation, the total development cost is reduced to a perpetual, annual annuity when the annual use rate under consideration is less than the mean annual supply. The development cost is reduced to a twenty-year annuity for annual use rates which exceed the mean annual supply. In the use levels of the resulting policy where the error is con-

Table 8

DEVELOPMENT COSTS

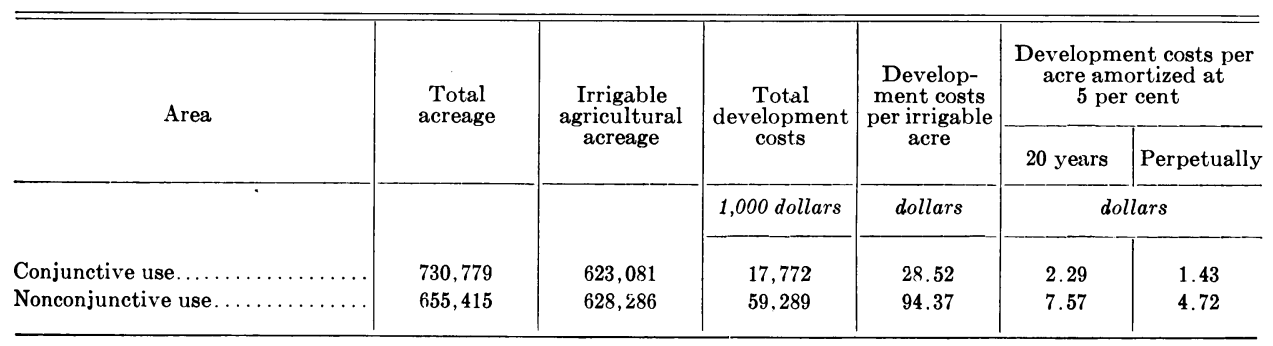

Source: Appendix tables A-10 and B-1. 
sidered significant, adjustments will be required and a new policy computed with the adjustments. Development costs are small enough that two iterations, at most, should be sufficient. For- tunately in this study the policy derived using this first approximation is consistent with the amortization periods chosen and no further adjustments are necessary.

\section{WATER CONSTRAINTS}

The discussion of estimating net output as a function of water in the last chapter indicates that one of our most difficult problems is specifying the longrun economic organization of the region under study. In general, estimates of levels of all unadjustable activities are necessary. Within the particular region of study, however, unadjustable activities are limited to tree crops. So far, it has been assumed that a public agency will control the pumping of ground water over time. Under this assumption individual firms would form plans on the basis of whatever policy was set forth by the public agency. Therefore, the quantity of water allocated to fixed activities is an integral part of the optimal policy and is a variable with which to optimize.

The public agency does not specify in its water management policy how much water is to be allocated to unadjustable activities, but the policy of temporal water allocation (without requirements as to how the water is used) does determine the quantity of water which individual firms would devote to unadjustable activities. The firms within the region are seeking to maximize present value of profits and, in so doing, must evaluate the risk of an uncertain water supply in connection with the large sunk costs of establishing an orchard, vineyard, or other unadjustable activity. The policy of the public agency controlling temporal water use determines the probability distribution of the water supply on which firms are dependent. We do not know, but must postulate, the behavior of firms under different probability distributions of water supply. Empirical investigation of firm behavior would be interesting but goes beyond the scope of this study.

Estimated quantity of water allocated to unadjustable activities is based on the assumption that firms' planning is such that the effect is equivalent to introducing long-run mean supply of water in the linear programming model as the water constraint. Under present conditions, a single firm cannot rely on ground water in the future with any certainty. A single firm's pumping (by itself) has little influence on the quantity in storage. The pumping of other firms as an aggregate controls future ground water reserves, and each firm individually cannot plan for future use. However, firms in the immediate vicinity of recharge, i.e., in the present conjunctive use area, can rely on their proportionate share of annual recharge, even in the future. Thus the mean annual total supply of water for the area is the quantity of water firms in the aggregate will take as their annual water constraint for long-run planning. We use a slightly larger quantity of water to allow planned utilization of ground water reserves in long-run planning for urban water supplies.

A well-informed farmer in the area of present conjunctive use realizes that approximately one-half of the surface water released into the surface distribution system is recharged to ground water. Therefore, farmers within this immediate area of recharge can anticipate first opportunity of pumping the limited quantity which will be available in future vears. It is assumed that each farmer anticipates pumping a quantity of water annually in the future equal to his mean annual surface water supply, delivered at the farm. The surface supply delivered at the farm is one-half 
total surface supply. This corresponds to the estimated recharge rate of onehalf for water released into the surface distribution system. No allowance is made for urban use, i.e., we assume urban supplies are always satisfied from ground water reserves. No difficulty is anticipated since projected urban use is relatively small. Also, when pumping costs instead of physical limitations determine the lower limit for pumping ground water, urban demands can be satisfied after agricultural demand is curtailed by high pumping cost.

The mean annual supply of water for the study area is from the following sources (measured in acre-feet):

Kings River ........ 1,730,350

Local minor streams ..... 24,400

Central Valley Project

(estimated future

entitlement) $\ldots \ldots \ldots \ldots 60,000^{8}$

Total .......... $\frac{6,814,750}{1,8140,000}$

A very small amount of the Kings River source is released for flood control and only the proportion of it recharged in the stream bed is available for use in the study area. The quantity not available is considered negligible for long-run planning purposes, but will be considered in detail in the next chapter where expected quantity released is estimated in order to obtain the probability distribution of ground water recharge.

The study area is not an isolated ground water basin, but a part of a larger basin. The study area's sources of ground water recharge are within the study area, thus making annual supply at least equal to that predicted when ground water within the area is being withdrawn more rapidly than in the surrounding region. Therefore, if the ground water management policy resulting requires withdrawal of water more rapidly than present practice indicates in adjacent areas, the policy will be on the conservative side with respect to quantities that should be pumped to maximize net output of the study area, independently of other regions. The reverse could be true, but it is not expected. The policy obtained by treating the area as a separate basin will be strictly optimum only if ground water movements are such that net losses (or gains) from adjacent areas are zero.

\section{NUMERICAL SOLUTION}

\section{Long-run organization}

Under a water constraint of 1,815 ,000 acre-feet, the land constraint of over one million acres will not be effective since all irrigated crops require more than two acre-feet of water per year. Therefore, the problem may be treated as one amenable to the calculus provided activities entering at a positive level can be identified (see Appen$\operatorname{dix} \mathrm{C}$ ). The results are equivalent to equating net returns per unit of water among activities entering the solution, with the added constraint that total water used does not exceed the quantity available. We require that all water available be used under the assumption
TABLE 9

NET RETURNS PER UNIT OF RESOURCES AT BASE PRICES

\begin{tabular}{|c|c|c|}
\hline \multirow{3}{*}{ Activity } & \multicolumn{2}{|c|}{ Resources } \\
\hline & Water & Land \\
\hline & $\begin{array}{c}\text { dollars per } \\
\text { acre-foot }\end{array}$ & $\begin{array}{l}\text { dollars per } \\
\text { acre }\end{array}$ \\
\hline Oranges........... & 131 & 483 \\
\hline Truck .............. & 111 & 399 \\
\hline Deciduous fruit............ & 59 & 236 \\
\hline Grapes..................... & 55 & 220 \\
\hline Cotton $\ldots \ldots \ldots \ldots \ldots \ldots \ldots$ & 54 & 180 \\
\hline Tree nuts................. & 37 & 147 \\
\hline 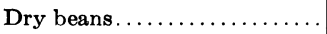 & 26 & 94 \\
\hline Field corn...$\ldots \ldots \ldots \ldots \ldots$ & 23 & 78 \\
\hline Dairy...$\ldots \ldots \ldots \ldots \ldots \ldots$ & 17 & 66 \\
\hline Barley-sorghum............. & 17 & 59 \\
\hline Beef $\ldots \ldots \ldots \ldots \ldots \ldots \ldots$ & 12 & 61 \\
\hline
\end{tabular}

${ }^{5}$ Computed average 1872-1959 minus estimated flood control releases of 25,000 acre-feet.

- Tentative estimates received from California Department of Water Resources. 
that the marginal net value of water is positive within the limits imposed. If the assumption should be violated, it would be apparent from the solution.

The set of activities entering the solution is determined by trial and error together with an inspection of returns at base prices. In this study, we were fortunate in selecting the correct set on the first trial. Returns at base prices per unit of land and water are given in table 9. The first four activities of table 9 were selected under the hypothesis that more than $1,815,000$ acre-feet of water would be required to equate returns per acre-foot of water in each activity to $\$ 54$, the return in the next activity down from the four selected.

The results of Appendix $\mathrm{C}$ show that equating average net returns among commodities being produced (subject to the water restriction) gives results which would tend to prevail in the longrun under pure competition. The notation of Appendix $\mathrm{C}$ is as follows:

$Q_{i}=$ quantity of the $i^{\text {th }}$ commodity produced and sold

$D_{i}\left(Q_{i}\right)=$ demand equation for the $i^{\text {th }}$ commodity

$K=$ fixed quantity of water available

$w_{i}=$ quantity of water used in production of $Q_{i}$

$Q_{i}=b_{i} w_{i}$, the production function for commodity $Q_{i}$

$C_{i}\left(Q_{i}\right)=d_{i} Q_{i}$, the cost function for commodity $Q_{i}$

$i=1,2, \ldots n, n$ equals the number of commodities being produced.

Our problem reduces to solving the system of equations

$$
\begin{aligned}
& b_{i}\left[D_{i}\left(Q_{i}\right)-d_{i}\right]=\lambda, i=1,2,3,4 \\
& \sum_{i=1}^{4} Q_{i} / b_{i}=K .
\end{aligned}
$$

The demand equations in table 7 are seen to be polynomials with noninteger exponents. Therefore, we have a system of four nonlinear equations and one linear equation. The solution procedure is to choose an arbitrary value for $Q_{1}$ and solve for $Q_{2}, Q_{3}$, and $Q_{4}$. Then define $y=Q_{1} / b_{1}+Q_{2} / b_{2}+Q_{3} / b_{3}+Q_{4} / b_{4}-$ $K(K=1,815,000)$ and evaluate $y$ for the set of $Q_{i}$ obtained by the arbitrary choice of $Q_{1}$. If $y$ is positive, choose another value for $Q_{1}$ which is small enough that $y$ is reasonably sure to be negative (and vice versa). Denote the first and second values of $y$ by $y_{1}$ and $y_{2}$, respectively, and the changes in $Q_{i}$ by $\Delta Q_{i}$.

The next step in solving the system is to use linear interpolation to get a new estimate of the $\left\{Q_{i}\right\}$. Denote the $\left\{Q_{i}\right\}$ associated with $y_{1}$ and $y_{2}$ by $\left\{Q_{i}{ }^{1}\right\}$ and $\left\{{Q_{i}}^{2}\right\}$, respectively. Then our estimate of $Q_{i}$, say $Q_{i}{ }^{\circ}$, is

$$
\boldsymbol{Q}_{i}{ }^{o}=\frac{\left|y_{1}\right|}{\left|y_{1}\right|+\left|y_{2}\right|} \cdot \Delta Q_{i} \pm Q_{i}{ }^{1}
$$

the plus or minus being dependent on whether $y_{1}$ is positive, or negative. If $y_{1}$ is positive, we know $\boldsymbol{Q}_{i}{ }^{1}$ is too large so the correction factor is subtracted, and vice versa.

The first estimates by this method equated average returns per unit of water to within one cent, and satisfaction of the water constraint was within 300 acre-feet, which was considered sufficiently accurate. If more accuracy is desired the procedure may be repeated substituting $Q_{1}{ }^{0}$ for either $Q_{1}{ }^{1}$ or $Q_{1}{ }^{2}$, whichever is appropriate by the sign of $y_{0}$ obtained from substituting $Q_{1}{ }^{\circ}$ in the system of equations and solving for $Q_{2}, Q_{3}$, and $Q_{4}$.

Solving for $Q_{2}, Q_{3}$, and $Q_{4}$ for a specified value of $Q_{1}$ was accomplished by repeated applications of Newton's method for solving equations. The method could undoubtedly be programmed for solution on a digital computer if a sufficiently large number of such problems were to be solved. However, an alternative which should be considered is approximation of the nonlinear demand curves by linear functions in the neighborhood at which solutions are expected.

The method described above was used to obtain a solution corresponding to a 
water restriction of 1,815,000 acre-feet. The levels of tree crop activities (oranges, deciduous fruits, and grapes) are assumed fixed at the levels resulting from the solution regardless of the amount of water made available in future years. These are the unadjustable activities. Tree nuts do not appear in the solution since returns from tree nuts per acre-foot of water are only $\$ 37$ at base prices while returns are equal to $\$ 83$ per acre-foot in the other tree crop activities at the solution levels. As indicated in preceding discussion, zero production of tree nuts in the study area reduces total national quantity by only 2.8 per cent from the base period level. A price of $\$ 660$ per ton for tree nuts would be required to bring returns of $\$ 83$ per acre-foot of water. Base price is $\$ 460$, which implies that a 2.8 per cent decrease in quantity would have to bring about at least a 43.5 per cent increase in price in order that tree crops would be produced. It is assumed that demand for tree nuts is not that inelastic, i.e., near - .06 .

Table 10 summarizes the solution derived in terms of the activities as previously defined. The unadjustable activities and net returns from them are given in table 11 . Total water and land requirements, including urban, are also given. These requirements must be met with first priority for any given quantity of water made available. No annual rate of water consumption significantly below the specified fixed requirement is considered as a feasible alternative.

TABLE 10

SOLUTION FOR LONG-RUN ECONOMIC ORGANIZATION

(Water constraint of 1,815,000 acre-feet)

\begin{tabular}{|c|c|c|c|c|c|c|c|}
\hline Activity & $\begin{array}{c}\text { Activity } \\
\text { level }\end{array}$ & $\begin{array}{c}\text { Water } \\
\text { require- } \\
\text { ment }\end{array}$ & $\begin{array}{l}\text { Land } \\
\text { require- } \\
\text { ment }\end{array}$ & $\begin{array}{l}\text { Study } \\
\text { area pro- } \\
\text { duction }\end{array}$ & Units & $\begin{array}{l}\text { Per } \\
\text { unit } \\
\text { price }\end{array}$ & $\begin{array}{l}\text { Net return } \\
\text { per acre-foot } \\
\text { of water }\end{array}$ \\
\hline & & acre-feet & acres & 1,000 units & & \multicolumn{2}{|c|}{ dollars } \\
\hline Oranges................ & $3,488.27$ & 512,078 & 139,531 & 38,371 & boxes & 2.9154 & 81.74 \\
\hline Deciduous fruit.......... & 75.91 & 48,582 & 12,146 & 156 & tons & 80.1518 & 81.73 \\
\hline Truck crops............ & 752.90 & 431,638 & 120,464 & 23,754 & cwt & 5.3119 & 81.74 \\
\hline Grapes............ & $1,285.92$ & 822,999 & 205,747 & 1,826 & tons & 69.4559 & 81.74 \\
\hline Other activities.......... & 0 & . & & & & & \\
\hline TOTAL. & & $1,815,297$ & 477,888 & & & & \\
\hline
\end{tabular}

TABLE 11

UNADJUSTABLE ACTIVITY LEVELS

(Mean water supply of $1,815,000$ acre-feet)

\begin{tabular}{|c|c|c|c|c|c|c|c|}
\hline Activity & $\begin{array}{c}\text { Activity } \\
\text { level }\end{array}$ & $\begin{array}{c}\text { Gross return } \\
\text { per activity } \\
\text { unit }\end{array}$ & $\begin{array}{c}\text { Labor and } \\
\text { capital } \\
\text { costs }\end{array}$ & $\begin{array}{c}\text { Net return } \\
\text { per activity } \\
\text { unit }\end{array}$ & $\begin{array}{c}\text { Total } \\
\text { net } \\
\text { output }\end{array}$ & $\begin{array}{c}\text { Water } \\
\text { require- } \\
\text { ment }\end{array}$ & $\begin{array}{c}\text { Land } \\
\text { require- } \\
\text { ment }\end{array}$ \\
\hline & & \multicolumn{3}{|c|}{ dollars } & 1,000 dollars & acre-feet & acres \\
\hline Oranges......... & $3,488.27$ & 32,069 & 20,070 & 11,999 & 41,856 & 512,078 & 139,531 \\
\hline Deciduous fruit.... & 75.91 & 164,712 & 112,402 & 52,310 & 3,971 & 48,582 & 12,146 \\
\hline Grapes.............. & $1,285.92$ & 98,627 & 46,315 & 52,312 & 67,269 & 822,999 & 205,747 \\
\hline Urban and misc......... & & & & & .. & 122,484 & . \\
\hline TOTAL $\ldots \ldots \ldots \ldots$ & & & & & 113,096 & $1,506,143$ & 357,424 \\
\hline
\end{tabular}


TABLE 12

DERIVATION OF NET OUTPUT AT VARIOUS ANNUAL RATES

(Mean water supply of 1,815,000 acre-feet)

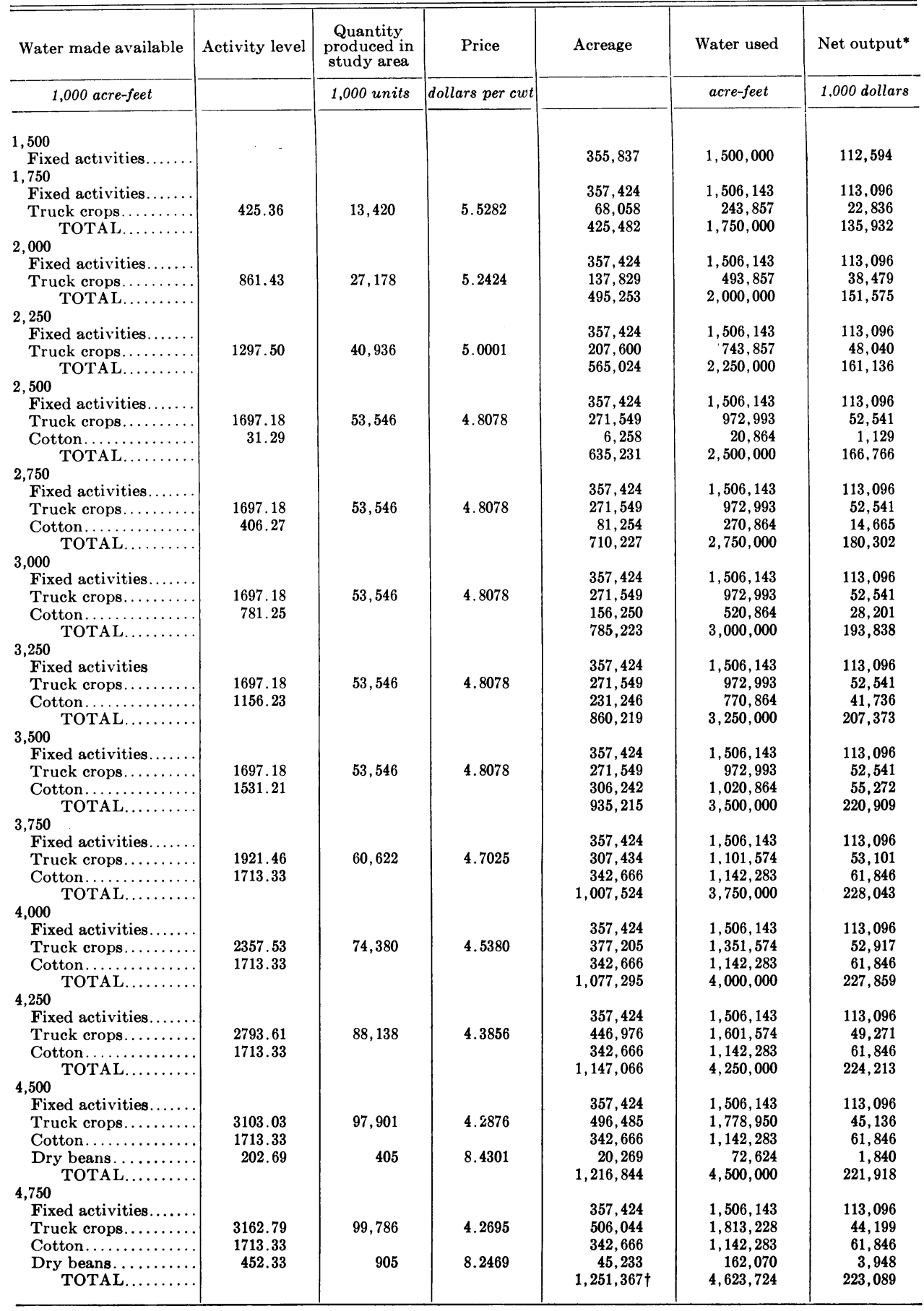

* Net output is gross output at projected market value minus basic labor and capital costs (land development and ground water pumping costs are excluded from costs).

$t$ Maximum irrigable land available for agricultural production. 


\section{Short-run adjustments}

Annual net output for various quantities of water made available periodically must now be computed, subject to the fixed requirements. Water is added by increments of 250,000 acrefeet, from 1,750,000 to 4,500,000 acrefeet. Each separate water constraint requires repeated application of the principles introduced in deriving the long-run economic organization. The set of activities is different, however, and the solution more easily obtained. The presence of fixed prices for some activities is particularly helpful in obtaining the solution. The results are summarized in table 12 . Net output, as defined there, is net only of labor and capital costs; development costs are not considered in determining the optimum activity levels.

Net output is not increased by added consumption of water above 3,750,000 acre-feet. The primary reason for this is the inelastic demand for net output from truck crops. The truck crop activity enters the solution at such a high level that a large proportion of the nation's truck crops are being produced in the study area ( 45 per cent in the most extreme situation). We note also that labor and capital are deducted from gross output. Elasticity of demand is less with respect to net output than gross output.

Table 13 shows net output per unit of land and water classified by activity and annual use rate of water. The unadjustable activities are not subject to change, and consequently, have the same net output for all annual use rates of water. Demand for cotton produced in the study area is assumed to be such that price is constant, but a maximum is imposed on quantity that may be produced (see table 7). Therefore, net output per unit of land and water attributable to cotton production is invariant with respect to annual water use rates. The quantity produced is variable, however. Truck crops and dry beans are the only two activities in the solution with continuous demand functions.

Calculation of net output with land development costs (as well as other labor and capital costs) deducted is given in table 14.

To determine the maximum price the study area can afford to pay for imported water, we consider a 250,000 acre-foot addition to the mean annual supply of water in the area. It is as-

TABLe 13

NET OUTPUT PER UNIT OF WATER AND LAND RESOURCES UNDER A MEAN ANNUAL SUPPLY OF 1,815,000 ACRE-FEET

\begin{tabular}{|c|c|c|c|c|c|c|c|c|}
\hline \multirow{2}{*}{$\begin{array}{c}\text { Annual rate } \\
\text { of water use } \\
(1,000 \text { acre- } \\
\text { feet })\end{array}$} & \multicolumn{4}{|c|}{ Net output per acre-foot of water (dollars) } & \multicolumn{4}{|c|}{ Net output per acre of land (dollars) } \\
\hline & $\begin{array}{c}\text { Fixed } \\
\text { activities }\end{array}$ & $\begin{array}{l}\text { Truck } \\
\text { crops }\end{array}$ & Cotton & $\underset{\text { beans }}{\text { Dry }}$ & $\begin{array}{c}\text { Fixed } \\
\text { activities }\end{array}$ & $\begin{array}{l}\text { Truck } \\
\text { crops }\end{array}$ & Cotton & $\underset{\text { beans }}{\text { Dry }}$ \\
\hline $1,500 \ldots \ldots \ldots \ldots$ & 82 & -* & - & - & 316 & - & - & - \\
\hline $1,750 \ldots \ldots \ldots \ldots$ & 82 & 94 & - & - & 316 & 336 & - & - \\
\hline $2,000 \ldots \ldots \ldots$ & 82 & 78 & - & 一 & 316 & 279 & - & - \\
\hline $2,250 \ldots \ldots \ldots \ldots$ & 82 & 65 & - & - & 316 & 231 & - & - \\
\hline $2,500 \ldots \ldots \ldots \ldots$ & 82 & 54 & 54 & - & 316 & 193 & 180 & - \\
\hline $2,750 \ldots \ldots \ldots \ldots$ & 82 & 54 & 54 & - & 316 & 193 & 180 & - \\
\hline $3,000 \ldots \ldots \ldots$ & 82 & 54 & 54 & - & 316 & 193 & 180 & - \\
\hline $3,250 \ldots \ldots \ldots \ldots$ & 82 & 54 & 54 & - & 316 & 193 & 180 & - \\
\hline $3,500 \ldots \ldots \ldots$ & 82 & 54 & 54 & - & 316 & 193 & 180 & - \\
\hline $3,750 \ldots \ldots \ldots \ldots$ & 82 & 48 & 54 & - & 316 & 173 & 180 & - \\
\hline $4,000 \ldots \ldots \ldots \ldots$ & 82 & 39 & 54 & - & 316 & 140 & 180 & - \\
\hline $4,250 \ldots \ldots \ldots \ldots$ & 82 & 31 & 54 & - & 316 & 110 & 180 & - \\
\hline $4,500 \ldots \ldots \ldots \ldots$ & 82 & 25 & 54 & 25 & 316 & 91 & 180 & 91 \\
\hline $4,750 \ldots \ldots \ldots \ldots$ & 82 & 24 & 54 & 24 & 316 & 87 & 180 & 87 \\
\hline
\end{tabular}

* Dashes signify no production with optimal combination of activities under pure competition. 
TABLE 14

DEDUCTION OF LAND DEVELOPMENT COSTS FROM NET OUTPUT (Mean annual water supply of $1,815,000$ acre-feet)

\begin{tabular}{|c|c|c|c|c|c|}
\hline $\begin{array}{c}\text { Annual rate of } \\
\text { water use }\end{array}$ & $\begin{array}{c}\text { Net output } \\
\text { including land } \\
\text { development costs }\end{array}$ & Acreage & $\begin{array}{l}\text { Weighted cost } \\
\text { per acre }\end{array}$ & $\begin{array}{l}\text { Development } \\
\text { costs }\end{array}$ & Net output \\
\hline 1,000 acre-feet & 1,000 dollars & & dollars & 1,000 dollars & 1,000 dollars \\
\hline 1,750 . & 135,932 & 425,482 & 1.4300 & 608 & 135,324 \\
\hline $2,000 \ldots \ldots$ & 151,575 & 495,253 & 1.4300 & 708 & 150,867 \\
\hline $2,250 \ldots \ldots \ldots \ldots \ldots$ & 161,136 & 565,024 & 1.5362 & 868 & 160,268 \\
\hline $2,500 \ldots \ldots \ldots \ldots \ldots$ & 166,766 & 635,231 & 1.7143 & 1,093 & 165,673 \\
\hline $2,750 \ldots$ & 180,302 & 710,227 & 2.3331 & 1,661 & 178,641 \\
\hline $3,000 \ldots$ & 193,838 & 785,223 & 2.8336 & 2,229 & 191,609 \\
\hline $3,250 \ldots$ & 207,373 & 860,219 & 3.2468 & 2,797 & 204,576 \\
\hline $3,500 \ldots \ldots \ldots \ldots$ & 220,909 & 935,215 & 3.5938 & 3,365 & 217,544 \\
\hline $3,750 \ldots \ldots \ldots \ldots \ldots$ & 228,043 & $1,007,524$ & 3.8788 & 3,912 & 224,131 \\
\hline $4,000 \ldots \ldots \ldots \ldots \ldots$ & 227,859 & $1,077,295$ & 4.1214 & 4,440 & 223,419 \\
\hline
\end{tabular}

TABLE 15

SOLUTION FOR LONG-RUN ECONOMIC ORGANIZATION

(Mean water supply of 2,065,000 acre-feet)

\begin{tabular}{|c|c|c|c|c|c|c|c|}
\hline Activity & $\begin{array}{c}\text { Activity } \\
\text { level }\end{array}$ & $\begin{array}{l}\text { Water } \\
\text { require- } \\
\text { ments }\end{array}$ & $\begin{array}{l}\text { Land } \\
\text { require- } \\
\text { ment }\end{array}$ & $\begin{array}{l}\text { Study } \\
\text { area pro- } \\
\text { duction }\end{array}$ & Units & $\begin{array}{l}\text { Per } \\
\text { unit } \\
\text { price }\end{array}$ & $\begin{array}{l}\text { Net return } \\
\text { per acre-foot } \\
\text { of water }\end{array}$ \\
\hline & & acre-feet & acres & 1,000 units & & \multicolumn{2}{|c|}{ dollars } \\
\hline Oranges........ & $3,806.45$ & 558,787 & 152,258 & 41,871 & boxes & 2.8636 & 77.86 \\
\hline Deciduous fruit. & 129.64 & 82,970 & 20,742 & 266.4 & tons & 78.9430 & 77.85 \\
\hline Truck crops . . . . . . & 863.84 & 495,239 & 138,214 & 27,254 & cwt & 5.2414 & 77.86 \\
\hline Grapes ............... & $1,451.41$ & 928,902 & 232,226 & 2,061 & tons & 67.7065 & 77.86 \\
\hline Other activities......... & 0 & 0 & 0 & 0 & & & \\
\hline TOTAL $\ldots \ldots \ldots \ldots$ & & $2,065,898$ & 543,440 & & & & \\
\hline
\end{tabular}

TABLE 16

UNADJUSTABLE ACTIVITY LEVELS

(Mean water supply of 2,065,000 acre-feet)

\begin{tabular}{|c|c|c|c|c|c|c|c|}
\hline Activity & $\begin{array}{c}\text { Activity } \\
\text { level }\end{array}$ & $\begin{array}{l}\text { Gross return } \\
\text { per activity } \\
\text { unit }\end{array}$ & $\begin{array}{l}\text { Labor and } \\
\text { capital } \\
\text { costs }\end{array}$ & $\begin{array}{l}\text { Net return } \\
\text { per activity } \\
\text { unit }\end{array}$ & $\begin{array}{c}\text { Total } \\
\text { net } \\
\text { output }\end{array}$ & $\begin{array}{l}\text { Water } \\
\text { require- } \\
\text { ment }\end{array}$ & $\begin{array}{l}\text { Land } \\
\text { require- } \\
\text { ment }\end{array}$ \\
\hline & & \multicolumn{3}{|c|}{ dollars } & 1,000 dollars & acre-feet & acres \\
\hline Oranges $\ldots \ldots \ldots \ldots \ldots$ & $3,806.45$ & 31,500 & 20,070 & 11,430 & 43,508 & 558,787 & 152,258 \\
\hline Deciduous fruit........ & 129.64 & 162,228 & 112,402 & 49,826 & 6,459 & 82,970 & 20,742 \\
\hline Grapes............. & $1,451.41$ & 96,143 & 46,315 & 49,828 & 72,321 & 928,902 & 232,226 \\
\hline Urban and misc........ & . & $\ldots$ & $\ldots$ & . & $\ldots$ & 112,484 & . \\
\hline TOTAL. . & & & & & 122,288 & $1,693,143$ & 405,226 \\
\hline
\end{tabular}

sumed that the imported water will be provided with certainty each year. The same method is used for obtaining the net output function with the increased supply of water. The long-run economic organization is first obtained under an assumed mean supply of $2,065,000$ acre-feet $\quad(250,000+1,815$,$000)$. This solution is given in table 15 , and the fixed activities are summarized in table 16.

Table 17 summarizes derivation of 
TABLE 17

DERIVATION OF NET OUTPUT AT VARIOUS LEVELS OF WATER CONSUMPTION

(Mean water supply of 2,065,000 acre-feet)

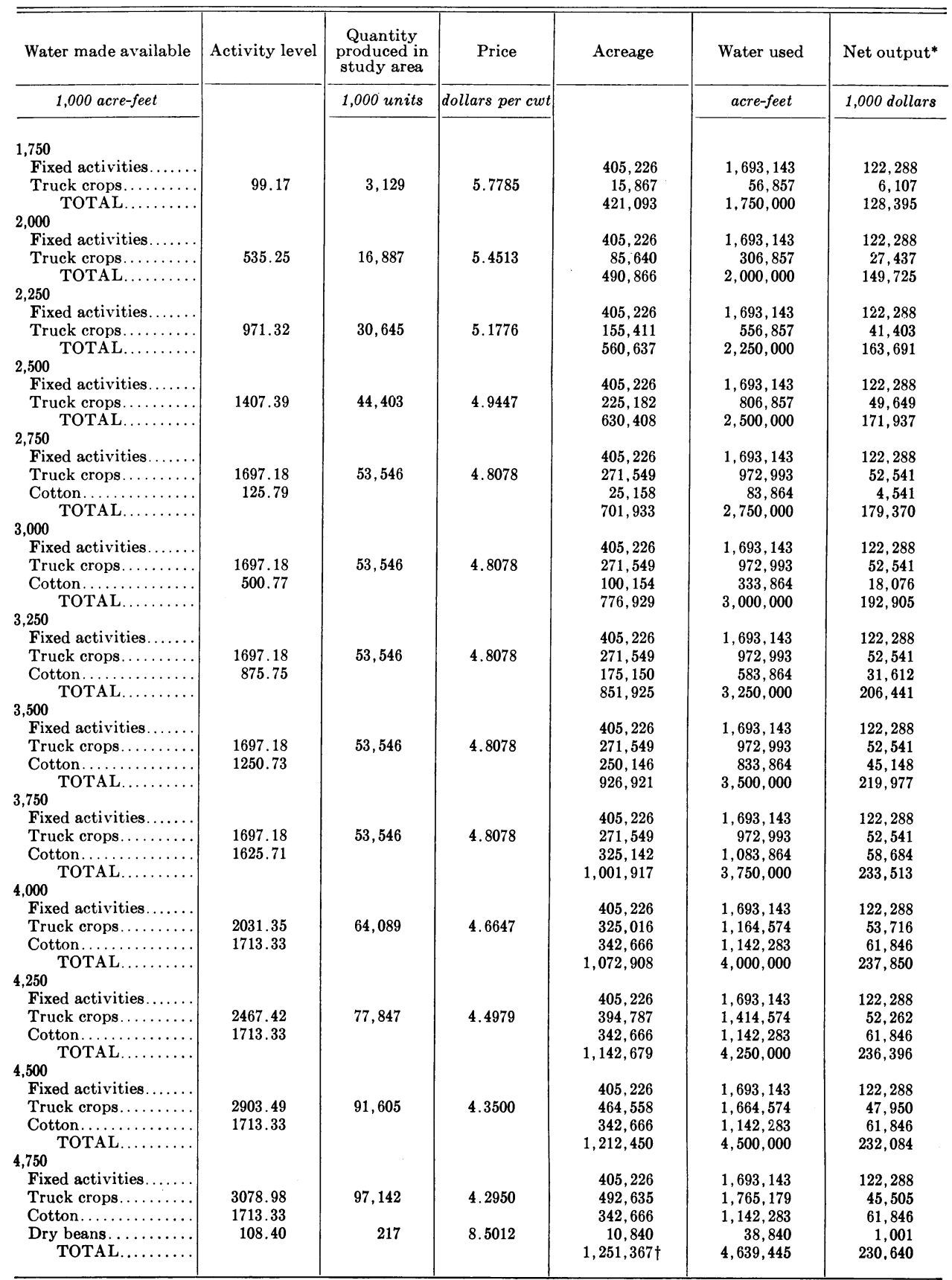

* Net output is gross output at projected market value minus basic labor and capital costs (land development and ground water pumping costs are excluded from costs).

$\dagger$ Maximum irrigable land available for agricultural production. 
the net output function for water by 250,000 acre-feet intervals starting from $1,750,000$ acre-feet under the assumption that the mean water supply is 2,065,000 acre-feet. Net output is not increased by additional quantities of water above 4,000,000 acre-feet.

Net output per unit of land and water classified by activity and annual use rate of water (with an annual mean supply of $2,065,000$ acre-feet) is given in table 18. Net output after subtraction of land development costs for various annual water use rates under a mean annual supply of $2,065,000$ acre-feet is given in table 19 .

TABLE 18

NET OUTPUT PER UNIT OF WATER AND LAND RESOURCES UNDER A MEAN ANNUAL SUPPLY OF 2,065,000 ACRE-FEET

\begin{tabular}{|c|c|c|c|c|c|c|c|c|}
\hline \multirow{2}{*}{$\begin{array}{c}\text { Annual rate } \\
\text { of water use } \\
(1,000 \text { acre- } \\
\text { feet })\end{array}$} & \multicolumn{4}{|c|}{ Net output per acre-foot of water (dollars) } & \multicolumn{4}{|c|}{ Net output per acre of land (dollars) } \\
\hline & $\begin{array}{c}\text { Fixed } \\
\text { activities }\end{array}$ & $\begin{array}{l}\text { Truck } \\
\text { crops }\end{array}$ & Cotton & $\underset{\text { beans }}{\text { Dry }}$ & $\begin{array}{c}\text { Fixed } \\
\text { activities }\end{array}$ & $\begin{array}{l}\text { Truck } \\
\text { crops }\end{array}$ & Cotton & $\begin{array}{c}\text { Dry } \\
\text { beans }\end{array}$ \\
\hline $1,750 \ldots \ldots \ldots \ldots$ & 78 & 107 & -* & - & 302 & 385 & - & - \\
\hline $2,000 \ldots \ldots \ldots$ & 78 & 89 & - & - & 302 & 320 & - & - \\
\hline $2,250 \ldots \ldots \ldots \ldots$ & 78 & 74 & - & - & 302 & 266 & - & - \\
\hline $2,500 \ldots \ldots \ldots \ldots$ & 78 & 62 & - & - & 302 & 220 & - & - \\
\hline $2,750 \ldots \ldots \ldots \ldots$ & 78 & 54 & 54 & - & 302 & 193 & 180 & - \\
\hline $3,000 \ldots \ldots \ldots \ldots$ & 78 & 54 & 54 & - & 302 & 193 & 180 & - \\
\hline $3,250 \ldots \ldots$ & 78 & 54 & 54 & - & 302 & 193 & 180 & - \\
\hline $3,500 \ldots \ldots$ & 78 & 54 & 54 & - & 302 & 193 & 180 & - \\
\hline $3,750 \ldots \ldots \ldots$ & 78 & 54 & 54 & - & 302 & 193 & 180 & - \\
\hline $4,000 \ldots \ldots \ldots \ldots$ & 78 & 46 & 54 & - & 302 & 165 & 180 & - \\
\hline $4,250 \ldots \ldots \ldots \ldots$ & 78 & 37 & 54 & - & 302 & 132 & 180 & - \\
\hline $4,500 \ldots \ldots \ldots \ldots$ & 78 & 29 & 54 & - & 302 & 103 & 180 & - \\
\hline $4,750 \ldots \ldots \ldots \ldots$ & 78 & 26 & 54 & 26 & 302 & 92 & 180 & 92 \\
\hline
\end{tabular}

* Dashes signify no production with optimal combination of activities under pure competition.

TABLe 19

DEDUCTION OF LAND DEVELOPMENT COSTS FROM NET OUTPUT (Mean annual water supply of 2,065,000 acre-feet)

\begin{tabular}{|c|c|c|c|c|c|}
\hline $\begin{array}{c}\text { Annual rate of } \\
\text { water use }\end{array}$ & $\begin{array}{c}\text { Net output } \\
\text { including land } \\
\text { development costs }\end{array}$ & Acreage & $\begin{array}{l}\text { Weighted cost } \\
\text { per acre }\end{array}$ & $\begin{array}{l}\text { Development } \\
\text { costs }\end{array}$ & Net output \\
\hline 1,000 acre-feet & 1,000 dollars & & dollars & 1,000 dollars & 1,000 dollars \\
\hline $2,000 \ldots \ldots \ldots \ldots \ldots$ & 149,725 & 490,866 & 1.4300 & 702 & 149,023 \\
\hline $2,250 \ldots \ldots \ldots$ & 163,691 & 560,637 & 1.5375 & 862 & 162,829 \\
\hline $2,500 \ldots \ldots \ldots \ldots \ldots \ldots \ldots$ & 171,937 & 630,408 & 1.6815 & 1,060 & 170,877 \\
\hline $2,750 \ldots \ldots \ldots \ldots \ldots \ldots$ & 179,370 & 701,933 & 2.2808 & 1,601 & 177,769 \\
\hline $3,000 \ldots$ & 192,905 & 776,929 & 2.7918 & 2,169 & 190,736 \\
\hline $3,250 \ldots \ldots \ldots \ldots \ldots \ldots$ & 206,441 & 851,925 & 3.2127 & 2,737 & 203,704 \\
\hline $3,500 \ldots \ldots \ldots \ldots \ldots \ldots$ & 219,977 & 926,921 & 3.5656 & 3,305 & 216,672 \\
\hline $3,750 \ldots \ldots \ldots \ldots \ldots \ldots$ & 233,513 & $1,001,917$ & 3.8656 & 3,873 & 229,640 \\
\hline $4,000 \ldots \ldots \ldots \ldots \ldots \ldots$ & 237,850 & $1,072,908$ & 4.1103 & 4,410 & 233,440 \\
\hline
\end{tabular}

\section{GROUND WATER PUMPING COSTS}

Net output for a specified quantity of water made available annually has been estimated, but without considering ground water pumping costs. The cost per acre-foot of water pumped actually has an influence on the relative activity levels. However, this is ignored along with land development costs in order to restrict the numerical problem to a manageable size. Pumping costs must be deducted from the output derived under our approximate proce- 
dures. This cost is a function of depth to ground water. Therefore, pumping costs are defined only when the ground water storage level is specified.

Twenty-one discrete ground water storage quantities are defined between depths of 50 and 407 feet. The depths to ground water with corresponding quantities of water in storage and pumping costs per acre-foot are given in table 20. Fifty feet was chosen as an upper limit since this is approximately the present level of ground water, and with a limited number of discrete values, the upper limit was made as low as possible. An optimal policy is not likely to permit accumulation of ground water above its current level.

A separate net output function must be defined for each ground water storage possibility. However, net output for a given storage level is a random variable. The amount of surface water used during any year is dependent on

TABLE 20

GROUND WATER PUMPING COSTS

\begin{tabular}{|c|c|c|}
\hline $\begin{array}{l}\text { Water in storage } \\
\text { above } 407 \text { feet }\end{array}$ & $\begin{array}{l}\text { Depth to } \\
\text { ground water* }\end{array}$ & $\underset{\text { cost }}{\text { Pumping }}$ \\
\hline 1,000 acre-feet & feet & $\begin{array}{c}\text { dollars per } \\
\text { acre-foot }\end{array}$ \\
\hline $0 \ldots \ldots \ldots \ldots$ & 407.4 & $\ldots$ \\
\hline $2,739 \ldots \ldots \ldots \ldots$ & 389.5 & 14.00 \\
\hline $5,478 \ldots \ldots \ldots \ldots$ & 371.6 & 13.40 \\
\hline $8,217 \ldots \ldots \ldots \ldots \ldots$ & 353.7 & 13.00 \\
\hline $10,956 \ldots \ldots \ldots \ldots \ldots$ & 335.8 & 12.30 \\
\hline $13,695 \ldots \ldots \ldots \ldots \ldots$ & 317.9 & 11.90 \\
\hline $16,434 \ldots \ldots \ldots \ldots \ldots$ & 300.0 & 11.20 \\
\hline $19,173 \ldots \ldots \ldots \ldots \ldots$ & 282.1 & 10.60 \\
\hline $21,912 \ldots \ldots \ldots \ldots$ & 264.2 & 10.10 \\
\hline $24,651 \ldots \ldots \ldots \ldots \ldots$ & 246.3 & 9.60 \\
\hline $27,390 \ldots \ldots \ldots \ldots \ldots$ & 228.4 & 9.20 \\
\hline $30,129 \ldots \ldots \ldots \ldots \ldots$ & 210.5 & 8.80 \\
\hline $32,868 \ldots \ldots \ldots \ldots \ldots$ & 192.6 & 8.10 \\
\hline $35,607 \ldots \ldots \ldots \ldots \ldots$ & 174.7 & 7.60 \\
\hline $38,346 \ldots \ldots \ldots \ldots \ldots$ & 156.8 & 7.10 \\
\hline $41,085 \ldots \ldots \ldots \ldots \ldots$ & 138.9 & 6.50 \\
\hline $43,824 \ldots \ldots \ldots \ldots \ldots$ & 121.0 & 5.90 \\
\hline $46,563 \ldots \ldots \ldots \ldots$ & 103.1 & 5.20 \\
\hline $49,302 \ldots \ldots \ldots \ldots$ & 85.4 & 4.60 \\
\hline $52,041 \ldots \ldots \ldots \ldots$ & 67.7 & 4.10 \\
\hline $54,780 \ldots \ldots \ldots \ldots \ldots$ & 50.0 & 3.30 \\
\hline
\end{tabular}

* Specific yield below 200 feet estimated to equal that from $100-200$ feet.

Sources: Water storage capacity in relation to depth: Davis et al., (1959)

Pumping costs: Calif. Dept. of Water Resources, unpublished graph of estimated pumping costs in Kern County, 1958. the quantity of water captured from the Kings River. Thus, surface water used annually is a random variable. Under a specific choice of total water to be consumed, the amount pumped is a random variable, being the residual not provided by surface water.

Suppose we are at a particular ground water storage level. Denote net output before deducting pumping costs under the $k^{\text {th }}$ alternative use rate by $\boldsymbol{O}_{k}$ and the cost per acre-foot of water pumped by $C$ ( $\boldsymbol{O}_{k}$ and $C$ are in dollars). Let $w_{k}$ be the total water consumed under the $k^{\text {th }}$ alternative use rate and denote surface water provided (a random variable) by $x$. Then $y_{k}$, net output after pumping costs, is defined as

$$
y_{k}=O_{k}-\left(w_{k}-x\right) C
$$

and the mathematical expectation of $y_{k}$ is

$$
E\left(y_{k}\right)=O_{k}-\left(w_{k}-E(x)\right) C
$$

where $E(x)$ is the expectation of $x$. That is, we can obtain the expectation of $y_{k}$ by substituting the expectation of $x$ for $x$ in equation (4.4). This avoids computing the probability distribution of net output; only the expected value is needed for solving the water inventory model. Under our assumptions about incidental recharge, the expectation of $x$ is 907,500 and 1,032,500 acrefeet with mean surface water supplies of 1,815,000 and 2,065,000 acre-feet, respectively.

Expected net output (with pumping costs deducted) is easily computed from tables 14 and 19 utilizing equation (4.5) and pumping costs from table 20. This expected annual net output is converted to a five-year basis. Five years is considered more practical than one year as a time interval upon which to formulate water policy. Farmers need a period longer than a year to plan their operations efficiently even when fixed investment enterprises have already been specified. The period chosen is arbitrary, but a stable water supply must be weighted against flexibility in 
inventory control under an uncertain water supply.

A completely exhausted ground water supply is a situation requiring special consideration. Investment in trees is endangered by inadequate water supply and net output associated with an empty ground water reservoir should reflect the expected loss of this investment. However, surface water is available to the present conjunctive use area when the ground water supply is exhausted, and the probability distribution for ground water recharge (to be explained in the next chapter) implies that surface water is consumed in the same manner regardless of ground water storage. We assume that the surface water available when in a state of no ground water in storage is sufficient to preserve investment in trees but inadequate to yield any current net output. Therefore, net output for no ground water in storage is set equal to zero.

Ground water storage capacity was estimated from a study by Davis et al. (1959). Several compromises had to be made. The units into which the valley was divided for that ground water study do not coincide with boundaries of the study area being considered here. However, units in the ground water study were subdivided into townships, and a good approximation to the study area was obtained by townships. For a large part of the study area not included in the ground water study, the average specific yields of the entire San Joaquin Valley for specified depths were used. The result for the entire study area was an estimate of $7,740,000$ acre-feet of storage between 50 and 100 feet and an estimate of $15,300,000$ acre-feet between 100 and 200 foot depth. (See appendix table D-1.) The capacity below 200 feet is estimated to be the same per foot as between 100 and 200 feet. The adoption of these estimates gives the storagedepth relations of table 20 listed on page 73 .

\section{SURFACE WATER POLICY AND PROBABILITY DISTRIBUTION FOR GROUND WATER STORAGE POLICY FOR THE SURFACE RESERVOIR}

The study area contains Pine Flat Reservoir on the Kings River, having a total capacity of one million acre-feet. The dam and reservoir are for flood control and irrigation only. The position taken here is that the surface reservoir is better utilized for meeting seasonal storage requirements and allowing underground storage to provide cyclical storage from year to year.

Using the surface reservoir for cyclical storage requires maintaining more water in the reservoir, on the average, and thereby foregoing the opportunity of capturing as much water from an uncertain supply. In many cases, cyclical storage on the surface might bring a gain because less water needs to be pumped over a long period of time, thus cutting down pumping cost. However, the region under study has an "over-built" canal system which makes it possible to use all water flowing in the river during every year except those of extremely high run-off.

Cyclical storage on the surface would be economical only at very low annual use rates of water. With such a rate, normal flow from the Kings River could not all be utilized, but the escape of a large part of the water from the area would be of no consequence (if, for the moment, we ignore problems of flood control). The surface storage capacity would be larger relative to annual use, making long-term storage more feasible. Therefore, cyclical storage on the surface is not a practical alternative unless capacity is large enough, relative to annual use, to make it unlikely that large quantities of water having potential use in the area 
are lost when the reservoir is utilized for cyclical storage.

The situation in the study area is unique because the large network of canals was built before the reservoir. The size of the surface distribution system is probably larger than would have been economical, had it been built after completion of the reservoir. If the irrigation demands are met as nearly as possible from surface water, hardly any water escapes the study area. The policy of using as much surface water as possible to meet irrigation demands is very favorable for flood control purposes. It is assumed, on the basis of the above argument, that this is the best surface water policy. We also assume that water released for flood control purposes using snow-melt projections results in the same amount of water lost as if the water were allowed to run over the dam uncontrolled.

The surface water distribution system is large enough so that it is not an effective constraint on the quantity of water utilized for irrigation. With a small canal system, the amount of water consumed each month is determined jointly by canal capacity and irrigation demand. The effective constraint is the minimum of these two factors. For Pine Flat Reservoir the minimum always is irrigation demand because of the over-built canal system.

Although present size of the canal system may have been justified at the time it was constructed, we may say now that it is over-built. We cannot say this unequivocally without an analysis of the question in detail. A superficial analysis of the question is given in the next paragraph which substantiates the hypothesis.

The capacity of the canal system has been estimated at 16,000-20,000 secondfeet. (U. S. Congress, 1940, p. 4.) There are 2,592,000 seconds per month; using the lower capacity, 16,000 secondfeet, we get a capacity of $41,472(10)^{6}$ cubic feet per month. Converting to acre-feet (one acre-foot $=43,560$ cubic feet), this represents a capacity of 952 ,000 acre-feet per month. The above method for estimating the lower bound of canal capacity in acre-feet per month assumes that flow is completely uniform second by second throughout the month. Of course, this condition will not be met, but a sizeable margin exists between our estimate of capacity and the largest monthly irrigation demand estimated. Table 21 indicates a maximum monthly irrigation demand of 679,000 acre-feet in July, leaving a margin for error of 273,000 acre-feet. This strongly supports the conclusion that canal capacity will always exceed irrigation demands as estimated in the table. Details of the estimating procedure used in table 21 are given later.

The validity of our assumption for a surface water policy can be checked against an alternative policy by comparing the present value of expected returns from each policy under an optimal ground water policy. The iterative method suggested in chapter II could also be used to verify our assumption. Neither of these analyses is carried out in this study because there can be little doubt as to the validity of the assumed policy.

\section{PROBABILITY DISTRIBUTION FOR GROUND WATER RECHARGE}

\section{Water demand by months}

Seasonal water demands, by months, are given for the activities in appendix table A-11. Demand for surface water is dependent on total quantity of water used in the conjunctive use area serviced by the surface distribution system. Thus demand is determined by the particular rate of use specified for the study area during any year and will not be the same over time, being 
dependent on the water inventory policy and the stochastic supply. Water will be used in the conjunctive use area to the extent possible with available land since development costs are lower there than elsewhere. If $1,750,000$ acrefeet of water represents the annual use rate, all will be used in the conjunctive use area since that quantity of water will not utilize all the land of the conjunctive use area. This is the lowest annual use rate permitted in the discrete set of possibilities chosen. Of the total, 122,500 acre-feet will be pumped from ground water for urban use, and 84,000 acre-feet will be supplied with certainty from sources other than the Kings River. Therefore, the lowest quantity determining water demand relevant to the flows of the Kings River is $1,543,500$ acre-feet. We specify an arbitrary value of 2,000,000 acre-feet as the use rate determining surface water demand for flows of the Kings River. This specification only serves to estimate the mean quantity of flow not captured for irrigation.

Allocation of the 2,000,000 acre-feet among activities is given in table 21 together with irrigation demand by months. Water demand at the canal headgates is twice the irrigation demand under the assumption that onehalf the water entering the surface distribution system is recharged to ground water. ${ }^{7}$

\section{Water supply by months}

The probability distributions of stream flows by months are not apt to reflect independence among month-tomonth flows. We would expect the flow to be dependent on the immediately preceding period's flow and possibly on earlier ones. An assumed Markov dependence among monthly stream flows would permit statistical estimation of the probability distribution from the available time series data, within the limits of a discrete approxi- mation. The estimation and subsequent calculations of expected values of random variables which are functions of the stream flows by months, go beyond our present purpose-which is to estimate expected water losses over the dam.

For present purposes time series data are used to estimate the average proportion of annual flow occurring in each month for various discrete intervals of annual flow. This average proportion is taken as fixed for each respective annual flow interval. The probability associated with each annual flow interval is estimated as the relative frequency of flows occurring in that interval during the 88 years for which records are available.

The 13 intervals, their midpoints, associated probabilities, and monthly proportion of the midpoint values are given in table 22. The expected annual stream flow computed from this discrete approximation is $1,754,000$ acrefeet compared to an actual mean flow of 1,755,000 acre-feet. The annual stream flows during 1872-1959 are summarized in appendix table D-2. (The water year is October 1 to September 30.)

Storage levels in the surface reservoir are divided into four discrete intervals, the midpoint of each interval being taken as the level of storage for that interval. The expected overflow, given that we started the season at each discrete magnitude of surface storage, is computed with the use of tables 21 and 22. A total reservoir capacity of 900,000 acre-feet instead of $1,000,000$ is used to allow for errors in projected snow melt. It is assumed that distribution of flow within the month corresponds to irrigation demands within the month.

The probability distribution of storage conditions at the end of the year, given the storage condition at the beginning of the year, is computed

\footnotetext{
${ }^{7}$ A tentative estimate given by the California Department of Water Resources.
} 


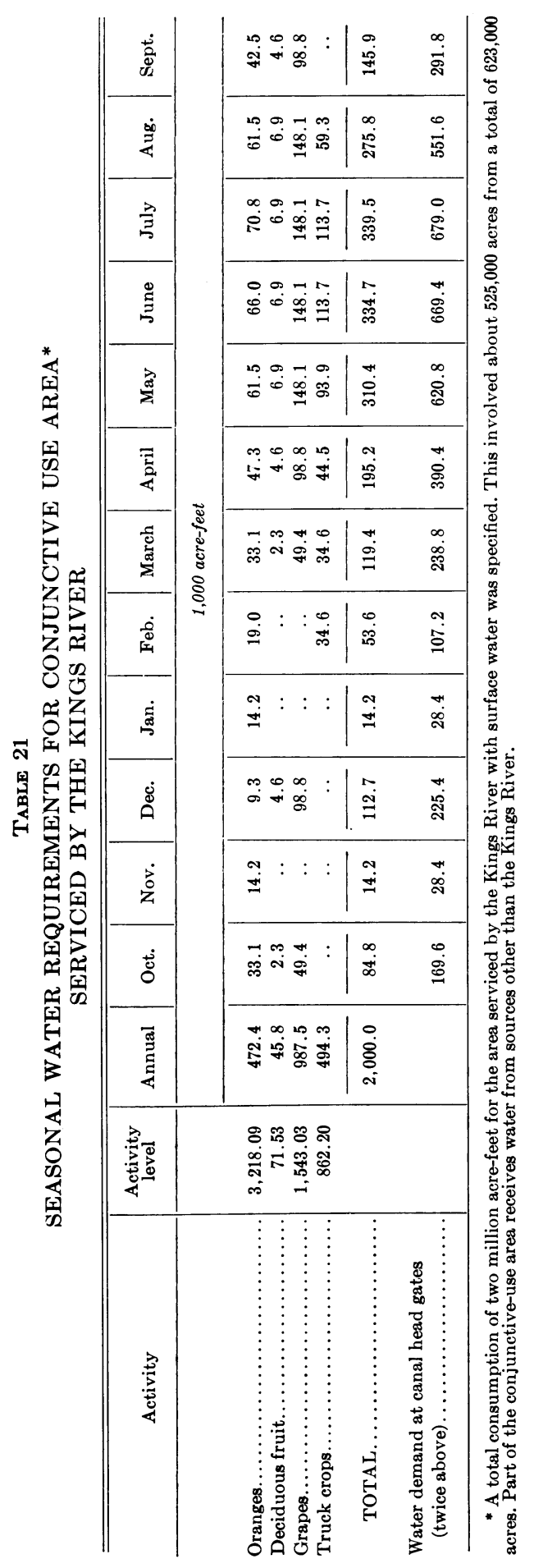

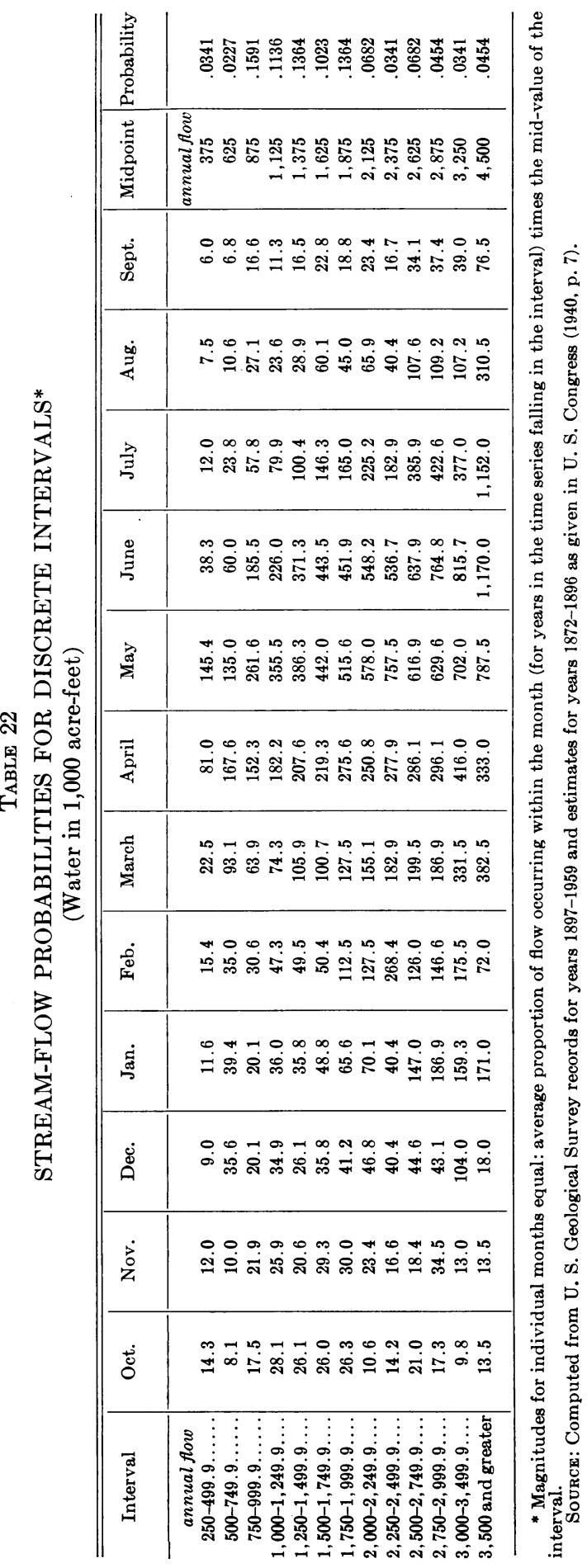


TABLE 23

CONDITIONAL PROBABILITIES OF FLOWS OVER THE DAM AND SURFACE STORAGE

\begin{tabular}{|c|c|c|c|c|c|c|c|c|c|}
\hline \multirow{2}{*}{$\begin{array}{l}\text { Stream } \\
\text { flow }\end{array}$} & \multicolumn{2}{|c|}{ Oct. 1 storage $=100$} & \multicolumn{2}{|c|}{ Oct. $1 \underset{(200-400)}{\text { storage }}=300$} & \multicolumn{2}{|c|}{ Oct. 1 storage $=500$} & \multicolumn{2}{|c|}{ Oct. 1 storage $=750$} & \multirow{2}{*}{ Probability } \\
\hline & $\begin{array}{l}\text { Storage } \\
\text { Sept. } 30\end{array}$ & $\begin{array}{c}\text { Flows over } \\
\text { the dam }\end{array}$ & $\begin{array}{l}\text { Storage } \\
\text { Sept. } 30\end{array}$ & $\begin{array}{c}\text { Flows over } \\
\text { the dam }\end{array}$ & $\begin{array}{l}\text { Storage } \\
\text { Sept. } 30\end{array}$ & $\begin{array}{c}\text { Flows over } \\
\text { the dam }\end{array}$ & $\begin{array}{l}\text { Storage } \\
\text { Sept. } 30\end{array}$ & $\begin{array}{l}\text { Flows over } \\
\text { the dam }\end{array}$ & \\
\hline & \multicolumn{9}{|c|}{1,000 acre-feet } \\
\hline $375 \ldots$ & 0 & 0 & 0 & 0 & 0 & 0 & 0 & 0 & .0341 \\
\hline $675 \ldots$ & 0 & 0 & 0 & 0 & 0 & 0 & 0 & 0 & .0227 \\
\hline$\cdot \ldots \ldots$ & . & . & . & . & . & . & . & . & . \\
\hline$\cdot \ldots \ldots$ & · & $\cdot$ & $\cdot$ & $\cdot$ & $\cdot$ & $\cdot$ & . & . & . \\
\hline$\cdot \ldots \ldots$ & $\cdot$ & · & - & • & $\cdot$ & . & - & . & . \\
\hline . $\cdots$ & $\dot{0}$ & i & $\dot{0}$ & i & $\dot{0}$ & i & $\dot{0}$ & $\dot{0}$ & $\dot{2}$ \\
\hline $2,875 \ldots$ & 0 & 0 & 0 & 0 & 0 & 0 & 0 & $\mathbf{0}$ & .0454 \\
\hline $3,250 \ldots \ldots$ & 0 & 0 & 0 & 0 & 0 & 0 & 0 & 98 & .0341 \\
\hline $4,500 \ldots \ldots$ & 444 & 434 & 444 & 434 & 444 & 552 & 444 & 806 & .0454 \\
\hline
\end{tabular}

Source: Computed from tables 21 and 22.

simultaneously with the probability distribution of flows over the dam. We thus obtain a four-dimensional matrix of conditional probabilities for a discrete Markov chain. The well-known theorem of convergence of a Markov chain after many repetitions, such that the probability of being in any particular state is independent of the initial state, is applied to the resulting matrix.

Table 23 summarizes the basic data needed to construct the matrix of transition probabilities. Only the two states covering intervals $(0,200)$ and $(400$,$600)$ are accessible with a positive probability. The matrix of transition probabilities is

$$
\left[p_{i j}\right]=\left[\begin{array}{rrrr}
.9546 & 0 & .0454 & 0 \\
.9546 & 0 & .0454 & 0 \\
.9546 & 0 & .0454 & 0 \\
.9546 & 0 & .0454 & 0
\end{array}\right]
$$

where $i$ and $j$ have the following definitions:

$$
\begin{array}{cc}
i, j & \text { Storage interval (1,000 acre-feet) } \\
1 & 0-200 \\
2 & 200-400 \\
3 & 400-600 \\
4 & 600-900
\end{array}
$$

The unusual form of the above matrix is due to the discrete categories chosen for stream flows. A state other than zero storage can be reached only with the highest stream flow of 4.5 million acre-feet. If additional categories had been defined between 4.5 and 3.25 million acre-feet, additional elements of the matrix could be positive and the rows would not necessarily be identical. This additional precision did not seem warranted for present purposes. It was obvious that the smoothing effect of fitting a curve to the stream flow data would not have altered the conclusions reached by using observed relative frequencies (see next section).

It turns out in this case that the matrix $\left[p_{i j}\right]$ exemplifies the equilibrium condition of the Markov chain, i.e., the probability of being in a given state is independent of the initial state, and the vector of probabilities may be taken as a row of the matrix $\left[p_{i j}\right]$. 
Accordingly, the probability of being in the storage interval $(0,200)$ or $(400$,$600)$ is .9546 and .0454 , respectively; there is no chance of being in either of the other two states.

The expected flows over the dam are readily computed to be $(.9546)(.0454)$ $(434)+(.0454)^{2}(552)=20$. Note that the numbers are in thousands of acrefeet so the mean flow over the dam is 20,000 acre-feet. The probability, .0454, is that associated with 4,500,000 acrefeet of stream flow which is the only flow at which water escapes over the dam.

If 20,000 acre-feet is expected overflow, then $1,755,000-20,000=1,735$,000 acre-feet is expected diversion into the surface distribution system. Consequently, expected recharge from the captured water is 867,500 acre-feet, one-half expected diversion. We assume one-quarter of the water overflowing the dam is recharged to ground water from the Kings River within the study area. This adds 5,000 acre-feet to expected recharge, giving a total of 872,500 acre-feet. This is 49.7 per cent of the mean flow in the Kings River.

Since it has seemed desirable to avoid policies in which farmers are uncertain about their water supply from year to year, it has been assumed that the public agency controlling annually pumped ground water will specify the rate of use for five years in advance. A policy based on five-year periods together with dissemination of information within the period on the likelihood that the policy would be in effect during the subsequent period should give a water supply sufficiently stable that efficient production can take place.
The longer period has an advantage also from a computational standpoint. The quantity of ground water in storage is a continuous variable which must be made discrete for computation. The number of discrete intervals is severely limited by computer capacity, thus, requiring a relatively large interval for each discrete storage level. When the quantity of water in storage is in a particular interval, storage is measured by the midpoint of that interval. Obviously, a change from one interval to an adjacent interval can take place only if the addition to or withdrawal from storage is at least as large as one-half of the interval. Defining the intervals too large when dealing with annual net recharge makes movement from the present storage interval impossible except when recharge is extremely high or low. This biases the probability distribution of movement among storage states such that the probability of remaining in the same state is always unreasonably high.

Adopting a period of five years instead of one year greatly increases the net recharge associated with a given probability and permits using larger storage intervals without unduly biasing the probability distribution for movement among storage states. Another source of bias is the discrete probability distribution for net recharge to ground water. We have discrete storage levels and discrete net recharge both contributing errors to the approximation to the actual continuous model. The discrete probability distribution of net recharges can be made continuous by fitting a continuous function to the time series data.

\section{FITTING THE FREQUENCY CURVE}

The incomplete gamma function is fitted to the time series data on annual stream flows of the Kings River. This function has given good results when fitted to precipitation data and is one of the most common choices of mete- orologists for such purposes. Since water in the Kings River is primarily the result of each year's snowfall, we may expect to get a good fit with the gamma distribution.

The gamma distribution has an ad- 
ditional advantage for our purpose. The sum of $n$ independent, identically distributed gamma variates also follows the gamma distribution with pa- rameters which are simple functions of the original parameters. The incomplete gamma function is defined

$$
F(x)=\int_{0}^{x} \frac{1}{\beta^{\gamma}} \frac{1}{\Gamma(\gamma)} t^{\gamma-1} e^{-t / \beta} d t, \quad \begin{aligned}
& x>0 \\
& \beta>0 \\
& \gamma>0
\end{aligned}
$$

Let $y=\sum_{i=1}^{n} x_{i}$ where the cumulative probability distribution of $x_{i}$ is defined by (5.1). Then the distribution of $y$ is

$$
G(y)=\int_{0}^{y} \frac{1}{\beta^{n \gamma} \Gamma(n \gamma)} t^{n \gamma-1} e^{-t / \beta} d t .
$$

Denoting the parameters in the distribution of $y$ by $\beta^{\prime}$ and $\gamma^{\prime}$, we have $\beta^{\prime}=\beta$ and $\gamma^{\prime}=n \gamma$. This property of the gamma distribution is easily established from its moment generating function and the general theorem that the moment generating function of the sum of $n$ independently distributed random variables is the product of the $n$ separate moment generating functions.

The parameters of the gamma distribution for annual stream flows are estimated from 88 annual time series observations. It has been shown that maximum-likelihood estimates of the parameters of the gamma distribution are jointly sufficient. (Thom, 1958, pp. 119-20). Maximum-likelihood estimates have been chosen since an approximating procedure to solution of the likelihood equations has been derived which gives very good results (Thom, 1958 , p. 119).

\section{TRANSITION PROBABILITIES FOR GROUND WATER STORAGE}

A separate set of transition probabilities must be estimated for each alternative annual use rate. We will speak in terms of annual use rates, but it must be kept in mind that the period of time relevant to movement from one storage level to another is five years. We define $p_{i j}{ }^{k}$ to be the probability of being in the $j^{\text {th }}$ state after five years, given that we were in the $i^{\text {th }}$ state at the
The maximum-likelihood estimates derived from the data of appendix table D-2 are $\hat{\beta}=434.64$ and $\hat{\gamma}=4.038$. A chisquare "goodness of fit" test was performed using the 13 intervals specified in table 22 and tables of the incomplete gamma function (Pearson, 1922). The results indicated that at least this poor a fit could be expected with probability .52 under the hypothesis that the Kings River annual flows follow the gamma distribution.

From the numerical analysis of this test, it was clear that the results of the last section would be essentially the same using either the fitted relationship or observed relative frequencies.

For a five-year period, maximumlikelihood estimators of the parameters are $\hat{\beta}=434.64$ and $\hat{\gamma}=20.19$. This is by virtue of the invariance property of maximum-l1kelihood estimators. If $\hat{\theta}$ is the maximum-likelihood estimator of $\theta$ and $f(\theta)$ is a single valued function of $\theta$, then the maximum-likelihood estimator of $f(\theta)$ is $f(\hat{\theta})$. (Mood, 1950, p. $159)$. In this case, the parameter is designated $\gamma$ and the function $f(\gamma)$ is $5 \gamma$.

current time and chose the $k^{\text {th }}$ annual use rate. The annual use rate specifies all water used, both ground and surface, from all sources. The annual use rates in terms of $k$ are defined to be $1,750,000+(k-1)(250,000)$ and 2,000 ,$000+(k-1)(250,000)$ acre-feet for mean annual supplies of $1,815,000$ and 2,065 ,000 acre-feet, respectively, $k=1,2, \ldots$. 9 . The quantity of water in storage as 
a function of $i$ (or $j$ ) is $(i-1)(2,739$,$000)$ acre-feet, $i=1,2, \ldots 21$.

If the continuous model being approximated is examined, we see that our probabilities, $p_{i j}{ }^{k}$, correspond to $P\left[\Delta_{L} \leqq S_{t+5}-S_{t} \leqq \Delta_{U}\right]$ under the $k^{\text {th }}$ alternative, where $\Delta_{U}$ and $\Delta_{L}$ are appropriately defined upper and lower bounds of a discrete interval and $S_{t}$ denotes storage at the beginning of year $t$. We shall examine the continuous analogue on an annual basis in order to see what is implied for a fiveyear basis. Some difficulties are encountered in expressing the probability distribution for a five-year period.

We note the following conditions implied by our assumptions:

(1) Ground water pumped annually for urban and miscellaneous use is 122,500 acre-feet.

(2) Surface water used from the Central Valley Project and local minor streams is 42,000 acrefeet annually.

(3) Annual recharge of 42,000 acrefeet takes place from the sources mentioned in (2).

(4) We define $x$ equal to the Kings River annual flow. For simplicity, ${ }^{8}$ we let $.4972 x$ be the random recharge to ground water and $.4943 x$ be the random quantity of surface water consumed directly. The probability distribution of $x$ has been estimated.

(5) A fixed quantity of water, $w_{k}$, is consumed annually.

Some reflection on the above lets us write

$$
\begin{aligned}
S_{t+5} & =S_{t}+[(5)(42)+.4972 y]-\left[5 w_{k}-(5)(42)-.4943 y\right] \\
& =S_{t}+420+.9915 y-5 w_{k}
\end{aligned}
$$

using the approximation of substituting mates of $p_{i j}{ }^{k}$, we must look at $w_{k}-42-.4943 x_{i}$ for $\operatorname{Max}\left(122.5, w_{k}-\right.$ $\left.42-.4943 x_{i}\right)$. In order to obtain esti- recalling that the probability distribu-

\footnotetext{
${ }^{8} \mathrm{We}$ are using the same proportion of stream flow as the proportion of the mean flow going to recharge and direct surface use to represent the random variables of recharge and direct surface use, respectively. Rounding to the proper number of significant digits is more convenient at a later stage of the analysis.
} 
tion of $y$ has been estimated by a con- tinuous frequency curve. We have the relation

$P\left[S_{t+5}-S_{t} \leqq m\right]=P\left[420+.9915 y-5 w_{k} \leqq m\right]=P\left[y \leqq \frac{5 w_{k}+m-420}{.9915}\right]$

These probabilities can be read from with parameters $\beta=434.64$ and $\gamma=$ tables of the incomplete gamma func- 20.19. The values of $m$ as given in table tion (Pearson, 1922, p. 56) since the 24 are based on a discrete storage inprobability distribution of $y$ has been terval of 2,739,000 acre-feet. The probestimated by the gamma distribution ability distribution was estimated for

TABLE 24

PROBABILITIES ASSOCIATED WITH VARIOUS UPPER LIMITS OF STREAM FLOWS PER FIVE-YEAR PERIOD*

(Mean annual supply of $1,815,000$ acre-feet)

\begin{tabular}{|c|c|c|c|c|c|c|c|c|c|c|}
\hline \multirow{2}{*}{$\begin{array}{c}\text { Annual water } \\
\text { consumption } \\
(1,000 \text { acre-feet }) \\
w_{k}\end{array}$} & \multicolumn{10}{|c|}{$\begin{array}{c}m \\
(1,000 \text { acre-feet })\end{array}$} \\
\hline & $-17,804$ & $-15,065$ & $-12,326$ & $-9,587$ & $-6,848$ & $-4,109$ & $-1,370$ & 1,370 & 4,109 & 6,848 \\
\hline $1,750 \ldots \ldots \ldots \ldots \ldots \ldots$ & 0 & 0 & 0 & 0 & 0 & .0024 & .1877 & .7158 & .9627 & .9976 \\
\hline $2,000 \ldots \ldots \ldots \ldots \ldots \ldots$ & 0 & 0 & 0 & 0 & 0 & .0321 & .4267 & .8748 & .9885 & .9995 \\
\hline $2,250 \ldots$ & 0 & 0 & 0 & 0 & .0013 & .1497 & .6765 & .9536 & .9969 & .9999 \\
\hline $2,500 \ldots$ & 0 & 0 & 0 & 0 & .0210 & .3781 & .8502 & .9855 & .9993 & 1 \\
\hline $2,750 \ldots \ldots \ldots \ldots$ & 0 & 0 & 0 & .0006 & .1187 & .6308 & .9433 & .9960 & .9998 & 1 \\
\hline $3,000 \ldots \ldots \ldots \ldots$ & 0 & 0 & 0 & .0138 & .3265 & .8245 & .9814 & .9990 & 1 & 1 \\
\hline $3,250 \ldots \ldots \ldots \ldots \ldots$ & 0 & 0 & .0003 & .0898 & .5861 & .9301 & .9948 & .9999 & 1 & 1 \\
\hline $3,500 \ldots \ldots \ldots \ldots \ldots \ldots$ & 0 & 0 & .0087 & .2809 & .7955 & .9769 & .9987 & 1 & 1 & 1 \\
\hline $3,750 \ldots$ & 0 & .0001 & .0674 & .5396 & .9158 & .9934 & .9997 & 1 & 1 & 1 \\
\hline $4,000 \ldots$ & 0 & .0050 & .2377 & .7605 & .9713 & .9983 & .9999 & 1 & 1 & 1 \\
\hline $4,250 \ldots \ldots \ldots$ & 0 & .0495 & .4877 & .8993 & .9914 & .9996 & 1 & 1 & 1 & 1 \\
\hline $4,500 \ldots \ldots \ldots \ldots$ & .0017 & .1942 & .7250 & .9639 & .9978 & .9999 & 1 & 1 & 1 & 1 \\
\hline
\end{tabular}

* The table values, $I(u, p)=P\left[y \leq\left(m+5 w_{k}-420\right) / .9943\right]$, were obtained by linear interpolation. The parameters in the Pearson tables have the following relation to our parameters: $p=\gamma-1$ and $u=y / \beta \sqrt{ } \gamma$. We used $p=19.2$ and $u=\left(m+5 w_{k}-420\right) / 1936$ to obtain the above probabilities

SOURCE: Pearson, 1922, pp. 54-56.

TABLE 25

PROBABILITIES OF MOVING FROM THE $i^{\text {th }}$ TO THE $j^{\text {th }}$ STORAGE STATE*

(Mean annual supply of $1,815,000$ acre-feet)

\begin{tabular}{|c|c|c|c|c|c|c|c|c|c|c|c|c|}
\hline \multirow{2}{*}{$\begin{array}{l}\text { Alternative annual } \\
\text { use rate }\end{array}$} & \multicolumn{12}{|c|}{$j$} \\
\hline & $k$ & $i-7$ & $i-6$ & $i-5$ & $i-4$ & $i-3$ & $i-2$ & $i-1$ & $i$ & $i+1$ & $i+2$ & $i+3$ \\
\hline \multicolumn{13}{|l|}{ 1,000 acre-feet } \\
\hline $1,750 \ldots \ldots \ldots \ldots \ldots$ & 1 & & 0 & 0 & 0 & 0 & .0024 & .1853 & .5281 & .2469 & .0373 & 0 \\
\hline $2,000 \ldots \ldots \ldots \ldots \ldots$ & 2 & & 0 & 0 & 0 & 0 & .0321 & .3946 & .4481 & .1137 & .0115 & 0 \\
\hline $2,250 \ldots \ldots \ldots \ldots \ldots$ & 3 & & 0 & 0 & 0 & .0013 & .1484 & .5268 & .2771 & .0433 & .0031 & 0 \\
\hline 2,500 & 4 & & 0 & 0 & 0 & .0210 & .3571 & .4721 & .1353 & .0138 & .0007 & 0 \\
\hline 2,750 . & 5 & & 0 & 0 & .0006 & .1181 & .5121 & .3125 & .0527 & .0038 & .0002 & 0 \\
\hline 3,000 . & 6 & & 0 & 0 & .0138 & .3127 & .4980 & .1569 & .0176 & .0010 & 0 & 0 \\
\hline $3,250 \ldots \ldots \ldots$ & 7 & & 0 & .0003 & .0895 & .4963 & .3440 & .0647 & .0051 & .0001 & 0 & 0 \\
\hline $3,500 \ldots \ldots \ldots$ & 8 & & 0 & .0087 & .2722 & .5146 & .1814 & .0218 & .0013 & 0 & 0 & 0 \\
\hline $3,750 \ldots$ & 9 & & .0001 & .0673 & .4722 & .3762 & .0776 & .0063 & .0003 & 0 & 0 & 0 \\
\hline $4,000 \ldots \ldots \ldots$ & 10 & & .0050 & .2327 & .5228 & .2108 & .0270 & .0016 & .0001 & 0 & 0 & 0 \\
\hline $4,250 \ldots \ldots \ldots$ & 11 & & .0495 & .4382 & .4116 & .0921 & .0082 & .0004 & 0 & 0 & 0 & 0 \\
\hline $4,500 \ldots \ldots \ldots \ldots$ & 12 & .0017 & .1925 & .5308 & .2389 & .0339 & .0021 & .0001 & 0 & 0 & 0 & 0 \\
\hline
\end{tabular}

* Defined as $p_{i j} k$ in the text

SoURCE: Computed from table 24. 
thousands of acre-feet so we drop the last three zeros from the numbers. To stay in the same interval of storage we must have $-1370<S_{t+5}-S_{t}<1370$ giving rise to $m= \pm 1370$. To move to the next higher interval $1370<S_{t+5}-$ $S_{t}<4109$; thus $m=4109$ is required. The same procedure is followed in obtaining other required values of $m$. The $\left\{p_{i j}{ }^{k}\right\}$ are then easily computed from the cumulative probabilities found for $m$ by considering $j=i \pm 0,1,2,3, \ldots$. The $\left\{p_{i j}{ }^{k}\right\}$ in this notation are given in table 25.

A table corresponding to table 25 for a mean annual supply of $2,065,000$ acre- feet instead of 1,815,000 acre-feet would be identical to table 25 except that the first column would have each value increased by 250,000 acre-feet. That is, the probability of moving to the $j^{\text {th }}$ storage state from the $i^{\text {th }}$ with the additional 250,000 acre-feet mean annual supply is the same as without the increment in mean supply if the annual use rate is also increased by 250,000 acre-feet. It is specified that the mean annual supply is increased with an increment of water provided with certainty, i.e., a mere translation of the probability distribution results from the increased supply.

\section{NUMERICAL SOLUTION}

The problem now confronted is described in Chapter II with reference to ground water storage only, and the method for finding the optimal policy is given there. Finding the present value of expected net output under an optimal policy requires solving 21 equations in the present empirical problem. This is also our means of verifying that recursive relation (2.2) has converged, following the procedure explained in Chapter II. If $r$ is the annual interest rate in $(2.2)$, the discount factor $(1+r)^{-5}$ is substituted for $(1+r)^{-1}$.

The solution, $\lim _{n \rightarrow \infty} f_{n}\left(S_{i}\right)$, for the first situation considered is used as the first approximation in subsequent problems. For example, suppose 5 per cent is the discount rate used first and it is desired to solve the same problem with a discount rate of 6 per cent. We use the optimal policy for a 5 per cent rate as a first approximation to the optimal policy for a 6 per cent rate and solve the 21 equations to obtain the vector of present values of net output under that policy. This vector of present values is substituted for $f_{o}\left(S_{i}\right)$ in the computational algorithm. The advantage lies in convergence to the optimal policy in a very few iterations. The same principle applies when the second problem differs from the first by a changed net output function; in our case, the output function associated with the mean supply increased by 250,000 acre-feet.

\section{EMPIRICAL RESULTS}

The steps in obtaining a dollar measure of value per acre-foot of an additional 250,000 acre-feet of water annually for the study area are summarized below.

(1) Derive an optimal ground water management policy and the discounted expected net output associated with it under
(a) present conditions and
(b) conditions which would exist with an additional 250,000 acre-feet of water per year.

(2) Reduce the difference in present value between (a) and (b) to an annuity.

(3) The ratio of the annuity to 250,000 is a measure of the value per acre-foot of the added water supply.

We shall begin with the optimal water inventory policy under two different discount rates. 


\section{MANAGEMENT POLICIES}

As previously specified, a management policy is a functional relationship between quantity of water in storage and quantity of water used at each stage of the multistage decision process. Our stage is a five-year time period and by virtue of the assumed constant net output function over time, the decision rule is invariant over stages. A constant decision rule does not mean the same quantity of water will be used during each period over time; but that for a given storage condition at the beginning of a five-year period defining a stage, the same quantity of water will be used.

Within the discrete model containing 21 storage possibilities, a policy is completely specified by 21 pairs of numbers. Each pair denotes the quantity of water to be used with the corresponding water storage level. A water storage level also defines a depth to ground water. Therefore, a policy can be defined by 21 depths to ground water and the associated quantity of water used. Table 26 gives optimal decision rules for the study area with its present mean supply of water and an additional 250,000 acrefeet of mean annual supply, under two interest rates.

The optimal policy is not sensitive to the interest rate. A change from 5 to 6 per cent leads to only a slight change in the rule under the existing supply of water, and changes the rule for only one storage level under the augmented supply. The optimal policy is quite stable within the discrete limitations of the model, always giving the same general pattern.

The results obtained conform quite closely to those expected from superficial examination of the data. The present mean supply will be used for discussion purposes. From table 12, we see that annual net output does not have a

TABLE 26

OPTIMAL WATER MANAGEMENT RULES

\begin{tabular}{|c|c|c|c|c|c|}
\hline \multirow{3}{*}{ Water in storage } & \multirow{3}{*}{$\begin{array}{l}\text { Depth to } \\
\text { ground water }\end{array}$} & \multicolumn{4}{|c|}{ Annual use rate in units of 1,000 acre-feet } \\
\hline & & \multicolumn{2}{|c|}{ Present mean supply } & \multicolumn{2}{|c|}{ Augmented mean supply } \\
\hline & & $\begin{array}{l}5 \text { per cent } \\
\text { interest rate }\end{array}$ & $\begin{array}{l}6 \text { per cent } \\
\text { interest rate }\end{array}$ & $\begin{array}{l}5 \text { per cent } \\
\text { interest rate }\end{array}$ & $\begin{array}{l}6 \text { per cent } \\
\text { interest rate }\end{array}$ \\
\hline 1,000 acre-feet & feet & & & & \\
\hline $0 \ldots$ & 407.4 & 1,750 & 1,750 & 2,000 & 2,000 \\
\hline $2,739 \ldots \ldots \ldots \ldots$ & 389.5 & 1,750 & 1,750 & 2,000 & 2,000 \\
\hline $5,478 \ldots \ldots \ldots \ldots$ & 371.6 & 1,750 & 1,750 & 2,000 & 2,000 \\
\hline $8,217 \ldots \ldots \ldots \ldots$ & 353.7 & 2,000 & 2,000 & 2,250 & 2,250 \\
\hline $10,956 \ldots \ldots \ldots$ & 335.8 & 2,000 & 2,000 & 2,250 & 2,250 \\
\hline $13,695 \ldots \ldots \ldots$ & 317.9 & 2,000 & 3,000 & 2,250 & 3,250 \\
\hline $16,434 \ldots \ldots$ & 300.0 & 3,500 & 3,500 & 3,750 & 3,750 \\
\hline $19,173 \ldots \ldots$ & 282.1 & 3,500 & 3.500 & 3,750 & 3,750 \\
\hline $21,912 \ldots$ & 264.2 & 3,500 & 3,500 & 3,750 & 3,750 \\
\hline $24,651 \ldots$ & 246.3 & 3,500 & 3,500 & 3,750 & 3,750 \\
\hline $27,390 \ldots$ & 228.4 & 3,500 & 3,500 & 3,750 & 3,750 \\
\hline $30,129 \ldots$ & 210.5 & 3,500 & 3,500 & 3,750 & 3,750 \\
\hline $32,868 \ldots \ldots \ldots \ldots \ldots \ldots$ & 192.6 & 3,500 & 3,500 & 3,750 & 3,750 \\
\hline $35,607 \ldots \ldots \ldots \ldots \ldots \ldots$ & 174.7 & 3,500 & 3,500 & 3,750 & 3,750 \\
\hline $38,346 \ldots$ & 156.8 & 3,500 & 3,750 & 3,750 & 3,750 \\
\hline $41,085 \ldots$ & 138.9 & 3,500 & 3.750 & 3,750 & 3,750 \\
\hline $43,824 \ldots$ & 121.0 & 3,750 & 3,750 & 3,750 & 3,750 \\
\hline $46,563 \ldots$ & 103.1 & 3,750 & 3,750 & 3,750 & 3,750 \\
\hline $49,302 \ldots \ldots \ldots$ & 85.4 & 3,750 & 3,750 & 3,750 & 3,750 \\
\hline $52,041 \ldots \ldots \ldots \ldots$ & 67.7 & 3,750 & 3,750 & 3,750 & 3,750 \\
\hline $54,780 \ldots \ldots \ldots \ldots \ldots \ldots$ & 50.0 & 3,750 & 3,750 & 3,750 & 3,750 \\
\hline
\end{tabular}


positive marginal value for magnitudes greater than 3,750,000 acre-feet. Therefore, no greater quantity than this amount would ever be used, but we would expect this largest amount yielding a positive marginal output to be used when an extremely large quantity of water is in storage. We would also expect that the optimal quantity should decrease as the amount of water in storage diminishes, and this is the result indicated by table 26 .

Two economic factors are working to reduce the optimal quantity of water used at a given level of storage: (1) increased expected pumping costs for the remainder of the planning horizon and (2) diminishing marginal returns from additional quantities of water used per period when quantity used becomes large. Two factors tending to increase the quantity used per period are: (1) time preference reflected by the discount factor and (2) increasing marginal returns at low levels of water use per period. The final decision rule is the end result of weighing these positive and negative factors against one another quantitatively within a stochastic model.

A rather severe penalty was assigned to a condition of zero water in storage, i.e., a zero net output for five years. This penalty leads to a decision rule which specifies a low annual use rate when storage is low. The returns associated with reaching a zero storage condition are arbitrary and chosen primarily for convenience. Any magnitude assigned is artificial since the reservoir is not actually empty at the point indicated (407 feet below the surface). We can be certain that relaxing the restriction of 407 feet would lead to higher consumption rates at greater pumping depths, but quantification is possible only with a more complete model.

The results indicate that mining ground water is not only optimal for an individual producer, but also for an area as a whole under some circum- stances. Without restraints, an individual producer will tend to use water to the point where marginal returns are equal to marginal pumping costs because he is pumping from a common aquifer and considers his contribution to overdraft negligible relative to other producers as a group. This situation may lead to uneconomic mining of ground water for the group as an aggregate. In this study, a policy evolves which specifies consumption considerably in excess of the mean supply, but for a different reason. Roughly speaking, the interest rate outweighs pumping costs and the need for storage as a contingency against future shortages in supply. A reserve of 50,000,000 acrefeet would not be expected optimal for an area with a mean supply of about $2,000,000$ acre-feet.

The effect of pumping costs on present value of net output should not be underestimated. A policy which permanently reduces the expected quantity of water in storage increases the cost of all pumping in the future. For example, if water in storage is expected to be reduced permanently to the point where the cost is increased by 50 cents per acre-foot and the interest rate is 6 per cent, 1 acre-foot of water pumped each year perpetually would have an increased cost at present value equal to $\$ 8.33$. For an area the size of the one under study, which might pump an average of 1,500,000 acre-feet, this is a decrease in present value of net output of $\$ 12,500,000$.

The estimated net output functions in this study were obtained under the assumption of complete mobility of labor and capital. In chapter II, we stated that the validity of this assumption was largely dependent on the optimal decision rule resulting. That is, a decision rule requiring frequent large changes in output, with a high probability, would not be consistent with reality. However, we put no restriction on mobility of labor and capital and proceeded to solve the empirical prob- 
lem. Fortunately, the decision rules re- ity of frequent, large changes in output. sulting do not indicate a high probabil-

\section{PRESENT VALUE OF NET OUTPUT AND PER UNIT VALUE OF ADDITIONAL WATER}

Each policy of table 26 implies a discounted expected net output for an infinite planning horizon. Each policy has a 21-dimensional matrix of transition probabilities associated with it and a 21 component vector of expected immediate net output. Denote the matrix by $P$ and the vector by $b$. The vector of discounted net output, $X$, is the solution of the system of linear equations (6.1)

$$
(I-\beta P) X=b
$$

where $\beta$ is the discount factor determined by the interest rate, and $I$ is the identity matrix. Table 27 gives the solution of (6.1) for the situations considered in table 26 . The $i^{\text {th }}$ component of $X$ is present value of expected net output over an infinite planning horizon, given that initial ground water storage is at the $i^{\text {th }}$ level.

The difference in discounted expected value of net output, with and without the 250,000 acre-feet of water per year, is given in columns 1 and 2 of table 28. These measures of present value are reduced to an annuity by multiplying by the appropriate interest rate. Division of the annuity by 250,000 gives the average, expected value per acre-foot of the additional water. These dollar values are given in columns 3 and 4.

TABLE 27

PRESENT VALUE OF NET OUTPUT

(Million dollars)

\begin{tabular}{|c|c|c|c|c|c|}
\hline \multirow{2}{*}{ Water in storage } & \multirow[b]{2}{*}{$\begin{array}{l}\text { Depth to } \\
\text { ground water } \\
\text { (1) }\end{array}$} & \multicolumn{2}{|c|}{ Present mean supply } & \multicolumn{2}{|c|}{ Augmented mean supply } \\
\hline & & $\begin{array}{c}5 \text { per cent } \\
(2)\end{array}$ & $\underset{(3)}{6 \text { per cent }}$ & $\begin{array}{c}5 \text { per cent } \\
(4)\end{array}$ & $\begin{array}{c}6 \text { per cent } \\
(5)\end{array}$ \\
\hline 1,000 acre-feet & feet & & & & \\
\hline $0 \ldots \ldots \ldots \ldots \ldots \ldots \ldots$ & 407.4 & 1,089 & 821 & 1,190 & 897 \\
\hline $2,739 \ldots \ldots \ldots \ldots \ldots \ldots \ldots \ldots$ & 389.5 & 2,108 & 1,765 & 2,303 & 1,929 \\
\hline $5,478 \ldots \ldots \ldots \ldots \ldots \ldots \ldots$ & 371.6 & 2,412 & 2,023 & 2,629 & 2,206 \\
\hline $8,217 \ldots \ldots \ldots \ldots \ldots \ldots$ & 353.7 & 2,540 & 2,137 & 2,754 & 2,315 \\
\hline $10,956 \ldots \ldots \ldots$ & 335.8 & 2,630 & 2,212 & 2,841 & 2,389 \\
\hline $13,695 \ldots \ldots \ldots$ & 317.9 & 2,696 & 2,280 & 2,906 & 2,457 \\
\hline $16,434 \ldots \ldots \ldots \ldots \ldots$ & 300.0 & 2,792 & 2,377 & 3,006 & 2,557 \\
\hline $19,173 \ldots \ldots \ldots \ldots \ldots \ldots \ldots$ & 282.1 & 2,875 & 2,449 & 3,088 & 2,628 \\
\hline $21,912 \ldots \ldots \ldots \ldots \ldots \ldots \ldots \ldots$ & 264.2 & 2,942 & 2,511 & 2,636 & 2,690 \\
\hline $24,651 \ldots \ldots \ldots \ldots \ldots \ldots \ldots \ldots$ & 246.3 & 3,014 & 2,580 & 3,229 & 2,759 \\
\hline $27,390 \ldots \ldots \ldots \ldots \ldots \ldots \ldots$ & 228.4 & 3,084 & 2,641 & 3,298 & 2,820 \\
\hline $30,129 \ldots \ldots \ldots \ldots \ldots \ldots \ldots \ldots$ & 210.5 & 3,147 & 2,695 & 3,360 & 2,875 \\
\hline $32,868, \ldots \ldots \ldots \ldots \ldots \ldots \ldots \ldots$ & 192.6 & 3,209 & 2,752 & 3,425 & 2,932 \\
\hline $35,607 \ldots \ldots \ldots \ldots \ldots \ldots \ldots \ldots$ & 174.7 & 3,268 & 2,803 & 3,484 & 2,984 \\
\hline $38,346 \ldots \ldots \ldots \ldots \ldots \ldots \ldots \ldots$ & 156.8 & 3,324 & 2,853 & 3,542 & 3,033 \\
\hline $41,085 \ldots \ldots \ldots \ldots \ldots \ldots \ldots \ldots$ & 138.9 & 3,379 & 2,901 & 3,597 & 3,081 \\
\hline $43,824 \ldots \ldots \ldots \ldots \ldots \ldots \ldots \ldots \ldots$ & 121.0 & 3,434 & 2,948 & 3,651 & 3,126 \\
\hline $46,563 \ldots \ldots \ldots \ldots \ldots \ldots \ldots \ldots$ & 103.1 & 3,489 & 2,994 & 3,705 & 3,172 \\
\hline $49,302 \ldots \ldots \ldots \ldots \ldots \ldots \ldots \ldots$ & 85.4 & 3,539 & 3,038 & 3,755 & 3,215 \\
\hline $52,041 \ldots \ldots \ldots \ldots \ldots \ldots \ldots \ldots \ldots \ldots$ & 67.7 & 3,588 & 3,079 & 3,804 & 3,254 \\
\hline $54,780 \ldots \ldots \ldots \ldots \ldots \ldots \ldots \ldots$ & 50.0 & 3,641 & 3,124 & 3,855 & 3,297 \\
\hline
\end{tabular}


TABLe 28

MARGINAL VALUE OF WATER (Million dollars)

\begin{tabular}{|c|c|c|c|c|}
\hline \multirow{3}{*}{$\begin{array}{l}\text { Water in } \\
\text { storage }\end{array}$} & \multicolumn{2}{|c|}{$\begin{array}{l}\text { Expected contribu- } \\
\text { tion of added water } \\
\text { to net output } \\
\text { (million dollars) }\end{array}$} & \multicolumn{2}{|c|}{$\begin{array}{l}\text { Average expected } \\
\text { value per acre-foot } \\
\text { of added water } \\
\text { (dollars) }\end{array}$} \\
\hline & 5 per cent & 6 per cent & 5 per cent & 6 per cent \\
\hline & (1) & $(2)$ & (3) & (4) \\
\hline \multicolumn{5}{|l|}{1,000 acre-feet } \\
\hline $0 \ldots$ & 100 & 76 & 20 & 18 \\
\hline $2,739 \ldots$ & 194 & 164 & 39 & 40 \\
\hline $5,478 \ldots \ldots \ldots$ & 218 & 183 & 43 & 45 \\
\hline $8,217 \ldots \ldots \ldots$ & 213 & 178 & 42 & 43 \\
\hline $10,956 \ldots \ldots \ldots$ & 211 & 177 & 42 & 42 \\
\hline $13,695 \ldots \ldots$ & 210 & 178 & 42 & 43 \\
\hline $16,434 \ldots \ldots \ldots$ & 214 & 179 & 42 & 43 \\
\hline $19,173 \ldots \ldots \ldots$ & 213 & 179 & 42 & 43 \\
\hline $21,912 \ldots \ldots \ldots$ & 213 & 179 & 42 & 43 \\
\hline $24,651 \ldots \ldots \ldots$ & 215 & 179 & 43 & 43 \\
\hline $27,390 \ldots \ldots \ldots$ & 214 & 179 & 42 & 43 \\
\hline $30,129 \ldots$ & 214 & 180 & 42 & 43 \\
\hline $32,868 \ldots \ldots \ldots$ & 216 & 180 & 43 & 43 \\
\hline $35,607 \ldots \ldots \ldots$ & 216 & 181 & 43 & 44 \\
\hline $38,346 \ldots \ldots \ldots$ & 217 & 180 & 43 & 43 \\
\hline $41,085 \ldots \ldots \ldots$ & 218 & 180 & 43 & 43 \\
\hline $43,824 \ldots \ldots \ldots$ & 217 & 179 & 43 & 43 \\
\hline $46,563 \ldots$ & 216 & 178 & 43 & 43 \\
\hline $49,302 \ldots \ldots \ldots$ & 216 & 177 & 43 & 42 \\
\hline $52,041 \ldots \ldots \ldots$ & 216 & 175 & 43 & 42 \\
\hline $54,780 \ldots \ldots \ldots$ & 214 & 174 & 42 & 41 \\
\hline
\end{tabular}

\section{MARGINAL VALUE OF WATER WITH RESPECT TO TIME OF RECEIPT}

Depth to ground water in the study area averages around 50 feet currently although there is considerable variation within the area. This depth corresponds to the largest ground water storage condition in the model. The results for this storage condition when the additional water is imported at some future period are summarized in table 29. An optimal policy at all times has been imposed to obtain the stated results.

The method used to evaluate additional water in future years was to set $f(0)$ equal to the values listed in columns 4 and 5 of table 27 and proceed to carry out iterations $f(1), f(2), \ldots$ using the probabilities associated with the present mean supply and the return function associated with the aug-
TABLE 29

EXPECTED MARGINAL VALUE OF WATER OVER TIME, GIVEN PRESENT STORAGE* (Dollars per acre-foot)

\begin{tabular}{|c|c|c|}
\hline \multirow{2}{*}{$\begin{array}{c}\text { Year } \\
(0=\text { present })\end{array}$} & \multicolumn{2}{|c|}{ Interest rate } \\
\hline & 5 per cent & 6 per cent \\
\hline 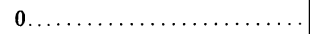 & 19 & 16 \\
\hline $5 \ldots \ldots \ldots \ldots \ldots \ldots \ldots$ & 22 & 19 \\
\hline $10 \ldots \ldots \ldots \ldots \ldots \ldots \ldots$ & 26 & 24 \\
\hline $15 \ldots \ldots$ & 31 & 29 \\
\hline$\ldots \ldots \ldots \ldots$ & 37 & 37 \\
\hline $25 \ldots \ldots \ldots$ & 46 & 46 \\
\hline $30 \ldots \ldots$ & 51 & 53 \\
\hline$\ldots \ldots \ldots \ldots \ldots \ldots$ & 55 & 58 \\
\hline$\ldots \ldots \ldots \ldots \ldots$ & 58 & 60 \\
\hline $45 \ldots \ldots \ldots \ldots \ldots \ldots \ldots \ldots$ & 60 & 61 \\
\hline $50 \ldots \ldots \ldots \ldots \ldots \ldots \ldots \ldots \ldots \ldots$ & 61 & 61 \\
\hline
\end{tabular}

* The return function estimated for a mean annual supply of $2,065,000$ acre-feet is assumed before and after the increment of water is received, and ground wate storage is assumed at $54,780,000$ acre-feet at year zero. 
mented supply after adjustments for pumping costs. Recall that $f(n)$ is a 21-component vector and use is made of the recursive relation

$$
f_{n}\left(S_{i}\right)=\operatorname{Max}_{k}\left[B^{k}\left(S_{i}\right)+(1+r)^{-5} \sum_{j=1}^{21} p_{i j}^{k} f_{n-1}\left(S_{j}\right)\right], i=1,2, \cdots 21
$$

where $f_{n}\left(S_{i}\right)$ is the $i^{\text {th }}$ component of $f(n)$, and $r$ is the interest rate. The method just explained assumes producers anticipate the future water supply and plan production of unadjustable activities (tree crops) at the same level as if they were to receive the augmented supply immediately.

Consider the case where $r=.05$ and $f_{o}\left(S_{i}\right)$ is an element of column 4 of table 27. The relation of $i$ to quantity

$$
f_{1}\left(S_{i}\right)=\operatorname{Max}_{k}\left[B^{k}\left(S_{i}\right)+(1.05)^{-5}\right.
$$

Solution of (6.2) for $f(1)$ gives the optimal policy and discounted expected value of net output for importation of 250,000 acre-feet of water annually starting five years hence; $f(2)$ gives the same results for importing the water ten years hence; etc.

The expected marginal value per acre-foot of water with respect to a point in time, $t$, is computed as follows (assuming a specified storage level at $t=0)$ :

(1) Obtain the difference in discounted expected net output between situations where the increment of water is received during the year in question and when it is received five years later. The value of net output is in current dollars regardless of the year, $t$, being considered.

(2) Compound the difference calculated in (1) to equivalent value for year $t$.

(3) Reduce the value obtained in (2) to an annuity for five years.

(4) Divide the annuity from (3) by 250,000 which yields the value per acre-foot being sought.

The data given in table 29 are for a storage level of $54,780,000$ acre-feet during the current period, $t=0$. This in storage is:

$\begin{array}{cc} & \begin{array}{c}\text { Storage } \\ (1,000 \text { acre-feet })\end{array} \\ i & 0 \\ 1 & 2,739 \\ 2 & 5,478 \\ 3 & : \\ \dot{-} & \dot{-} \\ 21 & 54,780\end{array}$

Relation (6.2) for $n=1$ gives

$$
\left.\sum_{j=1}^{21} p_{i j}^{k} f_{0}\left(S_{j}\right)\right], i=1,2, \cdots 21 \text {. }
$$

level corresponds to the estimated average pumping lift of 50 feet for the entire study area.

The results given in table 29 show a steadily increasing value of additional water as the time at which it is received is extended into the future. The difference in value for delivery 50 years in the future instead of now is approximately $\$ 40$ per acre-foot. We note that the difference is greater with a 6 per cent interest rate than with a 5 per cent rate.

The optimal decision rules with respect to annual use rates are given in table 30 for the situation where the water supply is increased at some future date. These decision rules are approximately equal for various delivery dates and the two interest rates considered. The general pattern of the rules indicates use of $3,750,000$ acrefeet annually when in the upper 14 storage levels and 1,750,000 acre-feet annually when in the bottom three storage levels. The four storage levels between have various intermediate quantities as optimal annual rates. The decision rules for the upper 14 storage levels are identical to the optimal rule for the situation where the additional water is received during the current 
TABLE 30

OPTIMAL DECISION RULES FOR FUTURE DELIVERY OF ADDED WATER (Annual use rate in 1,000 acre-feet)

\begin{tabular}{|c|c|c|c|c|c|}
\hline \multirow[b]{2}{*}{ Water in storage } & \multicolumn{5}{|c|}{ Delivery date of added water } \\
\hline & $t=5$ & $t=10$ & $t=15$ & $t=5$ & $t=10$ \\
\hline \multirow[t]{3}{*}{1,000 acre-feet } & \multicolumn{5}{|c|}{ Interest rate } \\
\hline & \multicolumn{3}{|c|}{5 per cent } & \multicolumn{2}{|c|}{6 per cent } \\
\hline & 1,750 & 1,750 & 1,750 & 1,750 & 1,750 \\
\hline $2,739 \ldots \ldots \ldots \ldots \ldots \ldots \ldots \ldots \ldots$ & 1,750 & 1,750 & 1,750 & 1,750 & 1,750 \\
\hline $5,478 \ldots \ldots \ldots \ldots \ldots \ldots \ldots \ldots$ & 1,750 & 1,750 & 1,750 & 1,750 & 1,750 \\
\hline $8,217 \ldots \ldots \ldots \ldots \ldots \ldots \ldots \ldots$ & 2,000 & 2,000 & 2,000 & 2,000 & 2,000 \\
\hline $10,956 \ldots \ldots \ldots \ldots \ldots \ldots \ldots \ldots \ldots$ & 2,250 & 2,250 & 2,250 & 2,250 & 2,250 \\
\hline $13,695 \ldots \ldots \ldots \ldots \ldots \ldots \ldots \ldots \ldots$ & 2,250 & 2,250 & 2,250 & 2,250 & 2,250 \\
\hline $16,434 \ldots \ldots \ldots \ldots \ldots \ldots \ldots \ldots \ldots$ & 3,500 & 3,250 & 2,250 & 3,750 & 3,500 \\
\hline $19,173 \ldots \ldots \ldots \ldots \ldots \ldots \ldots \ldots \ldots$ & 3,750 & 3,750 & 3,750 & 3,750 & 3,750 \\
\hline $21,912 \ldots \ldots \ldots \ldots \ldots \ldots \ldots \ldots \ldots$ & 3,750 & 3,750 & 3,750 & 3,750 & 3,750 \\
\hline $24,651 \ldots \ldots \ldots \ldots \ldots \ldots \ldots \ldots \ldots$ & 3,750 & 3,750 & 3,750 & 3,750 & 3,750 \\
\hline $27,390 \ldots \ldots \ldots \ldots \ldots \ldots \ldots \ldots \ldots$ & 3,750 & 3,750 & 3,750 & 3,750 & 3,750 \\
\hline $30,129 \ldots \ldots \ldots \ldots \ldots \ldots \ldots \ldots \ldots$ & 3,750 & 3,750 & 3,750 & 3,750 & 3,750 \\
\hline $32,868 \ldots \ldots \ldots \ldots \ldots \ldots \ldots \ldots$ & 3,750 & 3,750 & 3,750 & 3,750 & 3,750 \\
\hline $35,607 \ldots \ldots \ldots \ldots \ldots \ldots \ldots \ldots \ldots$ & 3,750 & 3,750 & 3,750 & 3,750 & 3,750 \\
\hline $38,346 \ldots \ldots \ldots \ldots \ldots \ldots \ldots \ldots$ & 3,750 & 3,750 & 3,750 & 3,750 & 3,750 \\
\hline $41,087 \ldots \ldots \ldots \ldots \ldots \ldots \ldots \ldots$ & 3,750 & 3,750 & 3,750 & 3,750 & 3,750 \\
\hline $43,824 \ldots \ldots \ldots \ldots \ldots \ldots \ldots \ldots \ldots$ & 3,750 & 3,750 & 3,750 & 3,750 & 3,750 \\
\hline $46,563 \ldots \ldots \ldots \ldots \ldots \ldots \ldots \ldots \ldots$ & 3,750 & 3,750 & 3,750 & 3,750 & 3,750 \\
\hline $49,302 \ldots \ldots \ldots \ldots \ldots \ldots \ldots \ldots \ldots$ & 3,750 & 3,750 & 3,750 & 3,750 & 3,750 \\
\hline $52,041 \ldots \ldots \ldots \ldots \ldots \ldots \ldots \ldots \ldots$ & 3,750 & 3,750 & 3,750 & 3,750 & 3,750 \\
\hline $54,780 \ldots \ldots \ldots \ldots \ldots \ldots \ldots \ldots$ & 3,750 & 3,750 & 3,750 & 3,750 & 3,750 \\
\hline
\end{tabular}

year (see table 26, last two columns), Therefore, the result of postponing delivery of the added water supply is primarily reflected in higher pumping costs in the future, with output in the immediate future being the same except for pumping costs.

With an interest rate of 5 or 6 per cent, the first 20 or 30 years dominate the present value of future net output. The marginal values of table 29 are for a specified initial storage level of 54 ,780,000 acre-feet. Thus, for the case where we consider the value of water imported currently instead of five years in the future, the present value of increased future pumping costs is the chief factor determining the value of the added water. This is true because approximately the same physical production will take place within the next 30 years whether the water is added to the supply in the current period or five years later. This observation is based on optimal decision rules under the two situations. The present value of increased pumping costs is less with a 6 than with a 5 per cent interest rate. Consequently, value of the water added during the next five years is less with a 6 per cent interest rate than with a 5 per cent rate.

The same argument can be used for receipt of water five years in the future instead of 10 , and 10 years in the future instead of 15 . However, the point is soon reached where the expected quantity of water in storage at the future date is low enough that changed pumping costs in the future from delaying delivery of additional water comes to be dominated by another factor. This other factor is reduction of expected quantity of water used within the immediately following periods. At low levels of storage the decision rules are such that more water is used with the additional supply of water than 
without it. This was not true at high levels of storage.

The dominant factor at some point in the future (20 years in table 29) is increased production from receipt of the water five years early. The greatest portion of this expected increase occurs during the first five years. Therefore, a 6 per cent interest rate instead of 5 per cent gives this immediate return a higher relative value and therefore, a higher value for the additional water received five years early.

Expected values of water per acrefoot for an additional 250,000 acre-feet annually during the next five years, under the specification that the added water will be received five years hence perpetually, are given in table 31 for the 21 storage levels. The increasing magnitudes of these values as quantity of water in storage declines are consistent with table 29 , which gives the increasing values over time of the additional water. The values of table 29 are (loosely speaking) weighted averages of the values in table 31 , the averaging taking place through the probability distribution for storage states over time. The first row of table 29 is identical to the last row of table 31 .

TABLe 31

EXPECTED VALUE OF WATER

DELIVERED NOW VERSUS

FIVE YEARS HENCE

(Dollars per acre-foot)

\begin{tabular}{|c|c|c|}
\hline \multirow{2}{*}{ Water in storage } & \multicolumn{2}{|c|}{ Interest rate } \\
\hline & 5 per cent & 6 per cent \\
\hline \multicolumn{3}{|l|}{1,000 acre-feet } \\
\hline $0 \ldots \ldots \ldots \ldots \ldots \ldots \ldots$ & $\mathbf{0}$ & 0 \\
\hline $2,739 \ldots \ldots \ldots \ldots \ldots \ldots \ldots$ & 78 & 78 \\
\hline $5,478 \ldots \ldots \ldots \ldots \ldots \ldots \ldots$ & 78 & 78 \\
\hline $8,217 \ldots \ldots \ldots \ldots \ldots \ldots \ldots$ & 48 & 49 \\
\hline $10,956 \ldots \ldots \ldots \ldots \ldots \ldots \ldots$ & 36 & 33 \\
\hline $13,695 \ldots \ldots \ldots \ldots \ldots \ldots \ldots \ldots$ & 32 & 40 \\
\hline $16,434 \ldots \ldots \ldots \ldots \ldots \ldots \ldots \ldots$ & 47 & 45 \\
\hline $19,173 \ldots \ldots \ldots \ldots \ldots \ldots \ldots \ldots$ & 34 & 30 \\
\hline $21,912 \ldots \ldots \ldots \ldots \ldots \ldots \ldots \ldots$ & 30 & 29 \\
\hline $24,651 \ldots \ldots \ldots \ldots \ldots \ldots \ldots \ldots \ldots$ & 34 & 33 \\
\hline $27,390 \ldots \ldots \ldots \ldots \ldots \ldots \ldots \ldots$ & 31 & 28 \\
\hline $30,129 \ldots \ldots \ldots \ldots \ldots \ldots \ldots \ldots$ & 28 & 26 \\
\hline $32,868 \ldots \ldots \ldots \ldots \ldots \ldots \ldots \ldots$ & 28 & 25 \\
\hline $35,607 \ldots \ldots \ldots \ldots \ldots \ldots \ldots \ldots$ & 27 & 24 \\
\hline $38,346 \ldots \ldots \ldots \ldots \ldots \ldots \ldots$ & 25 & 22 \\
\hline $41,085 \ldots \ldots \ldots \ldots \ldots \ldots \ldots \ldots$ & 23 & 21 \\
\hline $43,824 \ldots \ldots \ldots \ldots \ldots \ldots \ldots \ldots$ & 22 & 20 \\
\hline $46,563 \ldots \ldots \ldots \ldots \ldots \ldots \ldots \ldots$ & 22 & 18 \\
\hline $49,302 \ldots \ldots \ldots \ldots \ldots \ldots \ldots \ldots$ & 21 & 18 \\
\hline $52,041 \ldots \ldots \ldots \ldots \ldots \ldots \ldots \ldots$ & 19 & 17 \\
\hline $54,780 \ldots \ldots \ldots \ldots \ldots \ldots \ldots \ldots$ & 19 & 16 \\
\hline
\end{tabular}

\section{FU'TURE DEPTHS TO GROUND WATER}

A matrix of transition probabilities for the Markov chain describing ground water storage is given by each decision rule of tables 26 and 30 . To illustrate certain measures that can be derived, one of these decision rules is analyzed in detail. The rule chosen corresponds to present mean supply of water and a 6 per cent interest rate.

Let the matrix of probabilities be $P$. The probability of being in any storage state in the future can be computed from this matrix when the initial storage state is given. Our time interval is five years, which restricts the analysis to discrete points in time of five-year periods. If the initial storage state is $i$, the $i^{\text {th }}$ row of the $n^{\text {th }}$ power of the matrix $P$ gives the probabilities for storage conditions $5 n$ years in the future.
These probabilities are given in table 32 for $n=1,2, \ldots 10$, which corresponds to $t=5,10,15, \ldots 50$; where $t$ measures time from the current year $t=0$. Initial depth to ground water was specified at 50 feet, the largest storage condition in the total of 21 states. The limiting vector of probabilities, which is independent of initial conditions of storage, is given in the last column of table 32 . This set of probabilities for storage is appropriate when considering points of time very far into the future.

Expected depths to ground water are given in the first row of table 33 for points of time in the future. These expected values increase quite rapidly, from 50 feet initially to 337 feet in 25 years. 
TABLE 32

PROBABILITIES FOR FUTURE STORAGE*

\begin{tabular}{|c|c|c|c|c|c|c|c|c|c|c|c|c|c|}
\hline \multirow{2}{*}{$\begin{array}{l}\text { Depth to } \\
\text { ground water } \\
\text { (feet) }\end{array}$} & \multirow{2}{*}{$\begin{array}{c}\text { Num- } \\
\text { ber } \\
\text { of } \\
\text { state }\end{array}$} & \multicolumn{12}{|c|}{ Points in time $(t)$} \\
\hline & & 0 & 5 & 10 & 15 & 20 & 25 & 30 & 35 & 40 & 45 & 50 & $\lim _{t \rightarrow \infty}$ \\
\hline $407.4 \ldots \ldots \ldots \ldots \ldots$ & 1 & 0 & 0 & 0 & 0 & $\mathbf{0}$ & 0 & .0011 & .0084 & .0225 & .0397 & .0570 & .1488 \\
\hline $389.5 \ldots \ldots \ldots \ldots \ldots$ & 2 & 0 & 0 & 0 & 0 & 0 & .0045 & .0371 & .0835 & .1211 & .1475 & .1657 & .2211 \\
\hline $371.6 \ldots \ldots \ldots \ldots \ldots$ & 3 & & & & & .0007 & .1192 & .2681 & .3380 & .3610 & .3658 & .3636 & .3255 \\
\hline $353.7 \ldots \ldots \ldots \ldots$ & 4 & & & & & .0079 & .2974 & .4119 & .3692 & .3348 & .3097 & .2910 & .2219 \\
\hline $335.8 \ldots \ldots \ldots \ldots \ldots$ & 5 & & & & & .0443 & .2812 & .2242 & .1667 & .1347 & .1160 & .1042 & .0711 \\
\hline $317.9 \ldots \ldots \ldots \ldots \ldots$ & 6 & & & & 0 & .1369 & .1756 & .0502 & .0314 & .0238 & .0196 & .0171 & .0108 \\
\hline $300.0 \ldots \ldots \ldots \ldots \ldots$ & 7 & & & & .0018 & .2534 & .0827 & .0065 & .0027 & .0020 & .0016 & .0014 & .0008 \\
\hline $282.1 \ldots \ldots \ldots \ldots \ldots$ & 8 & & & & .0221 & .2793 & .0295 & .0007 & 0 & 0 & 0 & 0 & 0 \\
\hline $264.2 \ldots \ldots \ldots \ldots \ldots$ & 9 & & & & .1113 & .1786 & .0080 & .0001 & 0 & 0 & 0 & 0 & 0 \\
\hline $246.3 \ldots \ldots \ldots \ldots \ldots$ & 10 & & & 0 & .2665 & .0727 & .0016 & 0 & & & & & \\
\hline $228.4 \ldots \ldots \ldots \ldots \ldots$ & 11 & & & .0046 & .3454 & .0212 & .0003 & 0 & & & & & \\
\hline $210.5 \ldots \ldots \ldots \ldots \ldots$ & 12 & & & .0636 & .1847 & .0043 & 0 & & & & & & \\
\hline $192.6 \ldots \ldots \ldots \ldots$ & 13 & & 0 & .2736 & .0546 & .0006 & 0 & & & & & & \\
\hline $174.7 \ldots \ldots \ldots$ & 14 & & 0 & .3657 & .0116 & .0001 & & & & & & & \\
\hline $156.8 \ldots \ldots \ldots$ & 15 & & .0001 & .2157 & .0018 & 0 & & & & & & & \\
\hline $138.9 \ldots \ldots \ldots$ & 16 & & .0673 & .0644 & .0002 & 0 & & & & & & & \\
\hline $121.0 \ldots \ldots \ldots$ & 17 & & .4722 & .0111 & 0 & & & & & & & & \\
\hline $103.1 \ldots \ldots \ldots$ & 18 & & .3762 & .0012 & 0 & & & & & & & & \\
\hline $85.4 \ldots \ldots \ldots$ & 19 & & .0776 & .0001 & 0 & & & & & & & & \\
\hline $67.7 \ldots \ldots \ldots \ldots$ & 20 & 0 & .0063 & 0 & 0 & & & & & & & & \\
\hline $50.0 \ldots \ldots \ldots$ & 21 & 1 & .0003 & 0 & 0 & 0 & 0 & 0 & 0 & 0 & 0 & 0 & 0 \\
\hline
\end{tabular}

* Mean annual supply of 1,815,000 acre-feet and a decision rule for 6 per cent interest.

TABLE 33

EXPECTED PUMPING DEPTHS AND PROBABILITIES OF EMPTY RESERVOIR

\begin{tabular}{|c|c|c|c|c|c|c|c|c|c|c|c|c|}
\hline & \multicolumn{12}{|c|}{ Points in time $(t)$} \\
\hline & 0 & 5 & 10 & 15 & 20 & 25 & 30 & 35 & 40 & 45 & 50 & $\lim _{t \rightarrow \infty}$ \\
\hline $\begin{array}{l}\text { Expected depth to water } \\
\text { (feet) } \ldots \ldots \ldots \ldots \ldots \ldots \ldots \\
\text { Probability of empty state } \\
\text { in at least } t \text { years......... }\end{array}$ & 50 & $\begin{array}{c}112 \\
0\end{array}$ & $\begin{array}{c}175 \\
0\end{array}$ & $\begin{array}{c}232 \\
0\end{array}$ & 287 & $\begin{array}{c}337 \\
0\end{array}$ & $\begin{array}{l}354 \\
.0013\end{array}$ & $\begin{array}{l}359 \\
.0087\end{array}$ & $\begin{array}{l}362 \\
.0252\end{array}$ & $\begin{array}{l}365 \\
.0484\end{array}$ & $\begin{array}{l}367 \\
.0757\end{array}$ & $\begin{array}{c}374 \\
1\end{array}$ \\
\hline
\end{tabular}

Another interesting measure related to future water storage is the probability of not reaching the state of zero water in storage within a given time interval. An empty ground water reservoir would cause an interruption of agricultural production, and the probability of its occurrence in the near future should be helpful in evaluating a given policy more fully. In the present case, zero net output associated with reaching an empty state is somewhat arbitrary and the policy generated by this assumption should be given critical appraisal at the lower storage levels. The water policy at high storage levels is very unlikely to be affected by this assumption since there is no chance of reaching the empty state for at least 30 years (see table 32 ), and discounting makes effects beyond 30 years relatively unimportant.

A convenient method for obtaining the probability of reaching the empty state within at least $n$ stages of the Markov chain is to substitute the vector $\left(\begin{array}{llll}0 & \ldots & 1 & 0\end{array} \ldots 0\right)$ into the row of the matrix $P$ corresponding to the empty state, where the one is placed to appear in the $i^{\text {th }}$ column if the substitution is 
in the $i^{\text {th }}$ row. In our case the empty state is the first $(i=1)$, which implies substitution of $\left(\begin{array}{lllll}1 & 0 & 0 & \ldots & \ldots\end{array}\right)$ for the first row of $P$. The new matrix is raised to the $n^{\text {th }}$ power. The probability sought is the element in the $i^{\text {th }}$ column and $j^{\text {th }}$ row of the $n^{\text {th }}$ power of the matrix, where the initial state was $j$ and the substitution was in the $i^{\text {th }}$ row. In the present problem, $i=1$ and $j=21$ since state 1 is the empty state and state 21 (50 feet depth to ground water) is the initial state. Application of this technique for $n=1,2, \ldots 10$ yielded the results summarized in the second row of table 33.

There is less than one chance in 100 of reaching the empty state within 35 years and only one chance in 20 of reaching it in 45 years. This risk is sufficiently low that one can feel quite confident of the decision rule for the immediate future. This is not surprising since present value of output 45 or 50 years in the future is trivial compared to current output. Consequently, the optimal decision rule for large storage levels is not altered by risk of entering the empty state.

\section{CONTINUOUS VARIABLE REFINEMENT}

The refinements for periodic use and supply and 6 per cent interest (column storage treated as continuous variables, which were discussed in chapter II, are applied to the empirical study. Since the net output function is constant over time in the empirical model, $f_{n}(S)=$ $f_{n-1}(S)=f(S)$ as $n \rightarrow \infty$ in equation (2.7). Table 27 tabulates $f(S)$ for discrete values of $S$. The magnitudes of $f(S)$ are plotted in figure 2 in relation to water in storage for present mean 3 of table 27).

A quadratic function fitted to the data of figure 2 with the two lowest storage levels deleted gave (variables in million units ) :

$$
\text { (6.3) } \quad \begin{aligned}
f(S)= & 1865.62+33.5778 S \\
& -0.1984 S^{2} .
\end{aligned}
$$

Marginal value of stored ground water is given by:

(6.4) $\quad f^{\prime}(S)=33.58-0.3968 S$.

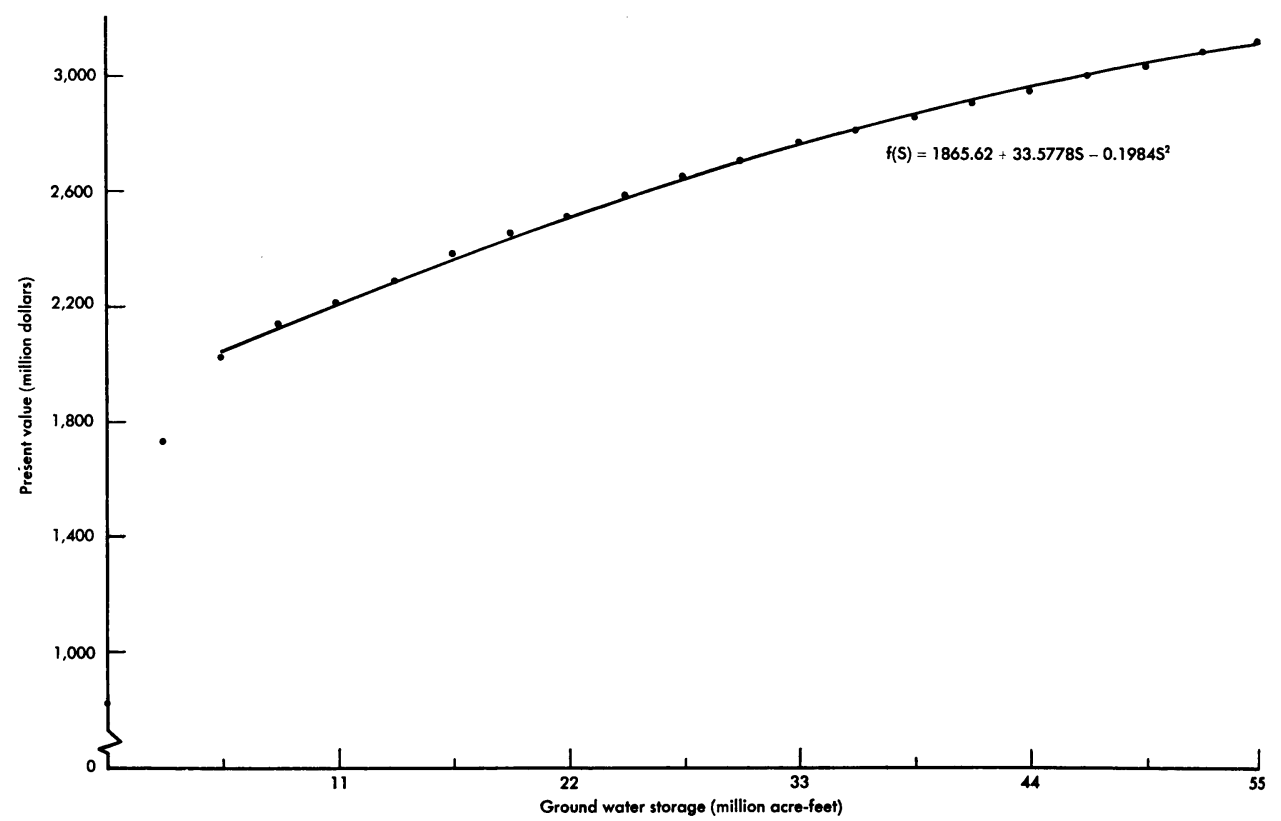

Fig. 2. Present value net output of the study area (in million dollars)., 
Ground water under a condition of maximum storage (54.78 million acrefeet) has a marginal value equal to $\$ 11.84$.

The fact that the optimal annual use rate is 3.75 million acre-feet in the discrete model when storage is 54.78 million acre-feet suggests that in a continuous variable formulation the optimal rate is between 3.5 and 4.0 million acre-feet. A quadratic function was fitted to net output (last column, table 14) at the three levels of use $3.50,3.75$, and 4.0 million acre-feet, giving relation

(6.5) $R(X)=-641.0690+449.6900 X$

$$
3.50 \leqq X \leqq 4.00
$$

$$
446.3900-116.7840 X=\frac{1}{1.06}[11.84+(1.815-X)(-.3968)]
$$

with solution $X=3.72$ million acre-feet.

Ground water pumping costs estimated by fitting a line to the discrete data of table 20 yield a marginal net output function which is linear in $X$ and continuous in the parameter $S$. The fitted pumping cost function is

$$
c(S)=14.58-0.2004 S \text {. }
$$

Substitution of the empirical functions into (2.12) gives the decision rule

$$
X=\frac{424.6218+0.2004 S}{117.1584}
$$

However, caution must be exercised in the use of (6.8) because it is appropriate only for relatively large levels

To get expected output net of pumping costs, expected pumping costs must be subtracted from (6.5).

Pumping cost per acre-foot with storage at 54.78 million acre-feet is $\$ 3.30$ (table 20). Therefore, marginal net output is

$$
\begin{aligned}
\frac{\partial B}{\partial X} & =R^{\prime}(X)-3.30 \\
& =449.6900-116.7840 X-3.30 \\
& =446.3900-116.7840 X
\end{aligned}
$$

Solution is obtained by substituting the empirically estimated relations into (2.12). Thus,

of storage. Relation (6.3) is a good approximation to $f(S)$ except for small magnitudes of $S$. When storage is at a high level, discounting makes the influence of the poor fit at low storage negligible.

A more adequate fit to the discrete values of $f(S)$ can be obtained by a higher degree polynomial and inclusion of all the data of figure 2. Difficulty is encountered by doing so because the equation for the decision rule becomes nonlinear. Since only large levels of storage are of interest for present conditions, there is little purpose in complicating the problem by a more refined fit for $f(S)$.

\section{IMPLICATIONS FOR THE STUDY AREA}

Any conclusions drawn are necessarily preliminary and subject to the limitations discussed in the next section. However, some general relationships can be inferred from the analysis.

Ground water decision rules evolving from the analysis suggest that there is no reason to be alarmed about a declining level of ground water in this region. Indeed, maximization of net output at present value implies overdrafts in the immediate future. Ground water reserves are so large relative to mean annual supply that it is more economical to consume some of the stored water rather than retain it as a contingency against an uncertain future supply. Under present water supply conditions and the decision rule derived, the expected ground water level in the future is considerably lower than that presently existing (see table 33 ). 
The analysis further suggests that if the region has an opportunity to purchase additional water at a price of less than $\$ 40$ per acre-foot, it should exercise the opportunity unless an option to purchase the added water at some future date can be obtained. However, the figure of $\$ 40$ should probably be reduced somewhat to account for the fact that our model made no adjustment for time lags in development and the associated delay in production. A reasonable but conservative figure might be $\$ 30$. Furthermore, the area should not necessarily purchase additional water immediately if rights to purchase water in the future will give adequate stability for long-run planning.
Consider a specific situation where the region can contract for future delivery of water. Suppose the area can contract for 250,000 acre-feet of water to be supplied at any future date of its choice, but once delivery is made it must continue indefinitely. What is the maximum price that can be paid for the water at various dates at which delivery could be started (delivery at farm)? The answer to this question is given in table 29 for five-year intervals starting from the present time and extending the delivery date to 50 years from the present. At a 6 per cent discount rate, the price is lowest for the first five-year period and equal to $\$ 16$. The price increases rapidly, reaching $\$ 60$ within 40 years.

\section{LIMITATIONS OF RESULTS}

A note of caution: since adopting the underlying decision model to the problem at hand has been the major objective of this study, the empirical implementation attempted must be regarded as tentative. Possible sources of error in variables employed and empirical measures derived may lie in the two major categories of variables, (1) hydrological and (2) economic.

\section{Hydrological}

The probability distribution of stream flows in the Kings River was estimated from a sample of observations and subject to sampling error. We do not expect this error to be large from a sample of 88 observations. The quantity of water recharged for a given stream flow has been estimated at approximately one-half the stream flow. This estimate could easily be wrong by a significant amount. The estimate implies percolation rates from the surface distribution system, surface water management through flood control releases, evaporation losses, and many other factors.

The study area is not a true basin and ground water can flow in and out of the area. These flows are not likely to be large under present conditions, but could be significant if large differentials in ground water levels existed between the study area and adjacent areas. One compensating factor is the large size of the study area and its partial isolation, making ground water movements small relative to the quantity in storage.

\section{Economic}

Net output per time period as a function of water consumption rate is subject to error from a number of sources and is the most equivocal datum entering the model. The most important sources of error in this function are:

(1) Statistical demand functions for agricultural activities.

(2) Labor and capital costs for various activities.

(3) Land development costs.

(4) Assumptions pertaining to producer behavior.

(5) Selection of agricultural commodities entered as activities in the linear programming part of the analysis.

The statistical demand functions for 
agricultural activities are extremely important in determining the level and shape of the net output function for the study area. The demand functions employed are relatively crude estimates and possibly subject to significant error. The demand functions are treated as independent among themselves as well as independent of commodities not included in the set of potential commodities for production within the study area. This simplification can be serious. For example, the truck crop activity contains only four crops. There exist close substitutes not included in our aggregate and effects of these substitutes are not incorporated in projected demand. The truckcrop demand function is probably somewhat more elastic than the estimated function used in the analysis.

Carrying this example with truck crops further, inclusion of more crops in the composite activity would help the situation but we are faced with number (2); labor and capital costs for other truck crops were not available in many cases. Also, some of the other truck crops are not adapted to the area. More complete econometric models taking account of the interrelationships are possible, but this was not practicable in the present study.

The restriction of net output to a constant function over time is an approximation which should be avoided when feasible. Also, certain constraints on immediate development of an area exist and should be taken into account. Tree crops require a waiting period for maturity and chemical treatment of alkaline soils requires considerable time for leaching.

Another factor which limits present results, a factor not directly classifiable as either economic or hydrological, is the artificial bottom placed in the underground storage reservoir.

\section{POTENTIAL USE OF THE MODEL FOR INVESTMENT AND INVENTORY DECISIONS IN THE FIELD OF WATER RESOURCES}

Derivation of an optimal inventory policy for ground water is of limited usefulness in most basins since the institutional structure does not exist to administer the policy. However, the optimal policy may serve as an indication of how far actual rate of use deviates from the ideal. Expected net output under the optimal policy, compared with that under current practice, gives a measure of the cost associated with maintaining present institutional arrangements. The pressure for controlling ground water may be expected to gain strength in the future, and thus increase the usefulness of ground water inventory analysis.

The inventory model should help clarify the implications of a given policy, whether optimal or nonoptimal. Formulation of water storage as a finite Markov chain permits application of the theory of finite Markov chains to the situation, which holds promise of generating useful results. Measures of mean passage times to various water storage conditions, the probability of reaching a certain critical water storage condition in $n$ years or fewer, and other relations are amenable to precise and meaningful interpretation within a range of water resource development situations.

The inventory model should prove useful for deriving optimal policies for surface reservoir management. Unlike ground water storage, surface water storage is usually placed under control of a public agency. Therefore, an optimal policy for surface water management has immediate application within the existing institutional structure.

A water inventory policy, either optimal or nonoptimal, must be assumed in order to estimate a point on the investment opportunities surface. Eval- 
uation of prospective investments in a basin requires estimation of the probability distribution of water utilization over time. Present expected value of net benefits under a given investment situation can be estimated only when an estimate of water utilization over time is available.

Theory of storage (inventory control) is a vital part of the theory of investment in water resources. Investment in water resources may be thought of as falling into one of two general classes. (1) Transportation of water from areas of surplus to areas of deficiency. In economic terms, trans- portation of water geographically to produce the largest economic value, net of transportation costs. (2) Creation of storage facilities, or making possible more efficient utilization of existing storage facilities, to alter the time at which water is available at a given geographic site. The theory of inventory control plays a vital role in investment decisions of the latter type and is of some consequence in the first category. Fluctuations in demand for and supply of water make inventory control a consideration in development of facilities for conveyance of water.

\section{ACKNOWLEDGMENTS}

The author extends his appreciation to Professor Ivan M. Lee for his guidance while serving as chairman of the thesis committee during early stages of the study, and also for his many helpful suggestions on earlier drafts of the manuscript. Appreciation is expressed to Professors Irving J. Hoch, Harold O. Carter, and David $\mathrm{K}$. Todd for their assistance as members of the thesis committee. The author is also indebted to Professors Gordon A. King and Samuel H. Logan, each of whom reviewed an earlier version of the manuscript.

The California Department of Water Resources was very helpful in providing basic data for the empirical part of the study. Special thanks are due Louis Mitchell for his generous help on many occasions.

Partial financial support for this work was provided by the Water Resources Center, University of California. 


\section{APPENDIX A}

TABle A-1

PRODUCTION, PRICES, AND YIELDS OF SELECTED COMMODITIES (1957-1959 averages)

\begin{tabular}{|c|c|c|c|c|c|c|}
\hline \multirow{2}{*}{ Commodity } & \multirow{2}{*}{$\begin{array}{c}\text { Unit } \\
\text { (1) }\end{array}$} & \multicolumn{2}{|c|}{ Price } & \multicolumn{2}{|c|}{ Production } & \multirow{2}{*}{$\frac{\text { Yield }}{\underset{(6)}{\text { Calif. }}}$} \\
\hline & & $\underset{(2)}{\mathrm{U}_{\text {. }} \mathrm{S}}$ & $\underset{(3)}{\text { Calif. }}$ & $\underset{(4)}{\mathrm{U}_{(4)} \mathrm{S}}$ & $\underset{(5)}{\text { Calif. }}$ & \\
\hline & & \multicolumn{2}{|c|}{ dollars } & \multicolumn{2}{|c|}{1,000 units } & \\
\hline 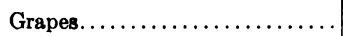 & tons & 61.19 & 57.36 & 2,926 & 2,659 & 6.60 \\
\hline 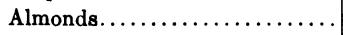 & tons & 519.91 & 519.91 & 47 & 47 & 0.52 \\
\hline Walnuts.................. & tons & 421.33 & 423.06 & 73 & 67 & 0.55 \\
\hline Oranges..................... & boxes & 3.00 & 3.58 & 121,408 & 31,097 & 221.00 \\
\hline Cantaloupes................. & cwt & 4.46 & 4.38 & 12,047 & 6,458 & 143.00 \\
\hline Watermelons............... & cwt & 1.45 & 2.67 & 29,825 & 2,937 & 149.00 \\
\hline Tomatoes.................. & cwt & 7.09 & 7.92 & 19,426 & 6,520 & 168.00 \\
\hline Sweet potatoes.............. & cwt & 3.60 & 7.44 & 17,892 & 1,003 & 79.00 \\
\hline Apricots.................... & tons & 121.06 & 120.45 & 173 & 156 & 4.20 \\
\hline Peaches..$\ldots \ldots \ldots \ldots \ldots \ldots \ldots$ & tons & 82.08 & 65.00 & 1,608 & 806 & 10.30 \\
\hline Olives..................... & tons & 166.01 & 166.01 & 43 & 43 & 1.50 \\
\hline Dry beans................. & cwt & 6.96 & 8.56 & 17,885 & 3,802 & 13.71 \\
\hline Cotton lint................ & bales & 157.15 & 161.50 & 12,345 & 1,690 & 2.09 \\
\hline Cotton seed................. & tons & 44.04 & 46.54 & 5,133 & 666 & 0.86 \\
\hline Corn...$\ldots \ldots \ldots \ldots \ldots \ldots \ldots \ldots \ldots$ & cwt & & 2.50 & & & \\
\hline Barley..$\ldots \ldots \ldots \ldots \ldots \ldots \ldots$ & cwt & & 2.13 & & & \\
\hline Grain sorghum $\ldots \ldots \ldots \ldots \ldots$ & cwt & & 2.11 & & & \\
\hline 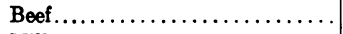 & cwt & & 22.63 & & & \\
\hline Milk....................... & cwt & & 4.41 & & & \\
\hline
\end{tabular}

SOURCEs:

Columns 2 and 3 except cantaloupes, watermelons, tomatoes, beef, and milk; columns 4 and 5 except sweet potatoes, dry beans, cotton, cantaloupes, watermelons, and tomatoes: U. S. Agricultural Marketing Service, Annual B.
Columns 2, 3, 4, 5, and 6 including only cantaloupes, watermelons, and tomatoes: U. S. Agricultural Marketing Service, Ánnual C.

Columns 4, 5, and 6 including only sweet potatoes, dry beans, and cotton: U. S. Agricultural Marketing Service,

Annual A. Livestock Reporting Service, Annual. 
TABle A-2

BASE PERIOD LABOR AND CAPITAL COSTS AND PRODUCTION BY ACTIVITIES*

\begin{tabular}{|c|c|c|c|c|c|c|}
\hline & $\begin{array}{l}\text { Oranges } \\
(1)\end{array}$ & $\begin{array}{c}\text { Dry beans } \\
(2)\end{array}$ & $\underset{(3)}{\text { Almonds }}$ & $\underset{(4)}{\text { Walnuts }}$ & $\begin{array}{c}\text { Tree nuts } \\
(3)+(4) \\
(5)\end{array}$ & $\begin{array}{l}\text { Cotton } \\
(6)\end{array}$ \\
\hline Acres.. & 40 & 100 & 40 & 60 & 100 & 200 \\
\hline Production $\ldots \ldots \ldots \ldots \ldots \ldots$ & $\begin{array}{c}11,000 \\
\text { (77 \# boxes) }\end{array}$ & $\begin{array}{l}2,000 \\
(\mathrm{cwt})\end{array}$ & $\begin{array}{c}30 \\
\text { (tons) }\end{array}$ & $\begin{array}{c}60 \\
\text { (tons) }\end{array}$ & $\begin{array}{c}90 \\
\text { (tons) }\end{array}$ & $\begin{array}{c}450 \S \\
\text { (bales) }\end{array}$ \\
\hline Costs (dollars) ............... & & & & & & 15,053 \\
\hline Fixed & & & & & & \\
\hline $\begin{array}{c}\text { Bldgs., power and equip- } \\
\text { ment................... }\end{array}$ & 3,233 & 611 & 1,113 & 883 & 1,996 & \\
\hline Trees...................... & 1,772 & .. & 992 & 2,910 & 3,902 & \\
\hline Variable............ & & & & & & 29,902 \\
\hline Pre-harvest...... & 8,687 & 2,923 & 4,511 & 5,341 & 9,852 & \\
\hline Harvesting ............. & 5,422 & 3,862 & 3,626 & 5,585 & 9,211 & \\
\hline Management $\dagger \ldots \ldots \ldots \ldots \ldots \ldots$ & 956 & 370 & 512 & 736 & 1,248 & $\ldots \ddagger$ \\
\hline TOTAL.. & 20,070 & 7,766 & 10,754 & 15,455 & 26,209 & 44,955 \\
\hline
\end{tabular}

* Costs are adjusted to 1957-1959 average by index of prices paid by farmers.

† 5 per cent of all other costs.

$\$$ Additional production as seed equal to 180 tons.

$\$$ Included in fixed costs.

Sources:

Column 1: University of California, 1959D

Column 2: Computed average from University of California, 1958B, C.

Column 3: University of California, 1959C

Column 4: University of California, 1959F.

Column 6: Douglas D. Caton et al., 1958.

TABLE A-3

BASE PERIOD LABOR AND CAPITAL COSTS AND PRODUCTION BY ACTIVITIES*

\begin{tabular}{|c|c|c|c|c|c|}
\hline & $\begin{array}{c}\text { Clingstone } \\
\text { peaches } \\
\text { (1) }\end{array}$ & $\begin{array}{l}\text { Freestone } \\
\text { peaches } \\
(2)\end{array}$ & $\begin{array}{l}\text { Apricots } \\
\text { (3) }\end{array}$ & $\begin{array}{c}\text { Olives } \\
(4)\end{array}$ & $\begin{array}{c}\text { Deciduous } \\
\text { fruit } \\
(5)\end{array}$ \\
\hline Acres............. & 65 & 55 & 10 & 30 & 160 \\
\hline Production $($ tons $) \ldots \ldots \ldots \ldots \ldots \ldots \ldots \ldots \ldots$ & 975 & 880 & 80 & 120 & 2,055 \\
\hline \multicolumn{6}{|l|}{ Costs (dollars) } \\
\hline \multicolumn{6}{|l|}{ Fixed } \\
\hline Bldgs., power, and equipment........... & 2,833 & 1,595 & 213 & 438 & 5,079 \\
\hline Trees. $\ldots \ldots \ldots \ldots \ldots \ldots \ldots \ldots \ldots \ldots$ & 3,047 & 1,983 & 349 & 823 & 6,202 \\
\hline \multicolumn{6}{|l|}{ Variable } \\
\hline Pre-harvest. ....... & 25,041 & 19,604 & 1,781 & 5,060 & 51,486 \\
\hline Harvesting. . . . . . . . . . . . & 11,366 & 20,141 & 2,158 & 10,617 & 44,282 \\
\hline Management $\uparrow \ldots \ldots \ldots \ldots \ldots \ldots \ldots \ldots \ldots \ldots \ldots \ldots \ldots$ & 2,114 & 2,167 & 225 & 847 & 5,353 \\
\hline TOTAL $\ldots \ldots \ldots \ldots \ldots \ldots \ldots \ldots$ & 44,401 & 45,490 & 4,726 & 17,785 & 112,402 \\
\hline
\end{tabular}

* Costs are adjusted to 1957-1959 average by index of prices paid by farmers.

$\dagger 5$ per cent of all other costs.

Sources:

Column 1: University of California, 1960

Column 2: University of California, 1959A

Column 3: University of California, 1958F.

Column 4: University of California, 1959E

Column 5: Sum of columns 1, 2, 3, and 4 . 
TABLE A-4

BASE PERIOD LABOR AND CAPITAL COSTS AND PRODUCTION BY ACTIVITIES*

\begin{tabular}{|c|c|c|c|c|c|}
\hline & $\begin{array}{c}\text { Standard } \\
\text { vine } \\
\text { varieties } \\
\text { (1) }\end{array}$ & $\begin{array}{l}\text { Thompson } \\
\text { seedless for } \\
\text { raisins } \ddagger \\
\text { (2) }\end{array}$ & $\begin{array}{c}\text { Emperor } \\
\text { for table } \\
\text { use§ } \\
\text { (3) }\end{array}$ & $\begin{array}{l}\text { Thompson } \\
\text { seedless for } \\
\text { table usell } \\
\text { (4) }\end{array}$ & $\begin{array}{c}\text { Aggregate } \\
\text { grape } \\
\text { activity } \\
(5)\end{array}$ \\
\hline Acres $\ldots \ldots \ldots \ldots \ldots \ldots \ldots$ & 55 & 55 & 25 & 25 & 160 \\
\hline Production (tons) $\ldots \ldots \ldots \ldots \ldots \ldots \ldots \ldots \ldots$ & 605 & 440 & 175 & 200 & 1,420 \\
\hline Costs (dollars) & & & & & \\
\hline Fixed & & & & & \\
\hline Bldgs., power, and equipment............ & 857 & 922 & 419 & 434 & 2,632 \\
\hline 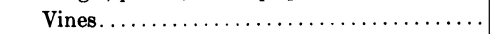 & 2,222 & 2,212 & 1,310 & 1,176 & 6,920 \\
\hline Variable & & & & & \\
\hline Pre-harvest...... & 5,184 & 5,690 & 3,141 & 4,611 & 18,626 \\
\hline Harvesting. ..... & 5,928 & 5,201 & 2,058 & 2,744 & 15,931 \\
\hline Management $\dagger \ldots \ldots \ldots$ & 709 & 702 & 347 & 448 & 2,206 \\
\hline TOTAL... & 14,900 & 14,727 & 7,275 & 9,413 & 46,315 \\
\hline
\end{tabular}

* Costs are adjusted to 1957-1959 average by the index of prices paid by farmers.

$\dagger 5$ per cent of all other costs.

Eight fresh tons per acre ( 2 tons of raisins).

Fresh market sales of 5.25 tons per acre and 1.75 tons per acre to winery.

Fresh market sales of 5.6 tons per acre and 2.4 tons per acre to winery.

Composition of the aggregate activity was determined so that the proportions of winery, raisin, and fresh grapes are the same as the California average; thus, California average price is appropriate for the aggregate grape activity. Sources:

Column 1: University of California, $1959 \mathrm{H}$.

Column 2: University of California, 1959I.

Column 3: University of California, 1959G.

Column 4: University of California, 1959J.

Column 5: Sum of columns 1, 2, 3, and 4 .

TABLE A-5

BASE PERIOD LABOR AND CAPITAL COSTS AND PRODUCTION BY ACTIVITIES*

\begin{tabular}{|c|c|c|c|c|c|}
\hline & $\begin{array}{c}\text { Cantaloupes } \\
\text { (1) }\end{array}$ & $\begin{array}{l}\text { Tomatoes } \\
\text { (fresh mkt.) } \\
\quad(2)\end{array}$ & $\begin{array}{c}\text { Watermelons } \\
\text { (3) }\end{array}$ & $\begin{array}{l}\text { Sweet } \\
\text { potatoes } \\
(4)\end{array}$ & $\begin{array}{c}\text { Aggregate } \\
\text { truck crop } \\
\text { activity } \\
\text { (5) }\end{array}$ \\
\hline Acres............ & 70 & 30 & 30 & 30 & 160 \\
\hline Production $(\mathrm{cwt}) \ldots \ldots \ldots \ldots \ldots \ldots \ldots \ldots \ldots$ & 9,800 & 12,150 & 7,200 & 2,400 & 31,550 \\
\hline Cost (dollars) & & & & & \\
\hline Fixed & & & & & \\
\hline Bldgs., power, and equipment. .......... & 285 & 863 & 395 & 332 & 1,875 \\
\hline Variable & & & & & \\
\hline Pre-harvest...... & 6,386 & 24,210 & 4,898 & 6,315 & 41,809 \\
\hline Harvesting. . . . . . . . . . & 23,112 & 43,557 & 3,229 & 3,196 & 73,094 \\
\hline Management $\dagger \ldots \ldots \ldots \ldots \ldots \ldots \ldots \ldots$ & 1,489 & 3,432 & 427 & 492 & 5,840 \\
\hline 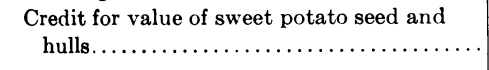 & $\cdots$ & . & . & $-1,890$ & $-1,890$ \\
\hline TOTAL.... & 31,272 & 72,062 & 8,949 & 8,445 & 120,728 \\
\hline
\end{tabular}

* Costs are adjusted to $1957-1959$ average by the index of prices paid by farmers.

$\dagger 5$ per cent of all other costs.

Sources:

Column 1: Stewart, 1954

Column 2: University of California, 1953.

Column 3: University of California, 1958D.

Column 4: University of California, 1956.

Column 5: Sum of columns 1, 2, 3, and 4. 
TABLE A-6

BASE PERIOD LABOR AND CAPITAL COSTS AND PRODUCTION BY ACTIVITIES*

\begin{tabular}{|c|c|c|c|c|c|c|c|}
\hline & $\begin{array}{l}\text { Grain } \\
\text { sorghum } \\
\text { (1) }\end{array}$ & $\begin{array}{c}\text { Barley } \\
\text { (2) }\end{array}$ & $\begin{array}{l}\text { Grain } \\
\text { sorghum- } \\
\text { barley } \\
\text { activity } \\
(3)\end{array}$ & $\begin{array}{c}\text { Field corn } \\
\text { (Tulare Co.) } \\
(4)\end{array}$ & $\begin{array}{c}\text { Field corn } \\
\text { (Fresno Co.) } \\
(5)\end{array}$ & $\begin{array}{l}\text { Field corn } \\
\text { (Kings Co.) } \\
(6)\end{array}$ & $\begin{array}{l}\text { Field corn } \\
\text { activity } \\
\text { (7) }\end{array}$ \\
\hline Acres................. & 100 & 100 & $\begin{array}{c}100 \\
\text { (double crop) }\end{array}$ & 100 & 100 & 100 & 100 \\
\hline $\begin{array}{l}\text { Production (cwt) ....... } \\
\text { Costs (dollars) } \\
\quad \text { Fixed }\end{array}$ & 4,000 & 3,000 & 7,000 & 6,000 & 6,000 & 6,000 & 6,000 \\
\hline $\begin{array}{l}\text { Depreciation. ...... } \\
\text { Interest on invest- }\end{array}$ & 396 & 307 & 703 & 437 & 901 & 389 & 576 \\
\hline$\underset{\text { Variable }}{\operatorname{ment} . \cdots \cdots \cdots \cdots}$ & 165 & 178 & 343 & 145 & 299 & 163 & 202 \\
\hline Pre-harvest......... & 3,459 & $\ldots \ddagger$ & 3,459 & 4,719 & 4,393 & 4,048 & 4,386 \\
\hline Harvesting........ & 1,246 & $\ldots \ddagger$ & 1,246 & 2,205 & 1,046 & 1,764 & 1,671 \\
\hline $\begin{array}{l}\text { Materials........... } \\
\text { Labor and field }\end{array}$ & $\ldots \S$ & 809 & 809 & $\ldots \S$ & $\ldots \S$ & $\ldots \S$ & $\ldots \S$ \\
\hline power........... & $\ldots \S$ & 1,463 & 1,463 & $\ldots \S$ & $\ldots \S$ & $\ldots \S$ & $\ldots \S$ \\
\hline Cash overhead...... & $\ldots \S$ & 512 & 512 & $\ldots \S$ & $\ldots \S$ & $\ldots \S$ & $\ldots \S$ \\
\hline Management $† \ldots . .$. & 263 & 164 & 427 & 375 & 332 & 318 & 342 \\
\hline TOTAL ........ & 5,529 & 3,433 & 8,962 & 7,881 & 6,971 & 6,682 & 7,177 \\
\hline
\end{tabular}

* Costs are adjusted to 1957-1959 average by the index of prices paid by farmers.

5 per cent of all other costs.

Included with pre-harvest and harvesting costs.

Included with materials, labor and field power, and cash overhead.

SOURCES:

Column 1: University of California, 1958E.

Column 2: University of California, 1955.

Column 3: Sum of columns 1 and 2.

Column 4: University of California, 1959K.

Column 5: University of California, 1958A.

Column 6: University of California, 1959B.

Column 7: Average of columns 4, 5, and 6 .

TABLe A-7

BASE PERIOD LABOR AND CAPITAL COSTS AND PRODUCTION BY ACTIVITIES*

\begin{tabular}{|c|c|c|}
\hline & $\begin{array}{l}\text { Beef on irri- } \\
\text { gated pasture }\end{array}$ & Dairy \\
\hline Acres................... & 88 & 220 \\
\hline \multicolumn{3}{|l|}{ Production } \\
\hline Beef (cwt) $\ldots \ldots \ldots \ldots \ldots$ & $1,725 \ddagger \S$ & . \\
\hline Barley (cwt) . .......... & .. & 1,260 \\
\hline Alfalfa hay (tons) $\ldots \ldots \ldots$ & .. & 35 \\
\hline Dairy stock (dollars)..... & . & 5,597 \\
\hline Milk (cwt) $\ldots \ldots \ldots \ldots \ldots$ & . & 13,000 \\
\hline \multicolumn{3}{|l|}{ Costs } \\
\hline Fixed $\ldots \ldots \ldots \ldots \ldots \ldots$ & 3,196 & 10,631 \\
\hline Variable............... & 28,737 & 37,641 \\
\hline Management $f \ldots \ldots \ldots \ldots$ & 1,779 & 3,504 \\
\hline TOTAL $\ldots . . . \ldots \ldots .$. & 33,712 & 51,776 \\
\hline
\end{tabular}

* Costs are adjusted to 1957-1959 average by the index of prices paid by farmers.

$\dagger 5$ per cent of all other costs (treating enterprises separately in dairy -5 per cent of $\$ 68,646$ ).

$\ddagger 196$ head at $880 \mathrm{lbs}$ ( 2 per cent death loss).

\$ Yield on pasture of 14 animal unit months per acre.

Sources:

Column 1: University of California, 1954

Column 2: University of California, 1957. 
TABLE A-8

BASE PERIOD LAND UTILIZATION BY SELECTED AGRICULTURAL ACTIVITIES WITHIN STUDY AREA

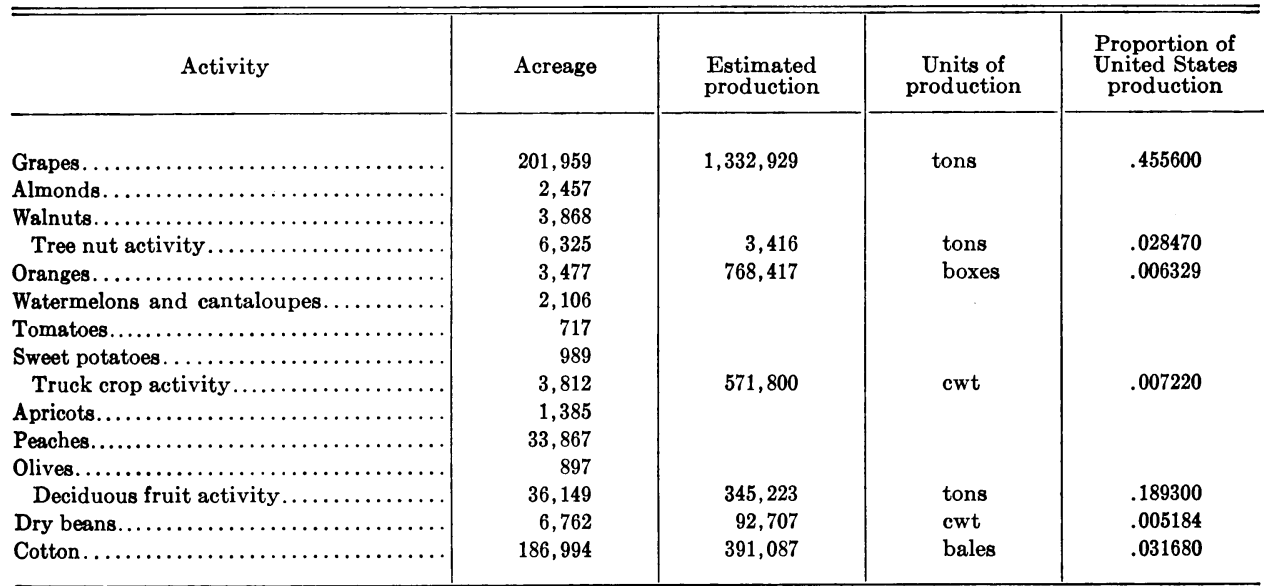

SoURCes:

Column 1: California Department of Water Resources, Land Use Classification (unpublished).

Column 2: Computed, using average California yields during the base period.

Column 4: Computed, using United States production during the base period.

TABLE A-9

BASE PERIOD PRICES AND PRODUCTION BY SELECTED ACTIVITIES

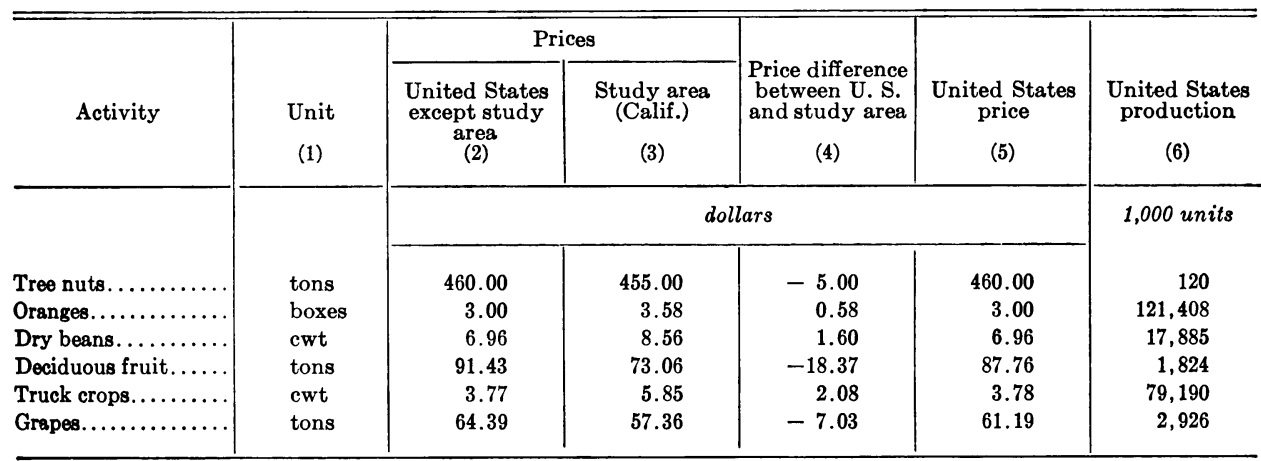

Sources:

Column 2: Computed using estimated study area production and a price for study area production equal to California price.

Columns 3,5, and 6: Table A-1.

Column 4: Column 2 minus column 3 


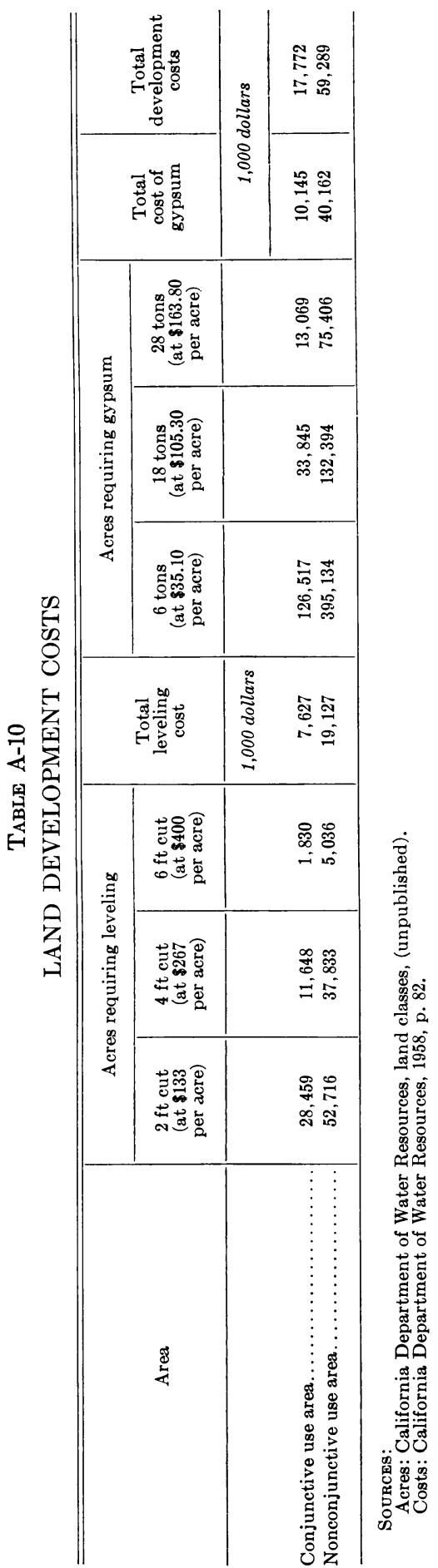

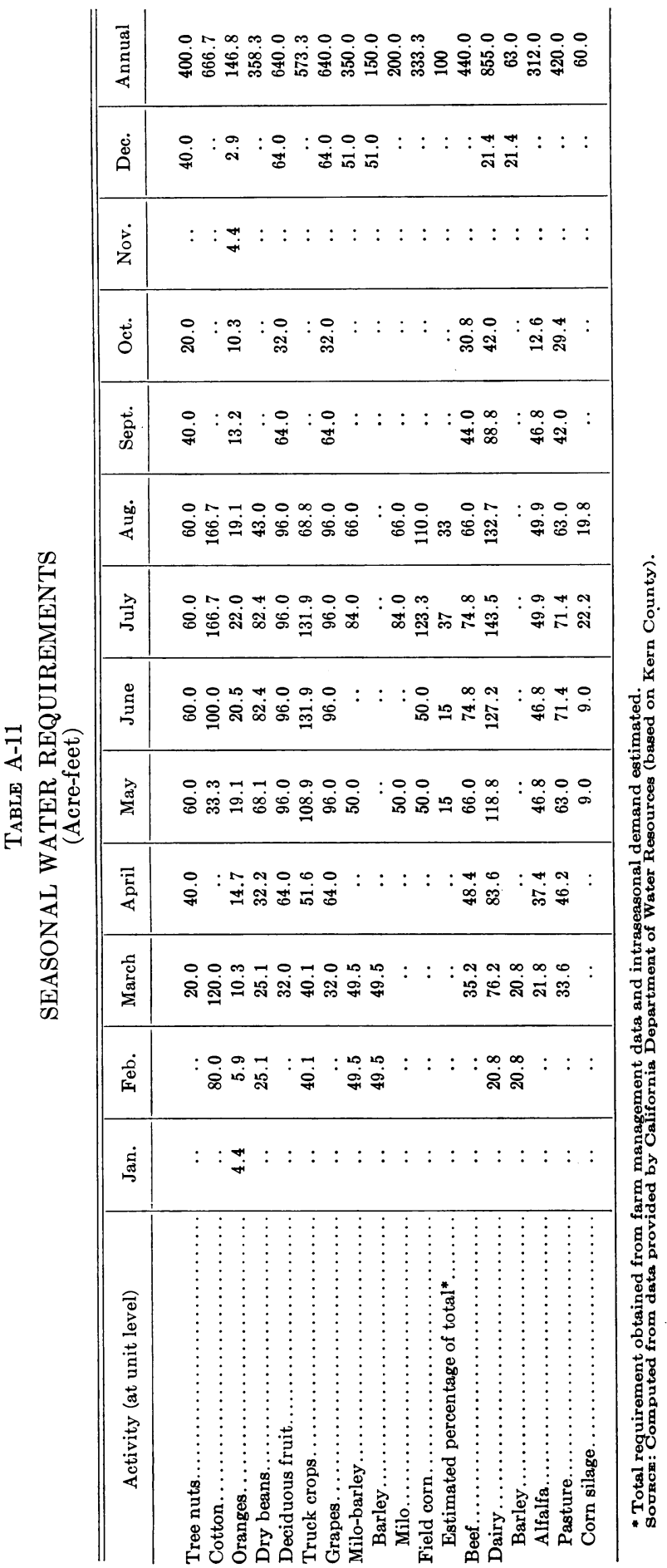




\begin{abstract}
APPENDIX B
Urban population projections to 1980 are used as a basis for estimating urban water requirements. Urban water use cannot be regarded as a fixed requirement for a given situation but is the quantity determined by an equilibrium between supply and demand, as in the case of any other commodity having economic value. When we speak of a fixed requirement, we are assuming a completely inelastic demand function.

Urban water consumption in the study region is small relative to agricultural use and, therefore, the error resulting from assuming a completely inelastic urban demand for water is not likely to be large relative to the over-all water management policy. Also, data available are primarily in the form of fixed requirements, presumably estimated under prevailing prices of water, which are not subject to wide fluctuations.

Water requirements per acre of land in urban use are taken as fixed as are land requirements per capita of urban population, thus making urban water requirements dependent only upon urban population. An estimate of urban water requirements in 1980 is obtained by projecting urban population to that date.

The Fresno metropolitan area is considered separately from other urban units in the region. The growth rate for $1950-60,1.44$, is used to project growth from 1960-70. The rate of growth for 1970-80 is estimated at 1.32. Other urban areas are estimated to grow at rates of 1.36 and 1.30 for $1960-70$ and 1970-80, respectively (U.S. Senate, 1960, pp. 10, 17).

Instead of projecting population and from the population projection, projecting land devoted to urban use, we can project urban land directly using the above rates and present acreages of land in urban use. This is the procedure followed by subareas in the region of study to derive projected acreages of urban land for both the conjunctive use and nonconjunctive use areas. Present acreages of urban land were obtained from unpublished material of the California Department of Water Resources, Sacramento. Projected urban acreage together with other land restricted from agricultural production is given in table B-1.
\end{abstract}




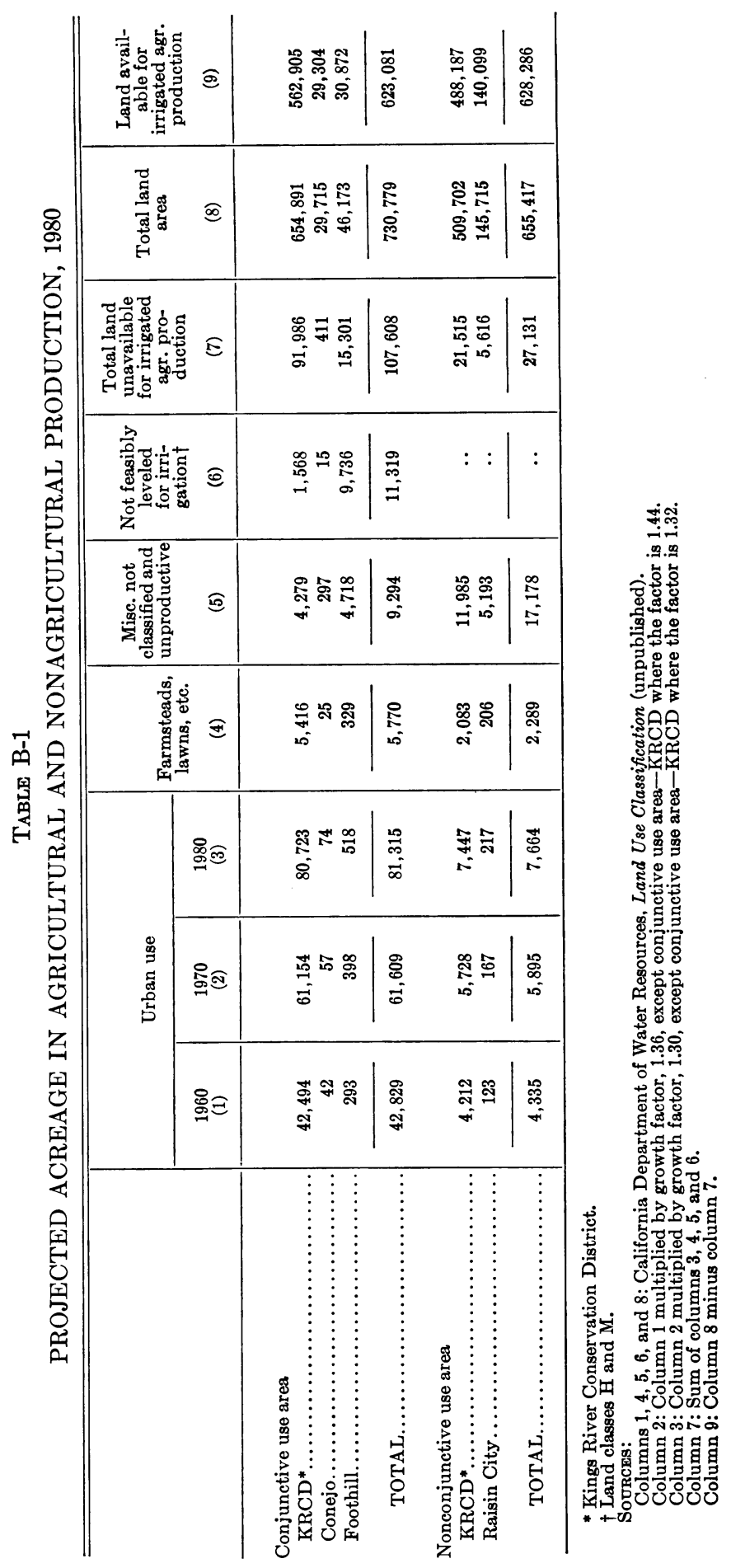


TABLE B-2

NONAGRICULTURAL WATER REQUIREMENTS ANNUALLY, 1980 PROJECTIONS (Acre-feet)

\begin{tabular}{|c|c|c|c|c|c|}
\hline & $\begin{array}{l}\text { Urban } \\
\text { demand } \\
\text { per acre }\end{array}$ & $\begin{array}{c}\text { Per acre } \\
\text { demand of } \\
\text { farmsteads, } \\
\text { lawn area, etc. }\end{array}$ & $\begin{array}{l}\text { Urban } \\
\text { acres }\end{array}$ & $\begin{array}{l}\text { Farmsteads, } \\
\text { lawn area, etc. } \\
\text { (acres) }\end{array}$ & $\begin{array}{l}\text { Fixed annual } \\
\text { requirements }\end{array}$ \\
\hline $\begin{array}{l}\text { Conjunctive use area............. } \\
\text { Nonconjunctive use area........ }\end{array}$ & $\begin{array}{l}1.3 \\
1.4\end{array}$ & $\begin{array}{l}.75 \\
.75\end{array}$ & $\begin{array}{r}81,315 \\
7,664\end{array}$ & $\begin{array}{l}5,770 \\
2,289\end{array}$ & $\begin{array}{r}110,037 \\
12,447\end{array}$ \\
\hline TOTAL................. & & & & & 122,484 \\
\hline
\end{tabular}

Sources:

Columns 1, 2, 3, and 4: California Department of Water Resources (unpublished).

Column 5: Computed from columns $1,2,3$, and 4 .

Table B-3

PROJECTED POPULATION AND DISPOSABLE PERSONAL INCOME, UNITED STATES, 1980

\begin{tabular}{|c|c|c|c|c|c|}
\hline & \multicolumn{4}{|c|}{ Observed } & \multirow{2}{*}{$\begin{array}{c}\text { Projected } \\
\begin{array}{c}1980 \\
(5)\end{array}\end{array}$} \\
\hline & $\begin{array}{c}1957 \\
(1)\end{array}$ & $\begin{array}{c}1958 \\
(2)\end{array}$ & $\begin{array}{c}1959 \\
(3)\end{array}$ & $\begin{array}{c}1957-59 \\
\text { average } \\
\quad(4)\end{array}$ & \\
\hline $\begin{array}{l}\text { Disposable personal income (billion dollars) } \ldots \ldots \ldots \\
\text { Gross national product (billion dollars) } \ldots \ldots \ldots \ldots \ldots \\
\text { Population (millions) } \ldots \ldots \ldots \ldots \ldots \ldots \ldots \ldots \ldots \ldots \ldots\end{array}$ & $\begin{array}{l}308.8 \\
442.8 \\
171.2\end{array}$ & $\begin{array}{l}317.9 \\
444.2 \\
174.1\end{array}$ & $\begin{array}{l}337.3 \\
482.1 \\
176.9\end{array}$ & $\begin{array}{l}321.3 \\
456.4 \\
174.1\end{array}$ & $\begin{array}{c}746^{*} \\
1,060^{*} \\
244\end{array}$ \\
\hline
\end{tabular}

- 1959 constant dollars

Sources:

Columns 1, 2, 3, and 4: Joint Economic Committee Staff and the Office of Statistical Standards, 1960, pp. 3 and 14 Column 5: Gross national product and population: U. S. Senate, 1960, p. 2

Disposable personal income: Computed by multiplying projected gross national product by the ratio of average disposable personal income to gross national product during the base period. 


\section{APPENDIX C}

\section{Case I (monopoly)}

We consider the problem of maximizing net returns subject to a limited supply of water (the resource could be some other resource such as land). It is assumed that the set of commodities being produced at a positive level can be delineated independently of the maximization problem. The following definitions are made: $P_{i}=$ price of the $i^{\text {th }}$ commodity

$Q_{i}=$ quantity sold of the $i^{\text {th }}$ commodity

$w_{i}=$ water used in producing the $i^{\text {th }}$ commodity

$K=$ fixed water supply

$C_{i}\left(Q_{i}\right)=$ cost function for the $i^{\text {th }}$ commodity

$i=1,2, \ldots n$

(1) $P_{i}=D_{i}\left(Q_{i}\right)$

(2) $Q_{i}=f_{i}\left(w_{i}\right)$

Our problem is to maximize $R=\sum_{i=1}^{n}\left(P_{i} Q_{i}-C_{i}\left(Q_{i}\right)\right)$ subject to $\sum_{i=1}^{n} w_{i}=K$.

Using Lagrange's method we define the function

$$
G=\sum_{i=1}^{n}\left(P_{i} Q_{i}-C_{i}\left(Q_{i}\right)\right)-\lambda\left(\sum_{i=1}^{n} w_{i}-K\right)
$$

setting $\frac{\partial G}{\partial w_{i}}=0$ :

$$
\frac{\partial Q_{i}}{\partial w_{i}}\left(P_{i}+Q_{i} \frac{\partial P_{i}}{\partial Q_{i}}-C_{i}^{\prime}\left(Q_{i}\right)\right)=\lambda, i=1,2, \cdots n .
$$

Substituting from (1) gives:

$$
\frac{\partial Q_{i}}{\partial w_{i}}\left(D_{i}\left(Q_{i}\right)+Q_{i} \frac{\partial P_{i}}{\partial Q_{i}}-C_{i}^{\prime}\left(Q_{i}\right)\right)=\lambda, i=1,2, \cdots n .
$$

Solution of $2 n+1$ equations yields the desired answer, i.e., equations (2), (4), and the constraint

$$
\sum_{i=1}^{n} w_{i}=K
$$

\section{Case II (pure competition)}

Our problem is to maximize returns in the above problem, but with the additional requirement that competitive conditions be imposed. Price is treated as a constant in the maximization of returns and we restrict the cost function to $C_{i}\left(Q_{i}\right)=d_{i} Q_{i}, d_{i}$ a constant. We also restrict the production function, $Q_{i}=f_{i}\left(w_{i}\right)$, to $Q_{i}=b_{i} w_{i}, b_{i}$ a constant. These are restrictions necessary for linear programming analysis.

Under these conditions setting $\mathrm{d} G / \partial w_{i}=0$ in (3) gives:

$$
b_{i}\left(P_{i}-d_{i}\right)=\lambda, i=1,2, \cdots n .
$$


Substitution gives the $n+1$ equations,

(6)

$$
b_{i}\left(D_{i}\left(Q_{i}\right)-d_{i}\right)=\lambda, i=1,2, \cdots n
$$

$$
\sum_{i=1}^{n} Q_{i} / b_{i}=K
$$

in $n+1$ unknowns.

Setting average returns per unit of water equal among the $n$ commodities gives (5). We may write average returns per units of water for the $i^{\text {th }}$ commodity,

$$
\frac{P_{i} Q_{i}-C_{i}\left(Q_{i}\right)}{w_{i}}=\frac{P_{i} b_{i} w_{i}-d_{i}\left(b_{i} w_{i}\right)}{w_{i}}=b_{i}\left(P_{i}-d_{i}\right),
$$

the left side of $(5)$.

We note that defining $C_{i}\left(Q_{i}\right)=d_{i} Q_{i}$ and $f_{i}\left(w_{i}\right)=b_{i} w_{i}$ permits simulation of pure competition from our aggregative model. These conditions could be relaxed somewhat by distinguishing between internal and external economies of seale with respect to production of a single commodity. An assumption of independence among commodities has been made with respect to costs and prices. 


\section{APPENDIX D}

TABLE D-1

ESTIMATION OF GROUND WATER STORAGE CAPACITY

\begin{tabular}{|c|c|c|c|c|c|c|}
\hline \multirow{2}{*}{$\begin{array}{l}\text { Storage unit } \\
\text { (ground water study } \\
\text { classification) }\end{array}$} & \multirow{2}{*}{$\begin{array}{c}\text { Estimated acres } \\
\text { of study area } \\
\text { included }\end{array}$} & \multicolumn{4}{|c|}{ Storage capacity ( 1,000 acre-feet) } & \multirow{2}{*}{$\begin{array}{l}\text { Specific yield } \\
\text { between } 100 \\
\text { and } 200 \text { feet }\end{array}$} \\
\hline & & $\begin{array}{c}10-50 \\
\text { feet depth }\end{array}$ & $\begin{array}{c}50-100 \\
\text { feet depth }\end{array}$ & $\begin{array}{c}100-200 \\
\text { feet depth }\end{array}$ & $\begin{array}{l}200-407.4 \\
\text { feet depth }\end{array}$ & \\
\hline San Joaquin Rivert........... & 192,000 & 910 & 1,110 & 2,470 & 5,137 & .129 \\
\hline Fresno Interstream $\ddagger \ldots \ldots \ldots \ldots$ & 49,000 & 160 & 180 & 260 & 535 & .053 \\
\hline Kings River $\ddagger \ldots \ldots \ldots \ldots \ldots \ldots \ldots$ & 576,000 & 3,250 & 3,520 & 7,160 & 14,813 & .124 \\
\hline Dinuba Interstream $\dagger \ldots \ldots \ldots \ldots$ & 68,000 & 170 & 270 & 350 & 776 & .055 \\
\hline San Joaquin Valley average..... & $501,000 \S$ & 2,120 & 2,660 & 5,060 & 10,495 & .101 \\
\hline TOTAL $\ldots \ldots \ldots \ldots \ldots \ldots$ & $1,386,000$ & 6,610 & 7,740 & 15,300 & 31,756 & \\
\hline
\end{tabular}

* Estimated by using specific yield between 100 and 200 feet.

Selected townships within the total unit were used to estimate specific yield.

Entire unit used to estimate specific yield.

Total study area acreage minus the preceding for which account has been taken $(1,386,000-885,000)$

Source: Davis, 1959. 
TABLE D-2

ANNUAL* SUMMARY OF DISCHARGE OF KINGS RIVER AT PIEDRA (1,000 acre-feet)

\begin{tabular}{|c|c|c|c|c|c|}
\hline Year & & Year & & Year & \\
\hline $1872 \ldots \ldots$ & 2,484 & $1908 \ldots$ & 977 & $1944 .$. & 1,168 \\
\hline $1873 \ldots \ldots$ & 1,030 & $1909 \ldots$ & 2,799 & $1945 \ldots$ & 2,062 \\
\hline $1874 \ldots \ldots$ & 1,788 & $1910 \ldots$ & 1,779 & $1946 \ldots$ & 1,612 \\
\hline $1875 \ldots \ldots$ & 786 & $1911 \ldots$ & 2,827 & $1947 \ldots$ & 1,107 \\
\hline $1876 \ldots$. & 2,701 & $1912 \ldots$ & 968 & $1948 \ldots$ & 996 \\
\hline $1877 \ldots$ & 696 & $1913 \ldots$ & 942 & $1949 \ldots$ & 961 \\
\hline 1878. & 2,204 & $1914 \ldots$ & 2,548 & $1950 \ldots$ & 1,281 \\
\hline 1879. & 334 & $1915 \ldots$ & 1,817 & $1951 \ldots$ & 1,601 \\
\hline 1880. & 3,143 & $1916 \ldots$ & 3,042 & $1952 \ldots$ & 2,856 \\
\hline $1881 \ldots$ & 2,592 & $1917 \ldots$ & 1,893 & $1953 \ldots$ & 1,155 \\
\hline 1882. & 903 & $1918 \ldots$ & 1,364 & $1954 \ldots$ & 1,339 \\
\hline $1883 \ldots$ & 1,328 & $1919 \ldots$ & 1,203 & $1955 \ldots$ & 1,143 \\
\hline $1884 \ldots$ & 5,221 & $1920 \ldots$ & 1,405 & $1956 \ldots$ & 2,695 \\
\hline $1885 \ldots$ & 1,147 & $1921 \ldots$ & 1,532 & $1957 \ldots$ & 1,259 \\
\hline $1886 \ldots$ & 4,778 & $1922 \ldots$ & 2,198 & $1958 \ldots$ & 2,615 \\
\hline $1887 .$. & 1,427 & $1923 \ldots$ & 1,556 & $1959 \ldots$ & 824 \\
\hline $1888 \ldots \ldots$ & 858 & $1924 \ldots$ & 392 & Average & 1,755 \\
\hline $1889 \ldots \ldots$ & 1,517 & $1925 \ldots$ & 1,290 & & \\
\hline 1890. & 4,019 & $1926 \ldots$ & 1,037 & & \\
\hline $1891 \ldots \ldots$ & 1,156 & $1927 \ldots$ & 1,984 & & \\
\hline $1892 \ldots \ldots$ & 1,852 & $1928 \ldots$ & 971 & & \\
\hline $1893 \ldots$ & 1,825 & $1929 \ldots$ & 850 & & \\
\hline $1894 \ldots \ldots$ & 1,265 & $1930 \ldots$ & 863 & & \\
\hline $1895 \ldots \ldots$ & 2,484 & $1931 \ldots$ & 465 & & \\
\hline 1896. & 1,871 & $1932 \ldots$ & 2,084 & & \\
\hline 1897. & 1,949 & $1933 \ldots$ & 1,181 & & \\
\hline $1898 \ldots$ & 881 & $1934 \ldots$ & 657 & & \\
\hline $1899 \ldots \ldots$ & 1,278 & $1935 \ldots$ & 1,621 & & \\
\hline $1900 \ldots$ & 1,307 & $1936 \ldots$ & 1,877 & & \\
\hline $1901 \ldots \ldots$ & 2,956 & $1937 \ldots$ & 2,341 & & \\
\hline $1902 \ldots \ldots$ & 1,505 & $1938 \ldots$ & 3,283 & & \\
\hline 1903. & 1,640 & $1939 \ldots$ & 974 & & \\
\hline $1904 \ldots \ldots$ & 1,687 & $1940 \ldots$ & 1,791 & & \\
\hline $1905 \ldots$. & 1,448 & $1941 \ldots$ & 2,543 & & \\
\hline $1906 \ldots$ & 3,900 & $1942 \ldots$ & 1,999 & & \\
\hline $1907 \ldots \ldots$ & 2,733 & $1943 \ldots$ & 2,027 & & \\
\hline
\end{tabular}

* Oct. 1 to Sept. 30, except 1872-1896 which are on a calendar year basis.

SoURCEs:

1872-1896: U. S. Congress 1940, p. 7.

1897-1959: U. S. Geological Survey records. 


\section{LITERATURE CITED}

ARRow, K. J., T. E. HARRIS and J. MARShaK

1951. Optmal inventory policy. Econometrica, $19(3)$.

BELLMAN, RICHARD

1957. Dynamic programming. Princeton Univ. Press.

1961. Adaptive control processes: A guided tour. Princeton Univ. Press.

Buras, N., and W. A. HaLL

1961. An analysis of reservoir capacity requirements for conjunctive use of surface and ground water storage. International Ass'n for Scientific Hydrology, Publ. 57:556-63.

BURT, OSCAR R.

1964. Optimal resource use over time with an application to ground water. Management Science, $11(1)$

California Crop and Livestock Reporting Service

Annual. California fruit report, annual summary. Sacramento.

California Department of Water Resources

1958. Report on proposed semitropic water storage district, Kern County. State of California.

Caton, Douglas D., Trimble R. Hedges, and Neill Schaller

1958. Inputs and costs for producing field crops (A statistical supplement to farm adjustments and earnings under 1955 cotton acreage allotments). 5. San Joaquin Valley Westside Cotton Farms, 1953-1955. Univ. of California Giannini Foundation Mimeo Report 212, Berkeley.

Cromarty, William A.

1959. An econometric model for United States agriculture. J. Amer. Statist. Ass'n., 54, Sept. DALY, REX F.

1956. The long-run demand for farm products. Agric. Econ. Research, 8, July.

Davis, G. H., J. H. Green, F. H. Olmsted, and D. W. Brown

1959. Ground water conditions and storage capacity in the San Joaquin Valley, California. Geological Survey Water-Supply Paper 1469, Govt. Print. Off., Wash., D.C.

D'Epenoux, F.

1963. A probabilistic production and inventory problem. Management Science 10(1), Oct.

DVORETZKx, A., J. KIEFER and J. Wolfowitz

1952. The inventory problem, I, II. Econometrica, $20(2,3)$.

Fox, KarL A.

1953. The analysis of demand for farm products, USDA Techn. Bull. 1081. Govt. Print. Off., Wash., D.C.

Howard, DONALD

1960. Dynamic programming and Markov processes. Technology Press and Wiley, N.Y.

International CotTon Advisory Committee

1960. Cotton-world statistics, 14(2) Part II. Washington, D.C.

Joint Economic Committee Staff and the OfFice of Statistical Standards

1960. 1960 supplement to economic indicators. Bureau of the Budget, Govt. Print. Off., Wash., D.C.

Kemeny, J. G. and J. L. SNell

1960. Finite Markov chains. D. Van Nostrand Co., N.Y.

LiTTLE, J. D. C.

1955. The use of storage water in a hydroelectric system. J. Operations Research Soc. of America, 3(3), May.

Manne, Alan S.

1960. Linear programming and sequential decisions. Management Science, 6(3).

Masse, Pierre

1945. Application des probabilités en chaîne à l'hydrologie statistique et au jeu des réservoirs. Rept. to the Société de Statistique de Paris June 21, 1944, Berger-Levrault, Paris.

Moop, A. M.

1950. Introduction to the theory of statistics. McGraw-Hill, N.Y.

Pearson, KarL

1922. Tables of the incomplete gamma function. Cambridge Univ., London.

Shuffett, D. Milton

1954. The demand and price structure for selected vegetables. USDA Techn. Bull. 1105. Govt. Print. Off., Wash., D.C.

STEWART, J. IAN

1954. Cantaloupes as a crop in Merced County. Farm Advisor's Office, Merced County, January. 
SuITS, DANIEL B.

1955. An econometric model of the watermelon market, J. Farm Econ., 37, May.

Tном, H. C. S.

1958. A note on the gamma distribution. Monthly Weather Rev., 86, April.

THOMAS, H. A. and P. WATERMEYER

1962. Mathematical models: A stochastic sequential approach. In: Maass, Arthur, et al., Design of water resource systems, Harvard Univ. Press, chapter 14.

Todd, David K.

1959. Ground water hydrology, Wiley, N.Y.

UNIVERSITY OF CALIFORNIA

1953. Staked tomatoes: Production costs in Tulare County. Farm Advisor's Office, Tulare County, April.

1954. Beef cattle on irrigated pastures, Berkeley: Agric. Ext. Serv. October.

1955. What will it cost to grow irrigated barley in Fresno County: West Side Farm Advisor's Office, Fresno County, January.

1956. Sample costs of growing sweet potatoes in Merced County, California. Farm Advisor's Office, Merced County, March.

1957. Sample dairy farm management budgets for the San Joaquin Valley. Agric. Ext. Serv., September.

1958a. Cost analysis work sheet: Field corn, single cropped, in Fresno County. Farm Advisor's Office, Fresno County, May.

1958b. Cost analysis work sheet: Sample costs to produce blackeye beans in Fresno County. Farm Advisor's Office, Fresno County, April.

1958c. Sample costs to produce blackeye beans in Tulare County. Farm Advisor's Office, Tulare County, May.

1958d. Cost analysis work sheet: Sample costs to produce watermelons in Fresno County on rented land. Farm Advisor's Office, Fresno County.

1958e. Milo in Kings County. Farm Advisor's Office, Kings County, May.

1958f. Sample costs to produce apricots, Kings County. Farm Advisor's Office, Kings County, January.

1959a. Cost analysis work sheet: Fay Elberta peaches. Farm Advisor's Office, Fresno County.

1959b. Cost analysis work sheet: Field corn, single cropped, in Kings County. Farm Advisor's Office, Kings County, March.

1959c. Cost analysis work sheet: Sample costs to produce almonds in Merced County. Farm Advisor's Office, Merced County, May.

1959d. Cost analysis work sheet: Sample costs to produce navel oranges in Tulare County. Farm Advisor's Office, Tulare County, March.

1959e. Cost analysis work sheet: Sample costs to produce Manzanillo olives in Tulare County. Farm Advsor's Office, Tulare County, April.

1959f. Cost analysis work sheet: Sample costs to produce walnuts in Tulare County. Farm Advisor's Office, Tulare County, December.

1959 . Costs of producing grapes in the San Joaquin Valley: Emperor grapes. Agric. Ext. Serv.

$1959 \mathrm{~h}$. Costs of producing grapes in the San Joaquin Valley: Standard wine varieties. Agric. Ext. Serv.

1959i. Costs of producing grapes in the San Joaquin Valley: Thompson seedless for raisins or wine. Agric. Ext. Serv.

1959j. Costs of producing grapes in the San Joaquin Valley: Thompson seedless for table use. Agric. Ext. Serv.

1959k. Growing hybrid corn in Tulare County. Farm Advisor's Office, Tulare County, February.

1960. Cost analysis work sheet: Sample costs to produce clingstone peaches in Tulare Countv. Farm Advisor's Office, Tulare County.

U. S. Agricultural Marketing Service

Annual A. Crop production, annual summary. Govt. Print. Off., Wash., D.C.

Annual B. Crop values, season average prices received by farmers, and value of production. Govt. Print. Off., Wash., D.C.

Annual C. Vegetables-fresh market, annual summary. Govt. Print. Off., Wash., D.C.

U. S. CONGRESS

1940. Kings River project in California, House Document 631. Govt. Print. Off., Wash., D.C. U. S. SENATE

1960. Water resources activities in the United States. Population projections and economic assumptions. Select Committee on National Water Resources, Print 5. Govt. Print. Off., Wash., D.C., March.

$4 m-12,64$ ( E6202) J.F. 


The journal HILGARDIA is published at irregular intervals, in volumes of about 650 to 700 pages. The number of issues per volume varies.

Single copies of any issue may be obtained free, as long as the supply lasts; please request by volume and issue number from:

$$
\begin{aligned}
& \text { Agricultural Publications } \\
& \text { University Hall } \\
& \text { University of California } \\
& \text { Berkeley, California } \mathbf{9 4 7 2 0}
\end{aligned}
$$

The limit to nonresidents of California is 10 separate titles. The limit to California residents is 20 separate titles.

The journal will be sent regularly to libraries, schools, or institutions in one of the following ways:

1. In exchange for similar published material on research.

2. As a gift to qualified repository libraries only.

3. On a subscription basis $-\$ 7.50$ a year paid in advance. All subscriptions will be started with the first number issued during a calendar year. Subscribers starting during any given year will be sent back numbers to the first of that year and will be billed for the ensuing year the following January. Make checks or money orders pay. able to The Regents of The University of California; send payment with order to Agricultural Publications at above address. 